\section{ENERGT}
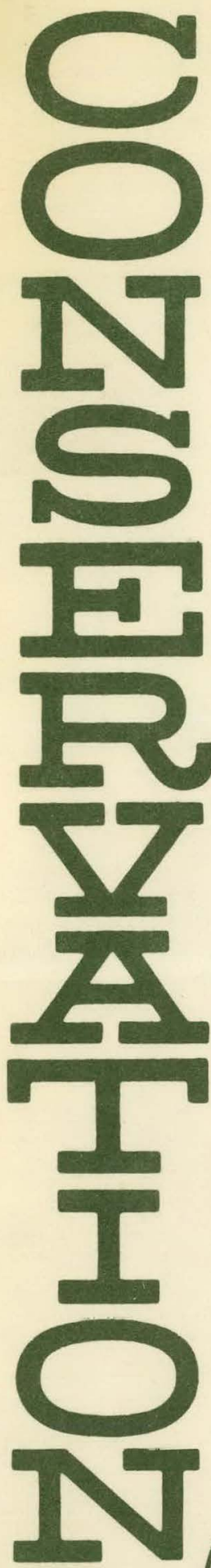

\section{A BIPHASE TURBINE BOTTOMING CYCLE FOR A DIESEL ENGINE}

\title{
Dr 1092
}

\author{
U.S. Energy Research and Development Administration \\ Under Contract No. E(04-3)-1207
}

\author{
FOR A DIESEL ENGINE
}

Biphase Engines, Inc.

2907 Ocean Park Blvd.

Santa Monica, California 90406

Prepared by:
Saifuddin Ahmad
Lance Hays

February 15, 1977 


\section{DISCLAIMER}

This report was prepared as an account of work sponsored by an agency of the United States Government. Neither the United States Government nor any agency Thereof, nor any of their employees, makes any warranty, express or implied, or assumes any legal liability or responsibility for the accuracy, completeness, or usefulness of any information, apparatus, product, or process disclosed, or represents that its use would not infringe privately owned rights. Reference herein to any specific commercial product, process, or service by trade name, trademark, manufacturer, or otherwise does not necessarily constitute or imply its endorsement, recommendation, or favoring by the United States Government or any agency thereof. The views and opinions of authors expressed herein do not necessarily state or reflect those of the United States Government or any agency thereof. 


\section{DISCLAIMER}

Portions of this document may be illegible in electronic image products. Images are produced from the best available original document. 
Available from:

National Technical Information Service (NTIS) U.S. Department of Commerce

5285 Purt Royal Road

Springfield, Virginia 22161

Price: Printed Copy: $\$ 6.75$

Microfiche: $\quad \$ 3.00$ 
Prepared for the

U.S. Energy Research and Development Administration Under Contract No. E(04-3)-1207

\section{A BIPHASE.TURBINE BOTTOMING CYCLE FOR A DIESEL ENGINE}

Report No. 101-F

Biphase Engines, Inc. 2907 Ocean Park Blvd. Santa Monica, California 90406

Prepared by:

Saifuddin Ahmad Lance Hays

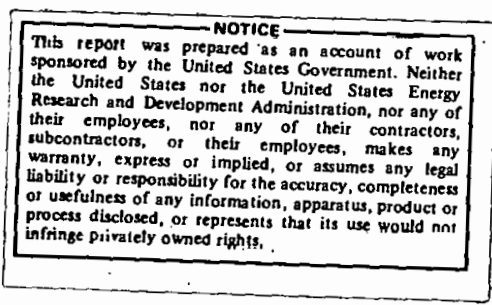

February 15, 1977 


\section{ACKNOWLEDGEMENT}

Technical direction for this program is provided by John Neal of the Conservation Division of ERDA headquarters.

The assistance of Robert Spies and Paul Thys in the turbine design is gratefully acknowledged.

Special thanks are also given to Ying Mei Chen for her calculations and to Miss Chen and Deborah Spies for their careful preparation of the text and figures. 
Application of a two-phase turbine system to waste heat recovery was examined. Bottoming cycle efficiencies ranging from 15-30\% were catculated for a $720^{\circ} \mathrm{F}$ diesel exhaust temperature. A single stage demonstration unit, designed for non-toxic fluids (water and DowTherm A) and for atmospheric seals and bearings, had a cycle efficiency of $23 \%$. The net output power was $276 \mathrm{HP}$ at $8,100 \mathrm{rpm}$, increasing the total shaft power from 1,800 HP for the diesel alone, to 2,076 HP for the combined system. A four stage organic turbine, for the same application, had a rotational speed of $14,700 \mathrm{rpm}$ while a four stage steam turbine had $26,000 \mathrm{rpm}$. Fabrication drawings were prepared for the turbine and nozzle. The major improvement leading to higher cycle efficiency and lower turbine rpm was found to be the use of a liquid component with lower sensible heat.

A reduction in capital cost was found to result from the use of a contact heat exchanger instead of tube-fin construction. The cost for a contact heat exchanger was only $\$ 35-52 / \mathrm{kWe}$ compared to $\$ 98 / \mathrm{kWe}$ for a tube-fin heat exchanger. Design drawings and materials list were prepared. A program resulting in the demonstration of a two-phase bottoming system was planned and the required cost estimated. The program would result in a feasibility test of the nozzle and turbine at the end of the first year, a laboratory performance test of the bottoming system by the end of the second year and a field demonstration test and laboratory endurance test of the bottoming system during the third year. The blowdown test rig for the first year's program and test turbine were designed. 


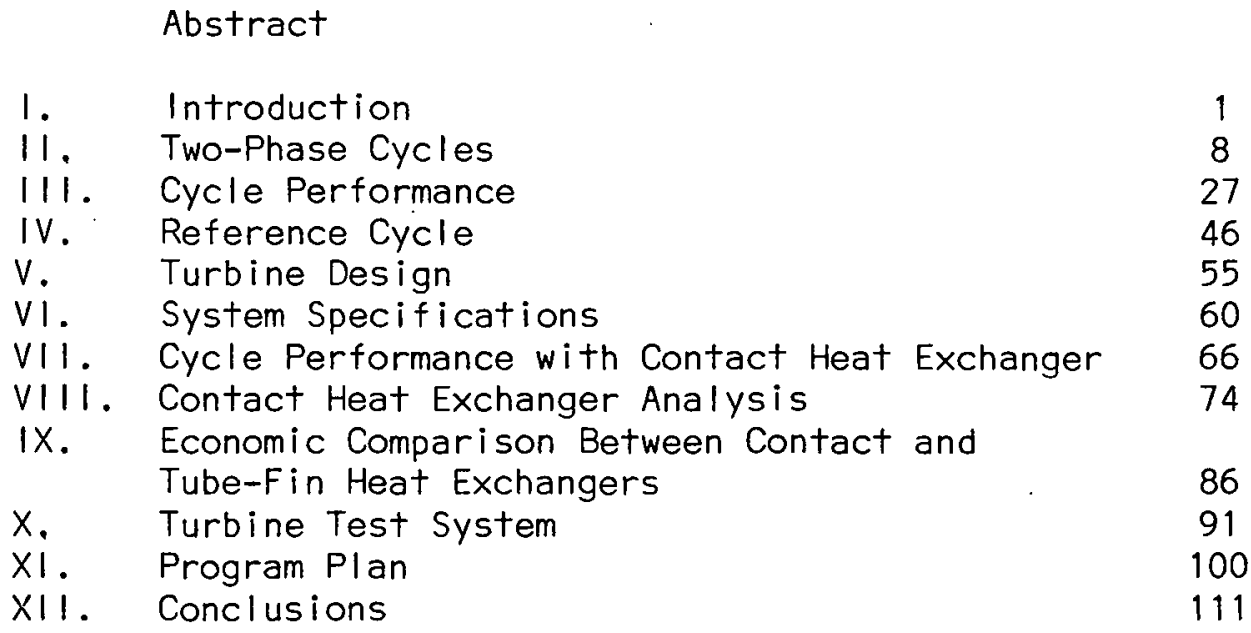

Appendices
A. Expander Relations
B. Analysis of Two-Phase Cycles
C. Summary of Turbine Design
D. Steam Turbine Analysis and Design
E. Contact Heat Exchanger Cycle Equations
F. Comparison of Fluid Properties
G. Summary of Contact Heat Exchanger Calculations 


\section{INTRODUCTION}

Effective utilization of waste heat is an energy conservation measure which can have a very large impact on fuel consumption in this country. Conversion of the waste heat into a useful form of energy (such as electricity or mechanical shaft power) has an added advantage in that the basic tooling and plant designs can be preserved. Furthermore, reduction of both air and thermal pollution is a direct consequence of increasing the useful power output for a given amount of fuel.

Many processes and devices have hot exhaust gases that would be suitable for the heat source for energy conversion systems. A particularly attractive class of devices are internal combustion engines, both diesel and spark ignition. These engines account for nearly one third of the country's energy consumption. Moreover, the available energy in the exhaust gases is equal in magnitude to the useful power output for the engine. Existing estimates of bottoming cycle performance have indicated improvements of $15-20 \%$ (1) in the fuel economy resulting in a large potential savings if all engines were so equipped. Figure 1 (after Ref. 2) shows an energy dlagram for a typical diesel engine with latent heat cooling. The exhaust gas energy is $33 \%$ of the heat input compared to $39 \%$ of the heat input which appears as useful work output. This diagram also shows a potential recovery of about $20 \%$ as the heat value of steam raised by the exhaust gases. For typical steam systems this heat can be converted to shaft power to raise the total engine shaft output by about $5-7 \frac{1}{2} \%(2)$

The subject of this study, and the simplest application of this type, is utilization of the waste heat from a large, stationary diesel engine. Stationary engines don't have the same space and weight limitations, or control and transient operation requirements as vehicular power

- plants. Therefore, the steady state performance and reliability aspects of bottoming systems can be demonstrated without the complications necessitated by mobile applications. 


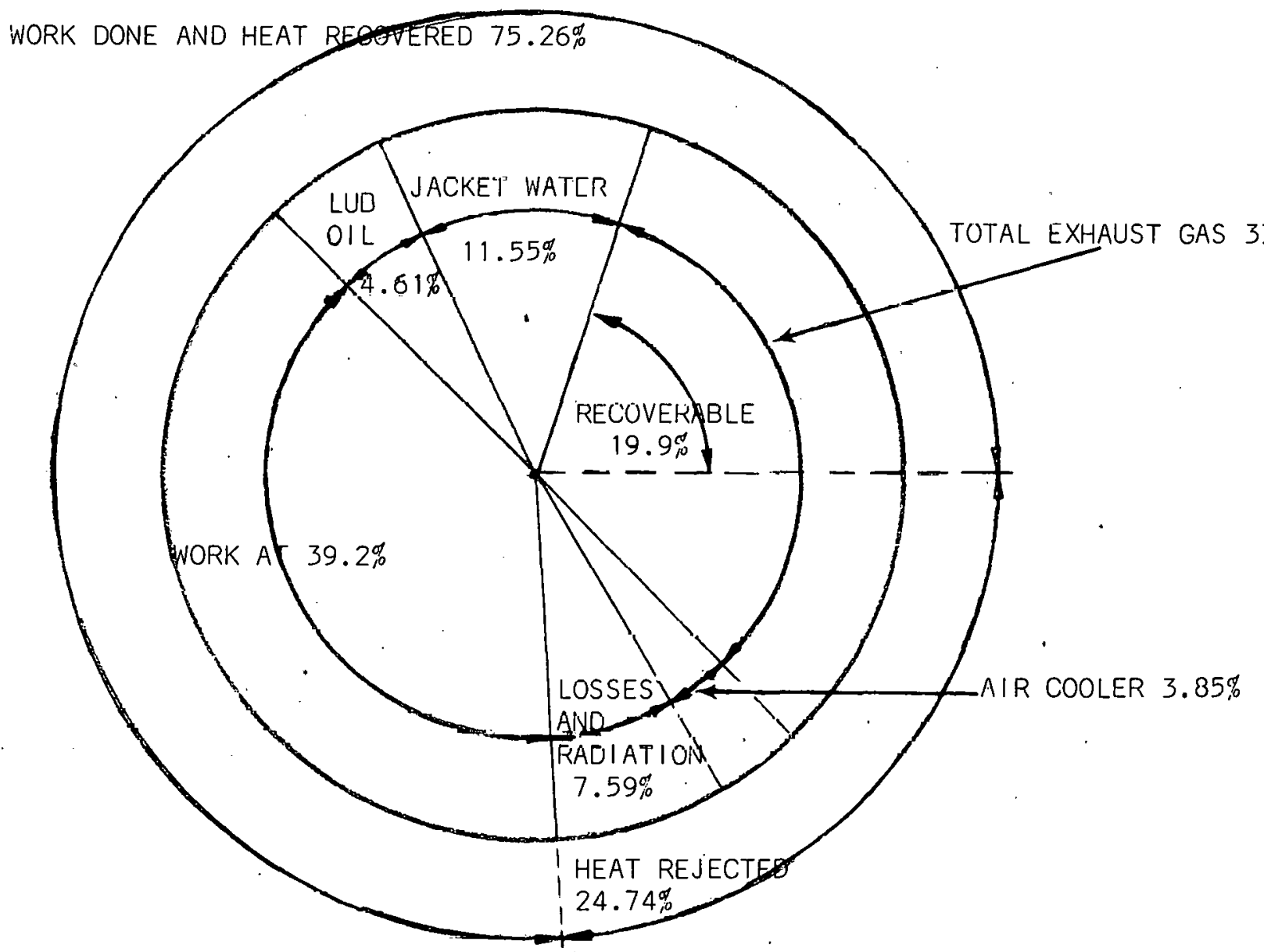

Fig. 1 - Diagrammatic Representation of Heat Balance with Latent Heat Cooling for Diesel Engine 
Current approaches for waste heat. conversion include both closed cycle and open cycle heat engines. Only the closed cycle variations will be considered here. The steam Rankine cycle has been used commercially as a bottoming system for gas turbines $(3,4)$ systems of this type have reduced the heat rate form $13,500 \mathrm{~B} / \mathrm{kWh}$ with a gas turbine alone to $9,600 \mathrm{~B} / \mathrm{kWh}$ for the combined cycle. Thus, a fuel savings of $30 \%$ results from the addition of this bottoming system. Commercial systems have also been placed in operation using steam bottoming cycles to recover waste heat from diesel engines. Figure 2 is a schematic of a typical system described in Ref. 2. As discussed previously, this type of system with $240 / 280$ psig, $600 / 650^{\circ} \mathrm{F}$ steam increases the shaft power output by $5 \frac{1}{2}$ to $7 \%$.

Another approach to waste heat conversion is the use of a Rankine cycle with an organic working fluid. Ref. 5 discusses the use of an organic vapor turbine system to bottom a diesel engine. A "bread board" system tested resulted in a $12 \%$ increase in power without an increase in fuel consumption. An organic vapor expander was also used by chapman ${ }^{(6)}$ to bottom a spark ignition engine. In this case, an orbital vane expander was used as the power conversion component. Advantages resulting from the use of an organic vapor instead of steam include a greater thermodynamic efficiency and a somewhat lower turbine or expander rpm. Disadvantages include expensive fluid and seal requirements, non-availability of commercial components and the high capital cost of the system components, and the use of toxic working fluids (e.g.. toluene and 'FS-85).

The subject of this design study is the use of a two-phase power system to convert the waste heat from a diesel engine to useful power. The two-phase power system while similar, has several potential advantages relative to a Rankine cycle bottoming system.

1. The turbine has a. lower rpm.than a vapor-alone turbine, simplitying transmission problems. For example, the single stage turbine of this design study has a shaft speed of 8,100 rpin compared to 14,700 for a four stage organic vapor turbine for the same application (7). A steam turbine with the same number of stages would have a rotation 


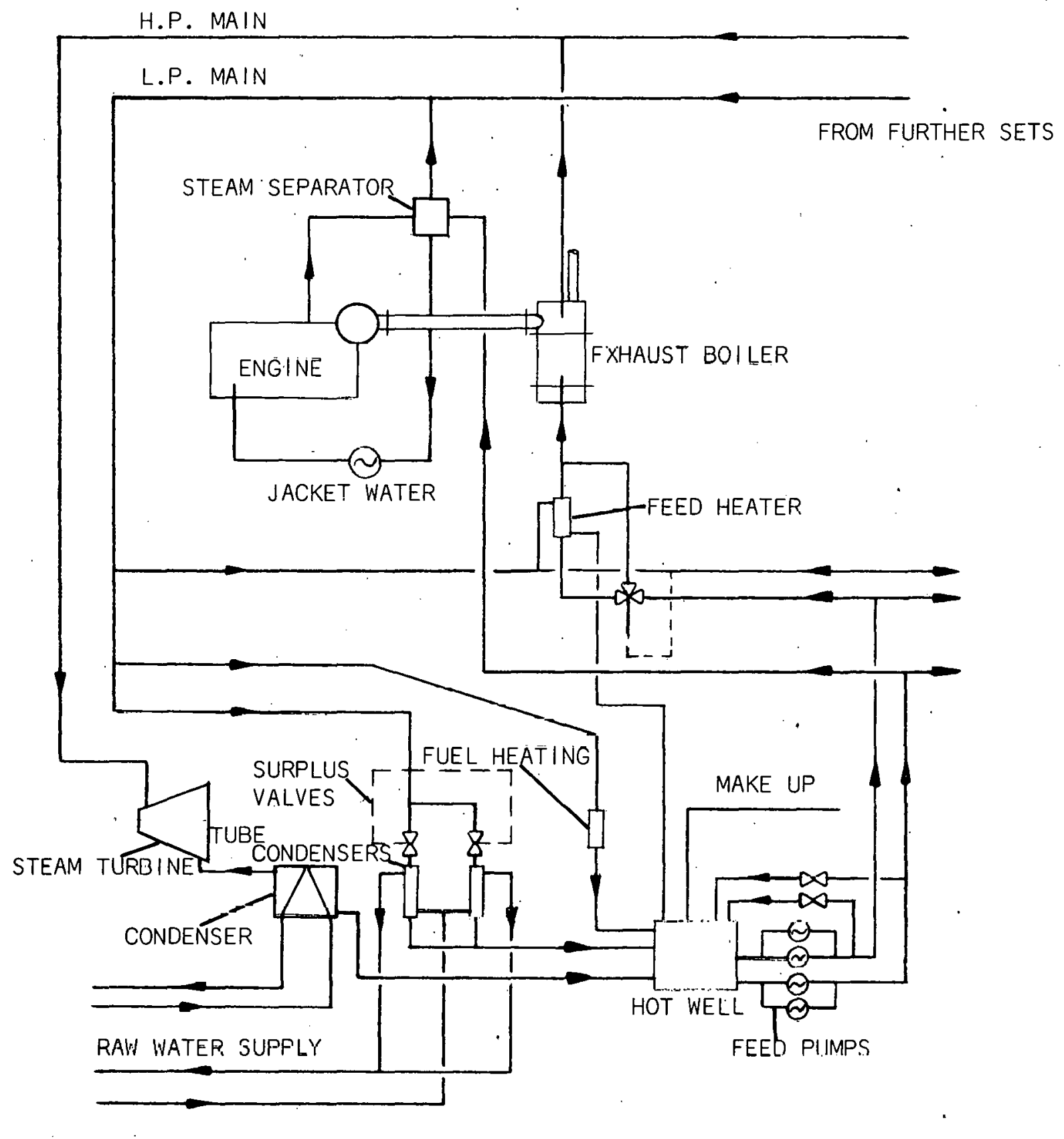

Fig. 2 - Layout of Complete Engine Heat-Recovery System 
speed of about 26,000 rpm. As discussed later the twophase turbine rpm can be reduced further by increasing the mass ratio of liquid to vapor, but at the expense of pumping losses.

2. The two-phase cycle has a gas to liquid heat exchanger instead of a boiler and maximizes the exhaust gas energy available for conversion. The available energy to the system can be maximized because heat transfer is to the liquid phase. Figure 3 illustrates temperature profiles for typical steam and organic vapor boilers compared to the liquid heat exchanger of the two-phase turbine engine. Since the loss of available. energy is proportional to the temperature difference it can be seen that a higher thermodynamic efficiency is possible with the two-phase cycle compared to the vapor cycle.

3. The turbine, seals, bearings and other items associated with the rotating unit are simple, low cost components. This is a consequence of the low rpm and the transformation of the energy, from the gas to the high density I iquid phase.

4. Variations of the two-phase power cycle exist which may allow the use of a contact heat exchanger for the exhaust gas, reducing the capital cost relative to a tube-fin heat exchanger.

Other possible advantageous features include higher ultimate efficiency; simplified control requirements, and good part load efficiency.

In order to determine the performance and design of a two-phase turbine, cycle calculations, were conducted for several two-phase systems. A reference cycle was selected which represented a compromise between efficiency, rpm, and simplicity of construction. The two-phase nozzle and 


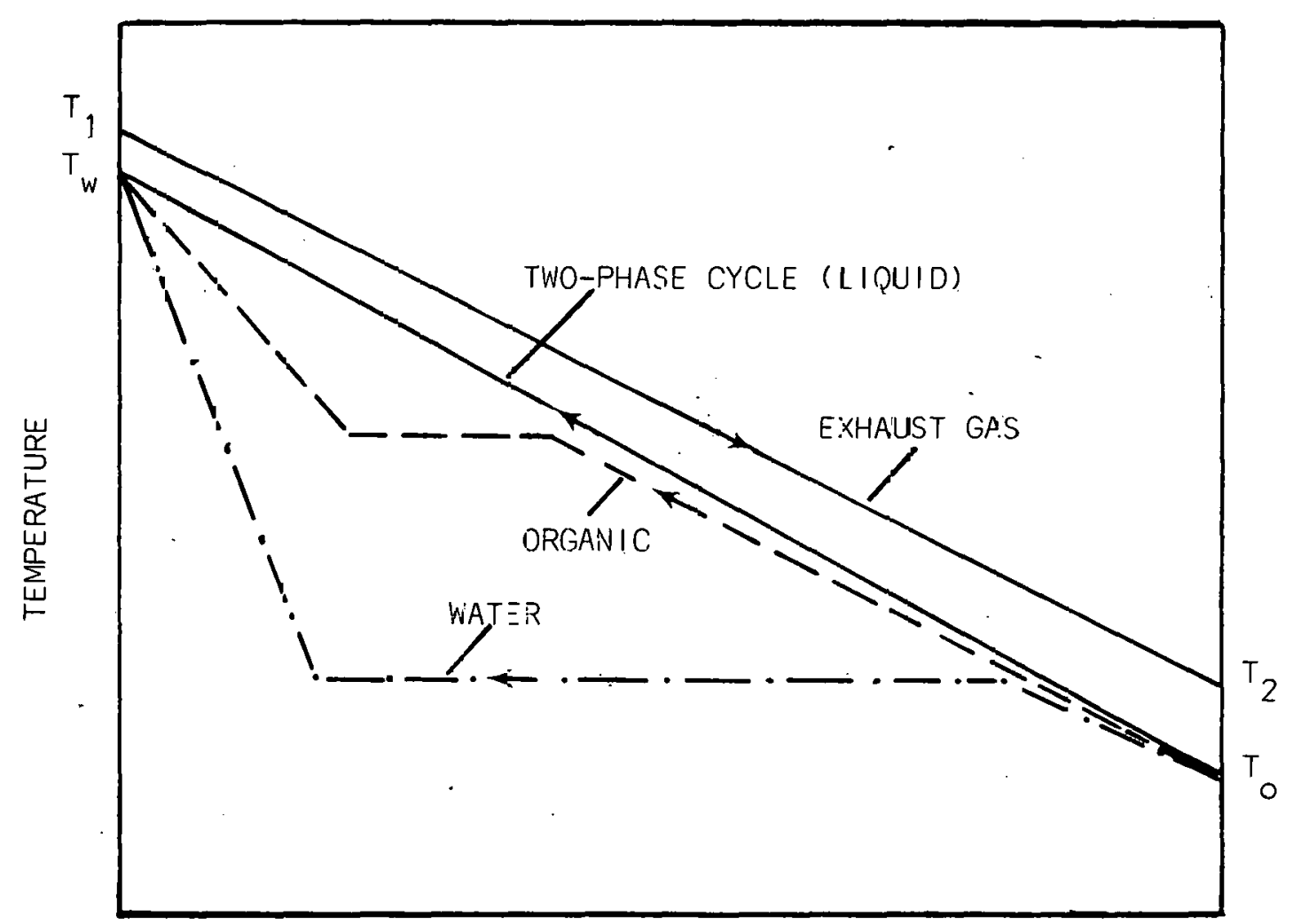

PERCENT OF TOTAL HEAT TRANSFERRED

Fig. 3 - Comparison of Temperature Profiles of Two-Fhase Cycle Heat Exchenger and Organic Steam Vapor Generators 
turbine were designed for the conditions of the reference cycle and fabprication drawings were prepared. Functional requirements of the major system components were specified and a program resulting in the demonstration of a two-phase bottoming cycle was formulated. 


\section{TWO-PHASE CYCLES}

Several different two-phase bottoming cycles were considered for the design study. In each variation, the common feature is that heat transfer occurs from the exhaust gas to the liquid phase. However, the working fluid may consist of one or more chemical species, staging can be used, and a contact heat exchangor can be used in plaree of a conventional tube-fin heat exchanger.

In this section, the basic principles of two-phase nozzles and turbines are discussed, followed by a brief description of each cycle.

TWO-PHASE NOZZLES AND TURBINES

The two elements which are responsible for the unique characteristics of the two-phase turbine engine are the two-phase nozzle and the turbine wheel. "The nozzle produces efficient conversion of liquid enthalpy to vaper enthalpy to vanor and liquid kinetlc eneryy. This is achieved by mixing a finely dispersed hot liquid of low vapor pressure (such as oil) with a liquid possessing higher vapor pressure (such as water or Freon). The water vaporizes to steam at high pressure. The steam is subsequently expanded to low pressure and high velocity, dragging the oil droplets to a high velocity also. The presence of. large amounts of finely dispersed liquid has a similar effect on the nozzle exit veluclity as a large increase in molocular woight of the vapor would, i.e. a high mass flow rale and low spouting velocity are obtained. Figure 4 shows the nozzle exit velocity as a function of the ratio of liquid to gas. Starting at a value of about 4,000 $\mathrm{ft} / \mathrm{s}$ for all gas, the exit velocity is reduced to less than $1,000 \mathrm{ft} / \mathrm{s}$ for a mass ratio of 30 . Thus, a much lower turbine wheel speed can be 
Fig. 4 - Exit Velocity of Two-Phase Nozzles

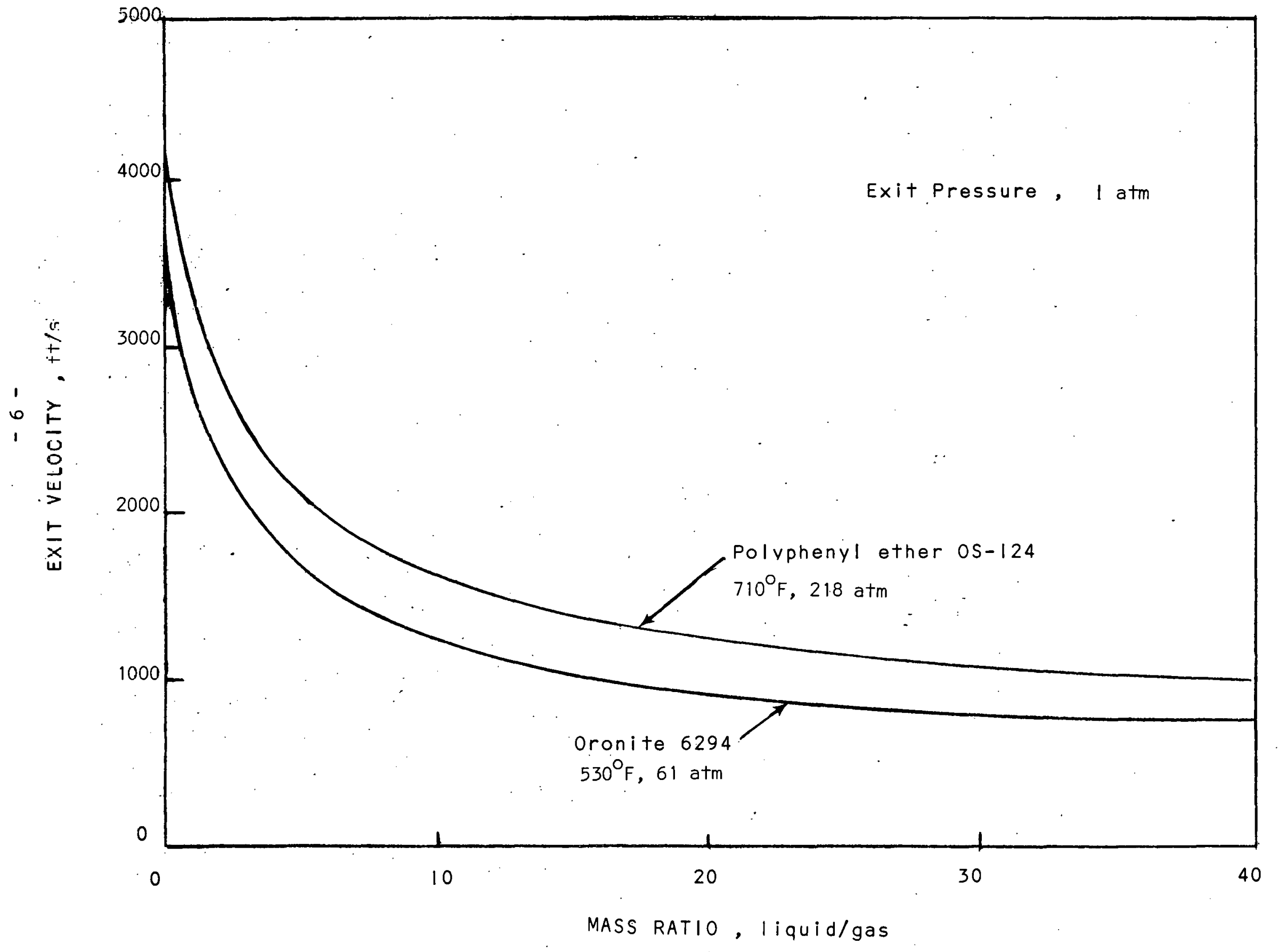


used for maximum efficiency than for the vapor alone.

The relation of the nozzle and turbine whee! for a single stage, impulse circumferential configuration is shown in Figures 5 and 6 . The geometry can be very similar to a simple Pelton wheel. The only difference is that the initial impingement zone is inclined at a more gradual angle than the Pelton Wheel, to avoid two-phase impact losses; and the surface area can be made' less than that of a Pelton wheel because of the concentration of the liquid phase after impingement. Another geometry which ran be used is very similar to a conventional axial flow impulse turbine.

A variation of the above turbine which offers elimination of the primary oil pump and may have a higher efficiency for some applications, is a rotary separator turbine. Here the two-phase mixture is impinged on a rotating separator surface which results in a high velocity liquid annulus. The liquid flows into a radial inflow turbine, which in its simplest case is a rotating pitot tube and diffuser. The liquid is discharged through the base and enough pressure is retained to enable circulation through the heat exchanger to the nozzle. Another version is the use of a simple "U-tube" to recover the liquid energy.

Figures 7 and 8 illustrate this turbine design, consisting of nozzle(s), rotating separator, and liquid turbine. The liquld and gas mixture comprising the working fluld is supplied al high piessure to the nozilc inlets. The mixlure expands to low pressure at the $n u \angle \angle l \theta \theta x i t s$, and the resulting high-velocity two-phase jets impinge on the inner surface uf llie i im al the rotnting soporator. The liguid besomes rnncentrated in a layer on the inner surface due to the inertia of the liquid and centrifugal force while the gas flows radially inward through passages and enters the gas discharge pipe through ports in the stationary housing. The rotating separator is supported by bearings mounted in the housing. 


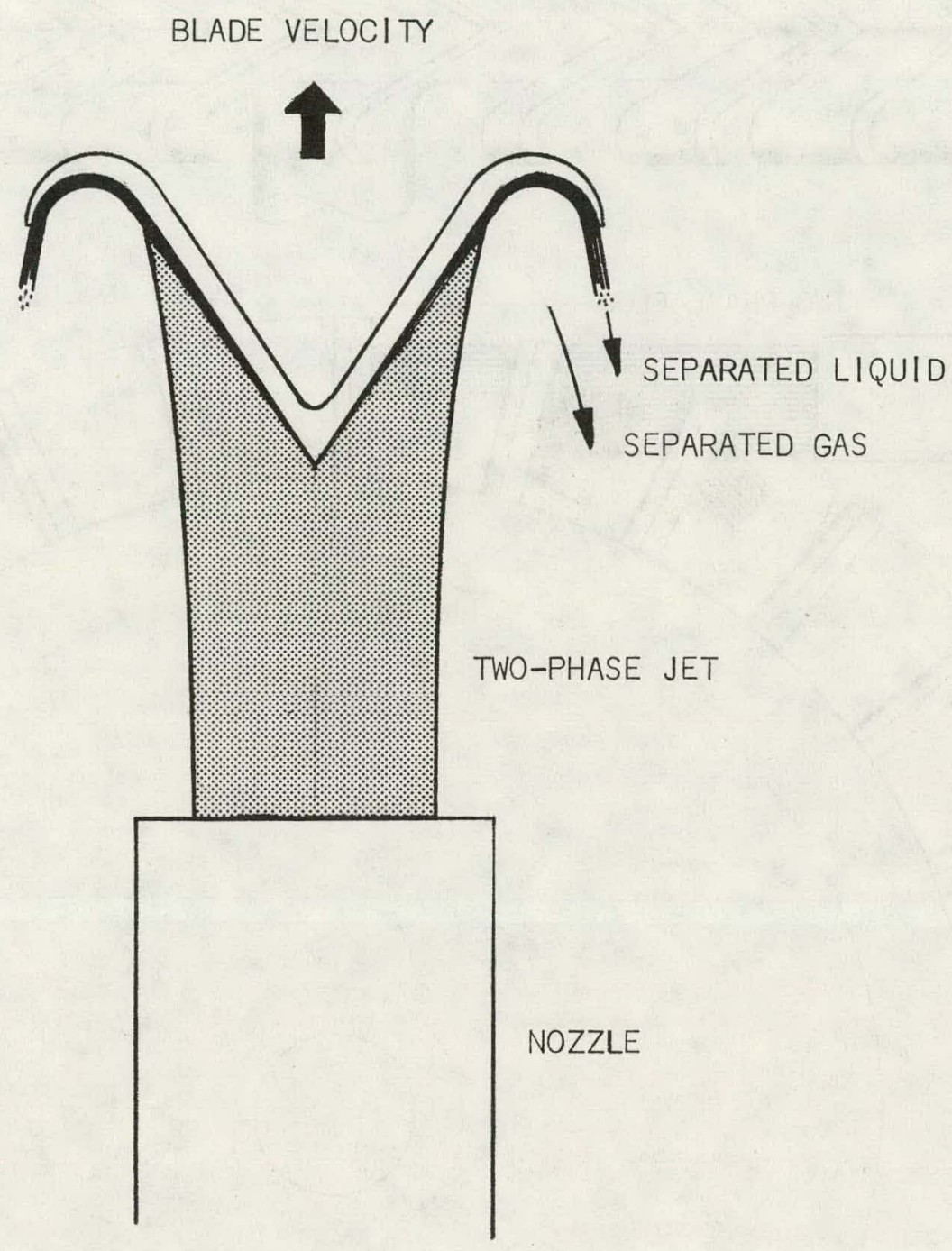

Fig. 5 - schematic of Flow in Two-Phase Impulse Turbine 

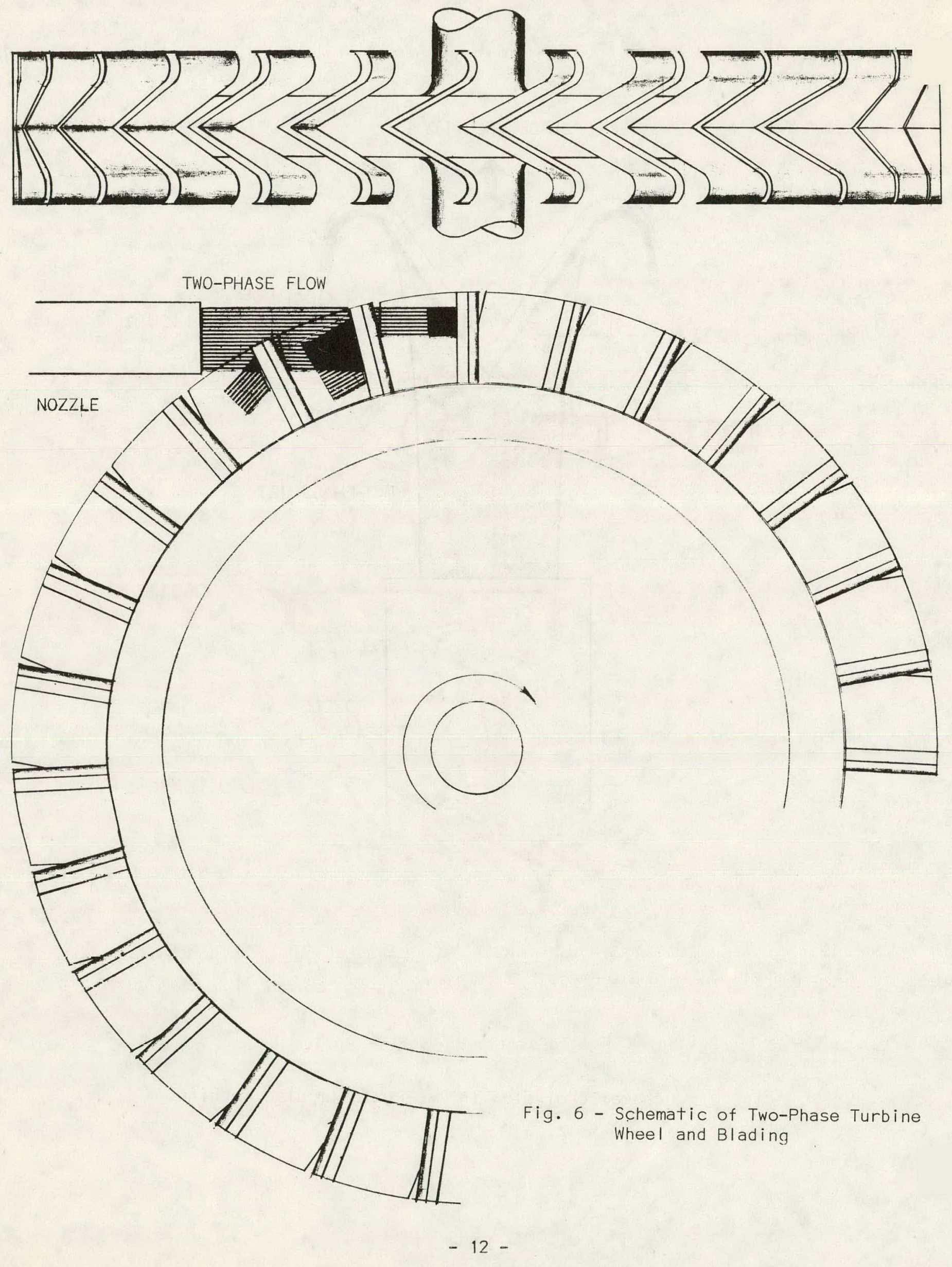


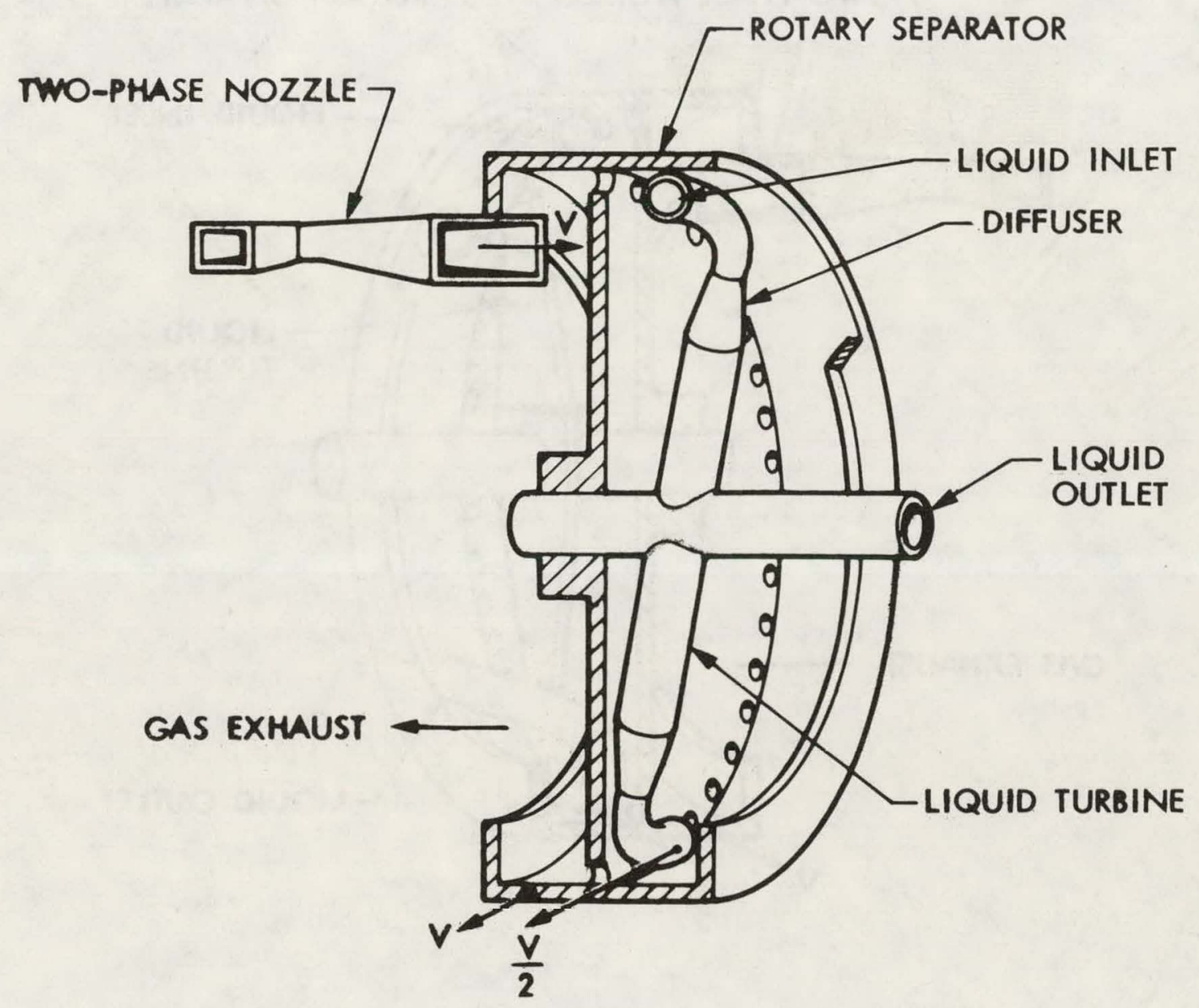

Fig. 7 - Separator-Turbine with Radial Inflow Liquid Turbine 


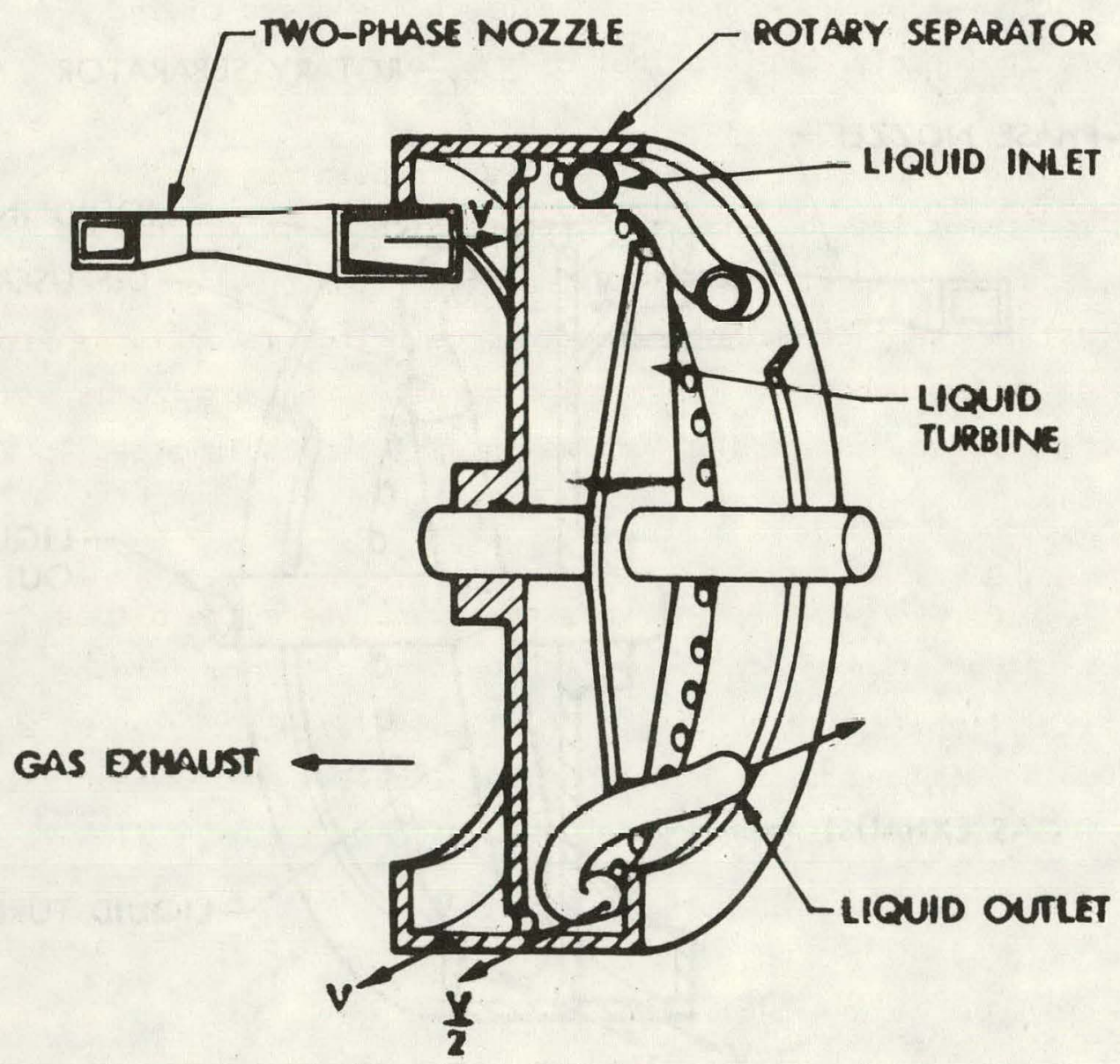

Fig. 8 - Separator-Turbine with U-Tube Liquid Turbine 
The rotation of the separator is impeded only by windage and bearing friction losses, which can be very small. Thus, only a very small relative velocity between the impinging jets and the surface, aided by the torque imparted to the rotating separator by the inward flow of the gas through passages, serves to maintain the speed of the liquid layer at a value nearly equal to that of the jets.

The liquid flows from the liquid layer through passages in the rotating separator into an annular chamber which forms an integral part of the separator wheel. As a result another liquid layer is formed, held against the surface by centrifugal force. This layer furnishes the fluid energy source for the turbine rotating concentrically within the separator wheel and having turbine inlet passages immersed in the liquid layer.

The turbine may be of any conventional type where the blades or passages can be arranged to intercept the liquid layer. Figure 7 shows a radial flow type of turbine. The turbine wheel rotates at a lower speed than the separator wheel causing liquid from the layer to enter the inlets, flow radially inward through passages, and flow to the liquid outlet pipe through apertures in the wall of the turbine shaft. The shaft is connected to the load to be driven. The turbine is supported on bearings.

The turbire passage can optionally incorporate a diffuser in which the velocity of the liquid entering the inlet can be partially converled lu pressure such that, even allowing for the pressure drop in the radial passages due to centrifugal force, the liquid pressure in the discharge pipe is substantially higher than the pressure in the turbine casing and, in fact, greater than the pressure at the nozzle inlets. Thus, the diffusers can supply the necessary pumping of the liquid, eliminating the need for a separate pump to return the liquid to the nozzles. 
For operation with high pressure at the discharge, the leakage of Iiquid between the shaft and the housing can be reduced by labyrinth seals and drains which return liquid leakage to the bottom of the housing where the liquid from this and other internal leakage sources is picked up by slinger blades and thrown back into the jets. Leakage to the outside of housing is prevented by a shaft seal.

SINGLE COMPONENT -- SINGLE STAGE

The single component - single stage system is shown in Figure 9. The waste heat from a diesel engine (or gas turbine) enters lhe heat exchanger at temperature $T_{i}$ with an exhaust flow rate of $\dot{m}_{e}$. The exhaust heat of an amount $Q_{i}$ is transferred to a single phase liquid in a counter current heat exchanger. The exhaust gas exits at temperature $T_{e}$. The heated liquid is flashed in a nozzle and expanded to pressure $p_{2}$ from pressure $p_{1}$. The saturated mixture of vapor and liquid with a quality $x_{2}$ impinges on a rotary separator. The vapor flows through a radial inflow turbine and the liquid flows through a radial inflow turbine, each on a common shaft, producing a net power output $P_{S}$. The vapor exhausts to the condenser where an amount of heat of $Q_{C}$ is rejected. The condensate is pressurized and merger with the high prossure outlet from the liquid turbine: The liquid flows back to the heater, closing the cycle.

Many varlations on this basic scheme are possible. For example, the vapor turbine and/or liquid turbine can be impulse type machines with an additional pump to pressurize the liquid. The main advantage lies in the simpler turbine construction, but of coulse a disadvantage is the presence of another component and a slight loss in efficiency.

SINGLE COMPOSANT - MULTISTAGE

A multistage version of the single component cycle is shown in Figure 10. 


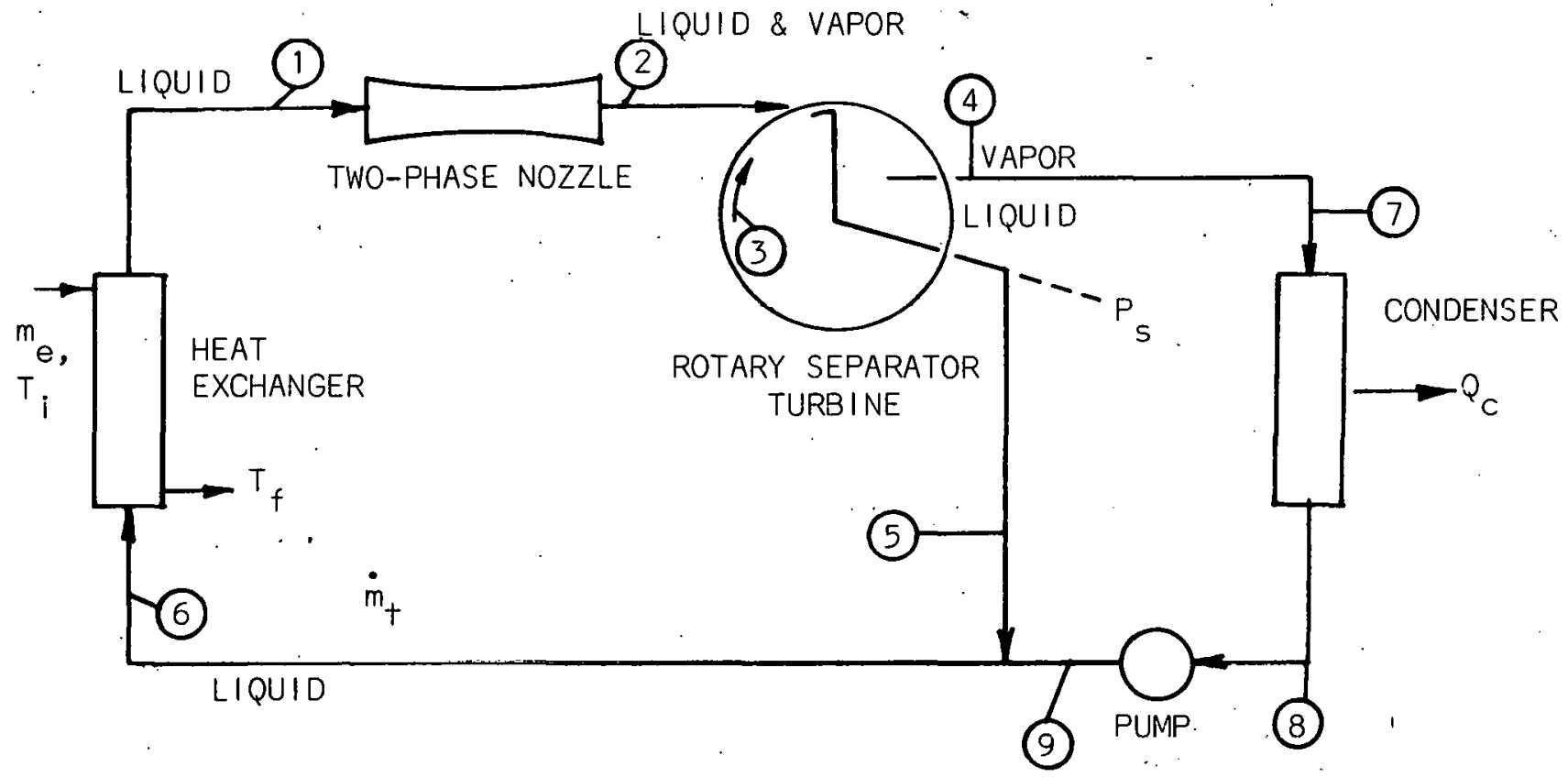

Fig. 9 - Single Component, Two-Phase Bottoming Cycle (Single Stage) 


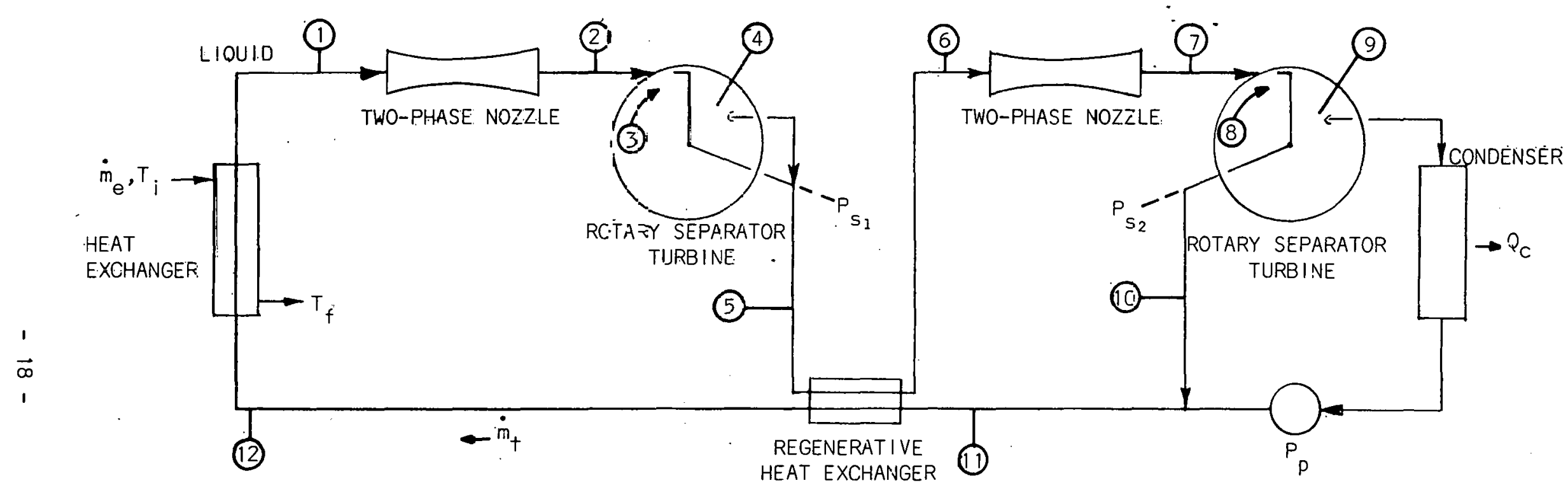

Fig. 10 - Single Component - Multistage Bottoming Cycle 
In this variation, the exit flow from the first stage is remixed and passed through a regenerative heat exchanger, condensing part of the first. stage vapor. The mixture is expanded through the second stage nozzle and turbine (as in the single stage cycle). The condensate and liquid discharge from the final (second) stage is passed through the regenerative heat exchanger increasing the temperature to the minimum dictated by combustor material considerations. The advantage of staging is that lower shaft rpm results and the lower velocities result in more efficient nozzle and turbine operation. Against these gains must be balanced the added complexity and possible interstage losses.

\section{TWO COMPONENT - CONVENTIONAL HEAT EXCHANGER}

The use of two components allows more flexibility in the choice of shaft rpm. A single stage two-component cycle is shown in Figure 11.

In this cycle the thermodynamic working fluid is component A. It is supplied to the nozzle as a liquid and flash vaporizes upon contact ' with the heated Iiquid, component $B$. Another variation of the twocomponent cycle is to $\mathrm{mix}$ the condensate (component $A$ ) with the turbine discharge (component B) sirculating the mixture through the heater. This variation has the same cycle diagram as the single-component variation.

In either case, the vaporizing component gradually vaporizes in the noz$z$ le as the pressure is reduced. Any degree of superheat can be provided by using large ratios of component " $B$ " to " $A$ ", "however, in the - Iimit of very large mass ratios, vaporization occurs at a nearly constant temperature which produces the same thermodynamic Iimitation as a Rankine cycle.

The resultant two-phase mixture impinges on the rotary separator. Component $A$, the vapor, flows through a radial inflow gas turbine. Component $B$ drives either a radial inflow or impulse liquid turbine. The 


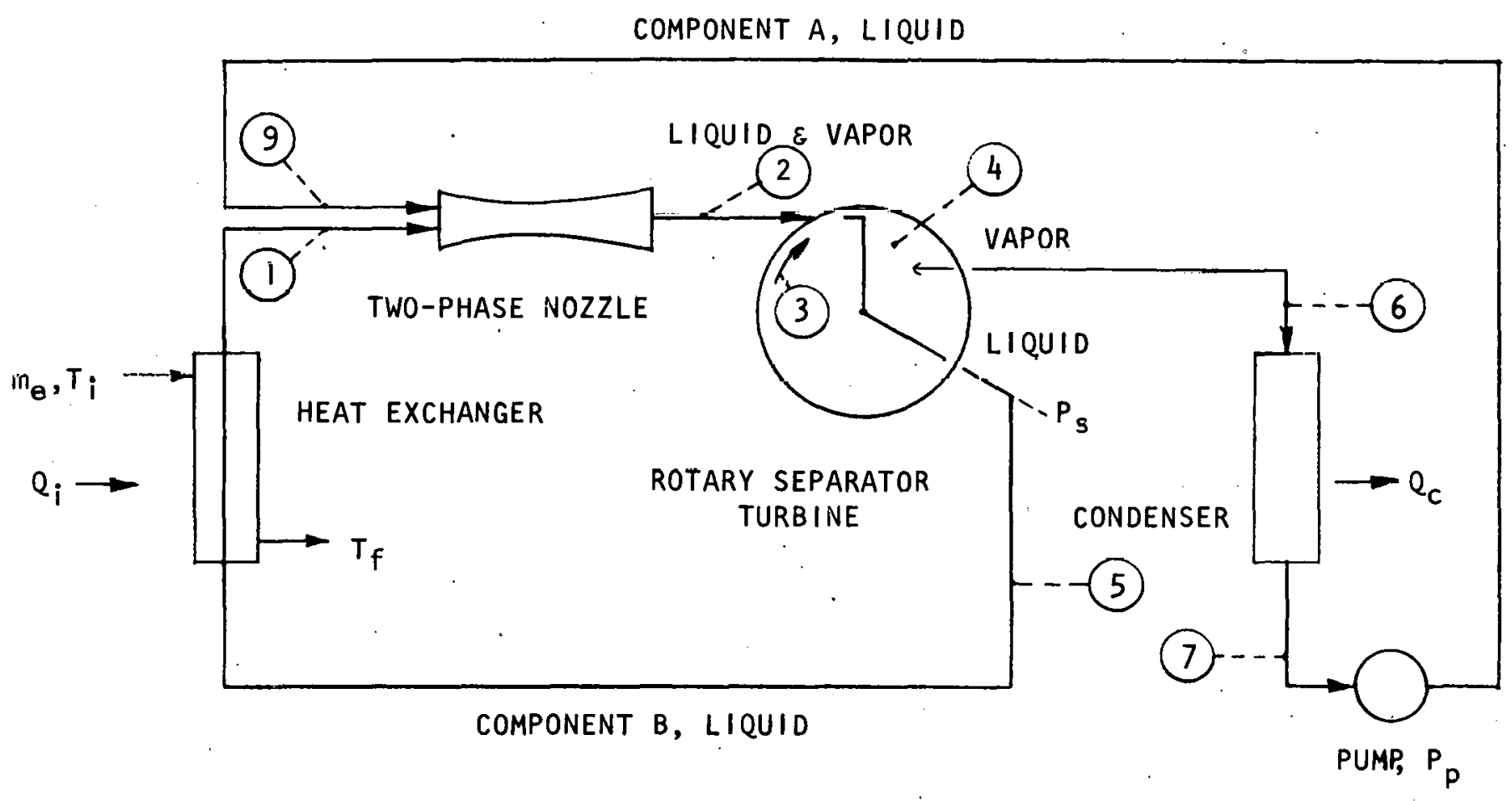

Fig. $1: 1$ - Two-Component, Two-Phase Bottoming Cycle with Tube-Fin Heat Exchanger 
vapor, after leaving the gas turbine flows to a regenerator (if superheated) and to the condenser. After rejecting the waste heat from the cycile the condensate is pressurized and returned to the nozzle inlet or to the primary heat exchanger. The liquid "B" leaving the liquid turbine is pressurized either by a pump or by conversion of the liquid kinetic energy to head and subsequently return to the primary heat exchanger.

TWO COMPONENT - CONTACT HEAT EXCHANGER

The final variation to be considered uses two components in a manner to enable the use of a contact heat exchanger for the waste gases. This version is illustrated by the schematic of Figure 12 .

The low vapor pressure liquid, component $B$, is sprayed into a vessel. The resulting droplets contact the hot exhaust gases which flow countercurrent to the falling droplets. The heated liquid is collected at the bottom of the vessel and pumped to the nozzle inlet. The cooled exhaust gas is exhausted (possibly through a mist eliminator) to the atmosphere. The remainder of the cycle is identical to the version with a tube-fin heat exchanger. The heat-exchanger construction is simpler with the high-pressure, tube-fin structure being replaced by a low pressure vessel with spray nozzle. In addition, the physical dimensions of the heat exchanger will be smaller because of the large surface area of the droplets. and abscence of fin losses. The pump power $\mathrm{P}_{\mathrm{p} 2}$ will be about the same required by the diffuser or pump in the cycle of Figure 11, so the efficiency of the two cycles should be similar.

In addition to the basic variations discussed above, other cycle combinations can be used. For example, Fi.gure 12a shows the use of a two-component two-phase cycle to bottom a two-phase cycle. By operating the two-component cycle with a high ratio of "B" to "A" (I iquid to gas), 
COMPONENT B, LIQUID

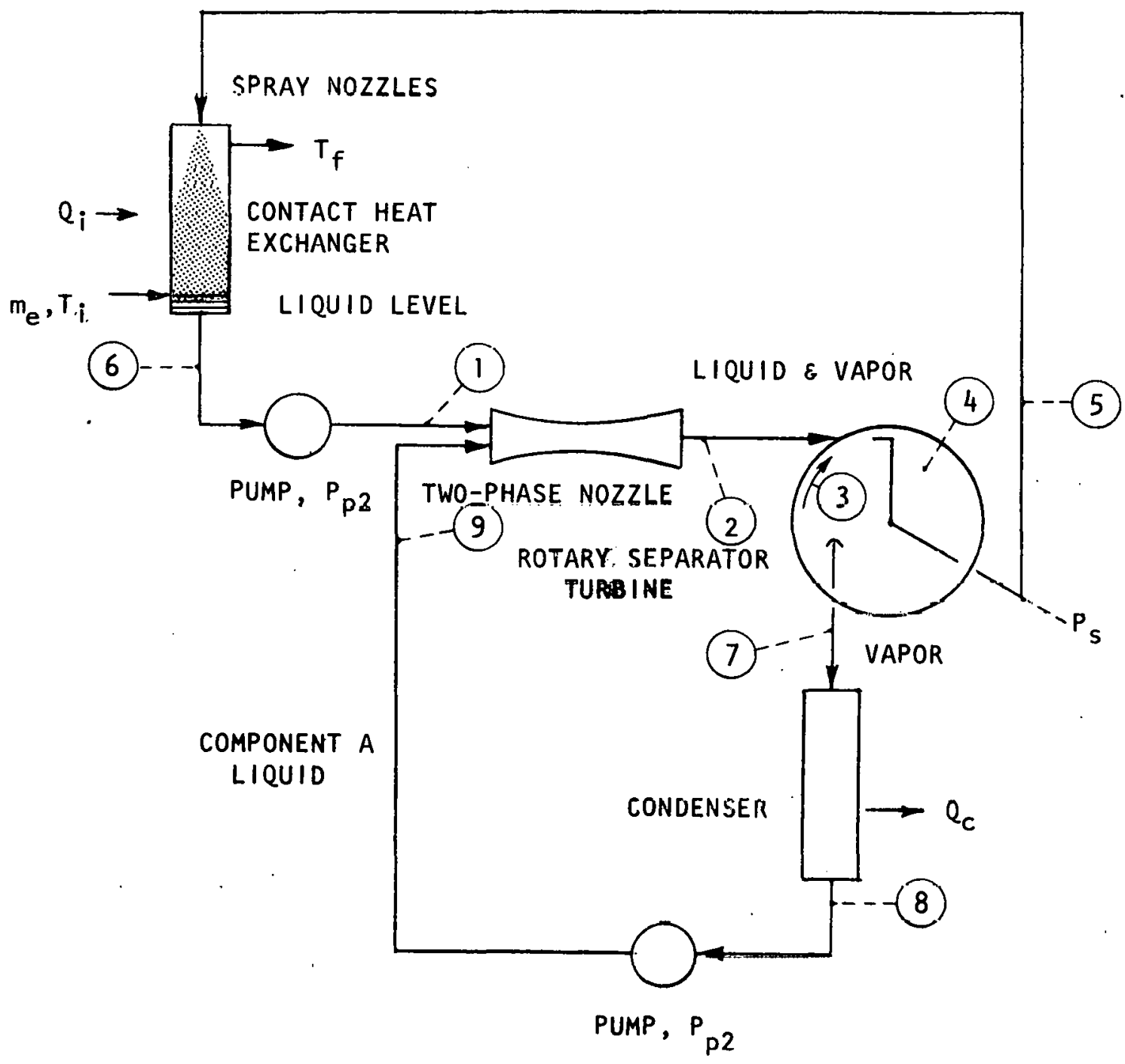

Fig. 12 - Two-Component, Two-Phase Bottoming Cycle with Contact Heat Exchangor 


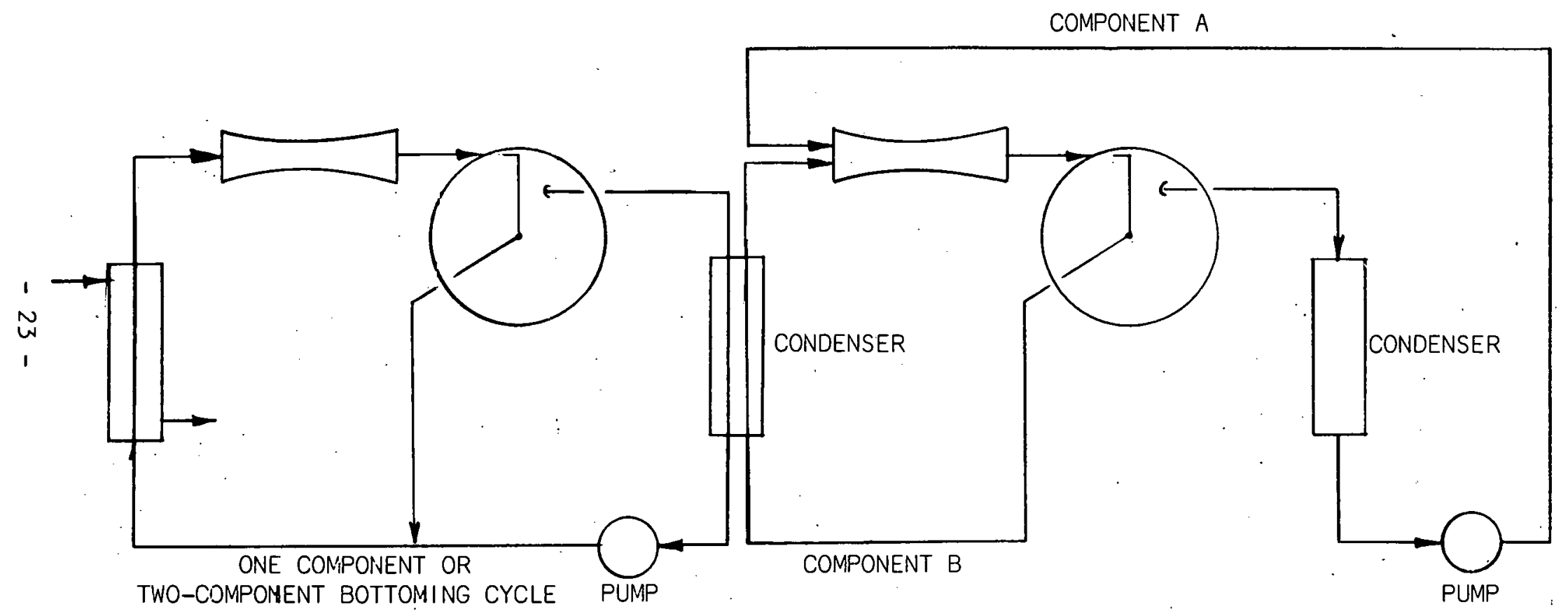

Fig. 12a - Use of Multiple Two-Phase Bottoming Cycles 
heat addition occurs at nearly a constant temperature resulting in effective use of the waste heat from the condenser. This waste heat is rejected at a nearly constant temperature as opposed to the exhaust gas waste heat which occurs over a wide temperature range. In general, the choice of cycle will depend upon the heat source temperature, power level and other factors to be discussed later.

TEMPERATURE - ENTROPY DIAGRAM

The temperature - entropy diagram for both single and two component cycles is shown in Figure 13. The temperature variation uf the nxhaust gus fol the diesel engine is illustrated by path $A$. The tomperature decreases trom $719^{\circ} \mathrm{F}$. to $242^{\circ} \mathrm{F}$. In a single component water system this exhaust heat is transferred to pressurized water following path $E$. The water is expanded in the two-phase nozzle following path $B$, if the process were isentropic, and path $C$ if real flow effects are included. The exit of the nozzle consists of a mixture of steam and water with high kinetic energy. This mixture drives the two-pliase turbine. The steam is condensed (path D), pressurized and remixed with the high pressure water laaving the turblne. An alternato methus is to extroct all of the liquid kinetic energy in the turbine and pressurize that liquid with the condensate pump. As can be seen, the two-phase bottoming cycle maximizes the energy available from the waste heat since the upper temperature of the bottoming cycle continunis!y incrcosas tu match the decrease of the heat source temperature.

In the case of a two-component cyrle tho therriudynamic wurking fluid (steam) follows path $F$ during the expansion. The reason the entropy increase is so large is the heat transfer from the all-liquid component into the steam. The net result is that the steam (for the reference cycle) is slightly superheated at the nozzle exit. In the case of the reference cycle, after separation of the steam. from the liquid, it is further expanded from the nozzle exit pressure, $14.7 \mathrm{psla}$, to a lower 
value, 1.2 psia, through a radial inflow gas turbine, producing added energy. This portion of the cycle diagram is path $G$. The steam is then condensed along path $H$, pressurized and remixed with the liquid from the liquid turbine. The heat input to the steam during the nozzle expansion is derived from the hot liquid which follows path $J$. This curve shows the entropy decrease per unit mass of component "B". However, since there are "r" Ibs. of "B" per Ib of "A", the total entropy change is given by path $K$. As can be seen, the areas under curves $K$ and $F$ are equal equating the heat transfer from the liquid into component $B$ into component $A$ during the expansion process. 


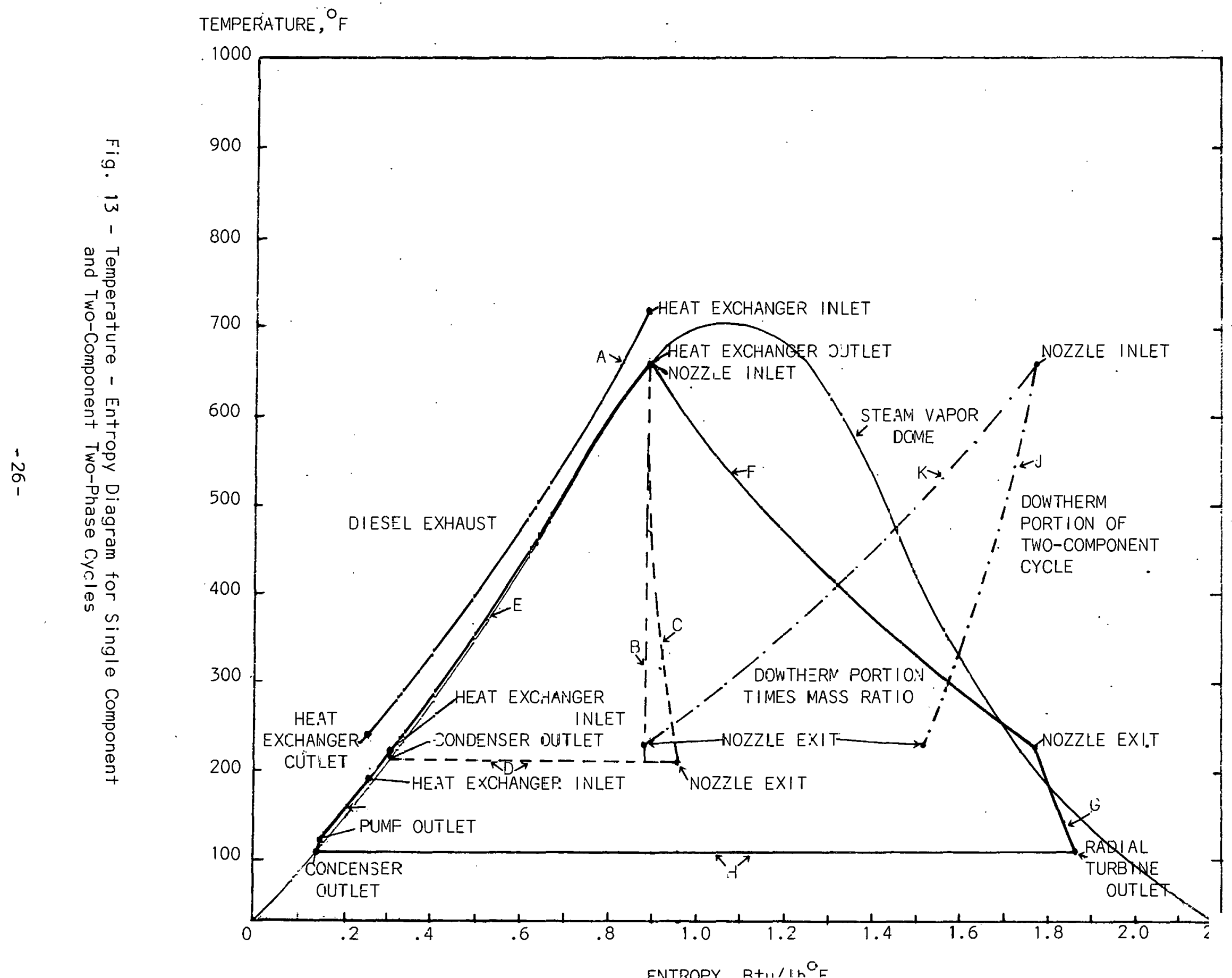




\section{CYCLE PERFORMANCE}

Performance of the different cycle variations was determined using the two-phase turbine relations of Appendix $A$ and the cycle equations of Appendix B. These calculations were performed for parametric variation of nozzle efficiency, turbine efficiency, rejection temperature and other variables of the power system. The final cycle selected was analyzed in somewhat greater detail as summarized in Section 4.

\section{SINGLE COMPONENT - SINGLE STAGE}

The single component cycle of Figure 9 was analyzed using water as the working fluid. Other possible working fluids considered were Dow-Therm $A$ and $E$ (Dow Chemical), Genetron 133a (Allied Chemical), CP-32 (Monsanto Co.), CP-34 (Monsanto Co.), the Freon family (Du Pont), Trichloroethylene (Dow Chemical), and mercury.

Water obviously has an advantage over the other fluids in terms of cost and the availability of equipment. Consideration of the thermodynamic properties showed most organics to be unsuited for a single component system because of the positive slope of the vapor saturation line. Expansion from pure liquid at a high enough temperature to be of interest for this application (exhaust temperature $=719^{\circ} \mathrm{F}$ ) leads to a superheated vapor ralliei than a two-phase mixtıre. This is illustrated in Figure 14 where nozzle expansion for water is compared to a nozzle expanslon for CP-32 (pyridine). The starting conditions are $600^{\circ} \mathrm{F}$. With an expansion to $200^{\circ} \mathrm{F}$, the water has a vapor quality of about 0.35 while the pyridine end point is far to the right of the saturated vapor line in the superheated region.

Mercury, on the other hand, is a very good fluid for a two-phase. system. The high ratio of latent heat of vaporization to sensible heat of the liquid $\left(\simeq 4,000^{\circ} \mathrm{F}\right)$ means a large ratio of liquid to vapor results from an 


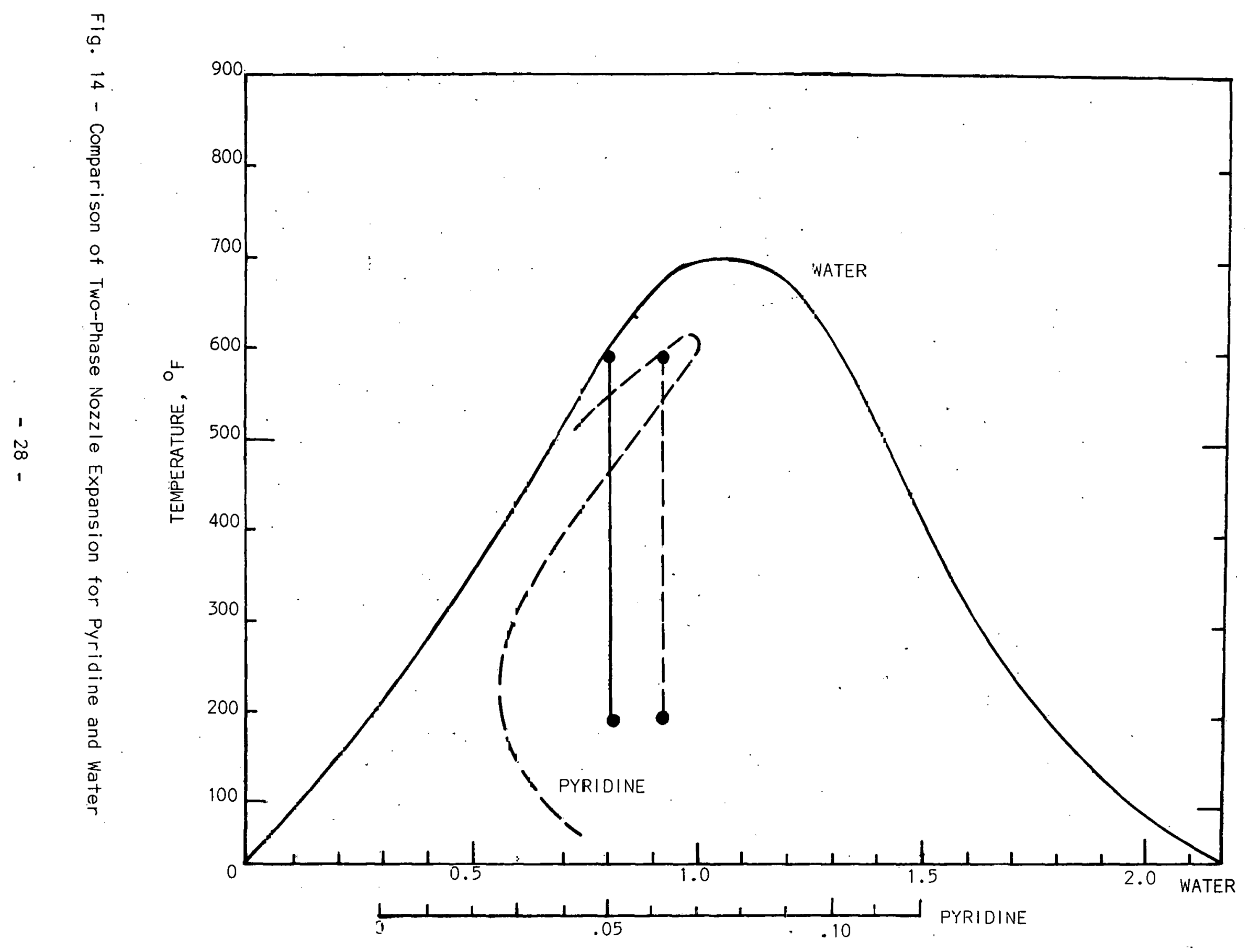


expansion. For example, expansion from liquid at $740^{\circ} \mathrm{F}$ to $240^{\circ} \mathrm{F}$ results in a vapor quality of only about. 10, giving a liquid/vapor ratio of 10 . Expansion of water $\left(L_{V} / C_{p} \simeq 1,000^{\circ} \mathrm{F}\right)$ with a similar temperature drop gives. a vapor quality of about .50 , for a liquid to vapor ratio of only one. Thus, the spouting velocity of the mercury nozzle (aside from the obvious molecular weight differences) would be much less with a higher mass flow rate and the corresponding two-phase turbine rpm would be much less. Of course, mercury is undesirable as a working fluid because of its cost and toxicity. In addition, the vapor pressure is too low for the application of interest. However, future working fluid searches for single components should concentrate on candidates with a high $L_{v} / C_{p}$ ratio.

The results of calculations for a single stage two-phase bottoming cycle using water are shown in Figures 15 thru 17. In Figure 15, the net cycle. efficiency is plotted versus condensing temperature for several values of maximum cycle temperature. A peak efficiency of about $28 \%$ is reached. at the maximum cycle temperature of $700^{\circ} \mathrm{F}$ and the condensing temperature of $90^{\circ} \mathrm{F}$. The efficiency is very sensitive to the minimum temperature, decreasing from a value of $28 \%$ at $90^{\circ} \mathrm{F}$ to about $21 \%$ at $212^{\circ} \mathrm{F}$ (rejection temperature). Changing the peak temperature from $700^{\circ} \mathrm{F}$ to $640^{\circ} \mathrm{F}$ at a condensing temperature of $90^{\circ} \mathrm{F}$, reduces the efficiency from $28 \%$ to about $25 \%$. This change is significant because it means dropping the peak pressure from 3100 psia to 2100 psia with attendent lessening of equipment requi rements.

These calculations were all performed for a turbine efficiency of .85 , a nozzle efficiency of .85 , a pump efficiency of .75 and a diffuser efficiency of .85 . The mass ratio of course is a dependent variable as the cycle conditions change.

In order to examine the influence of these component efficiencies (cf. Append $i x B$ ) on cycle efficiency, a reference cycle was chosen at 


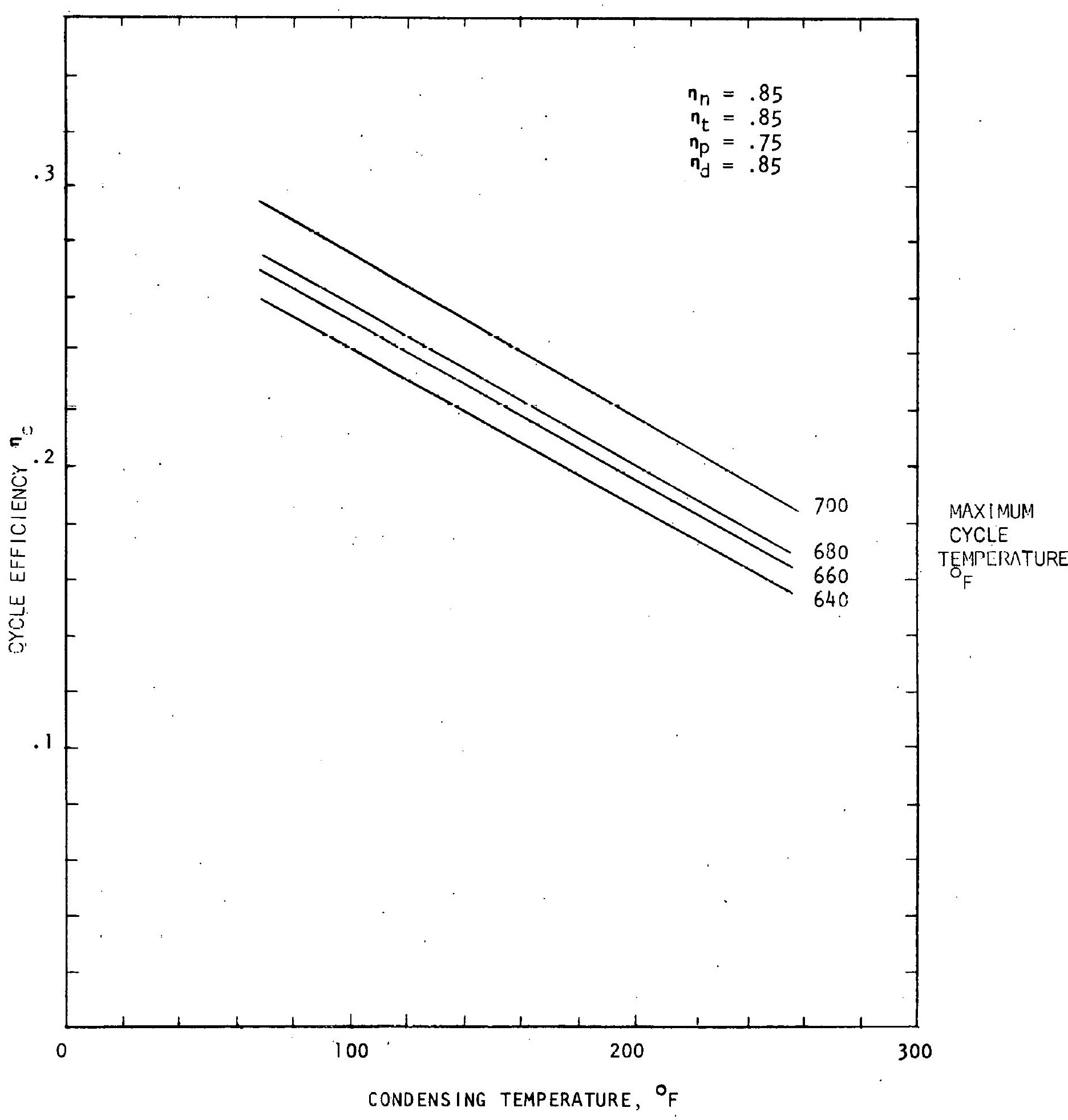

Fig. 15 - Efficiency of Single Stage - Single Component Cycle Versus Condensing Temperature and Maximum Cycle Temperature (Water Working Fluid) 


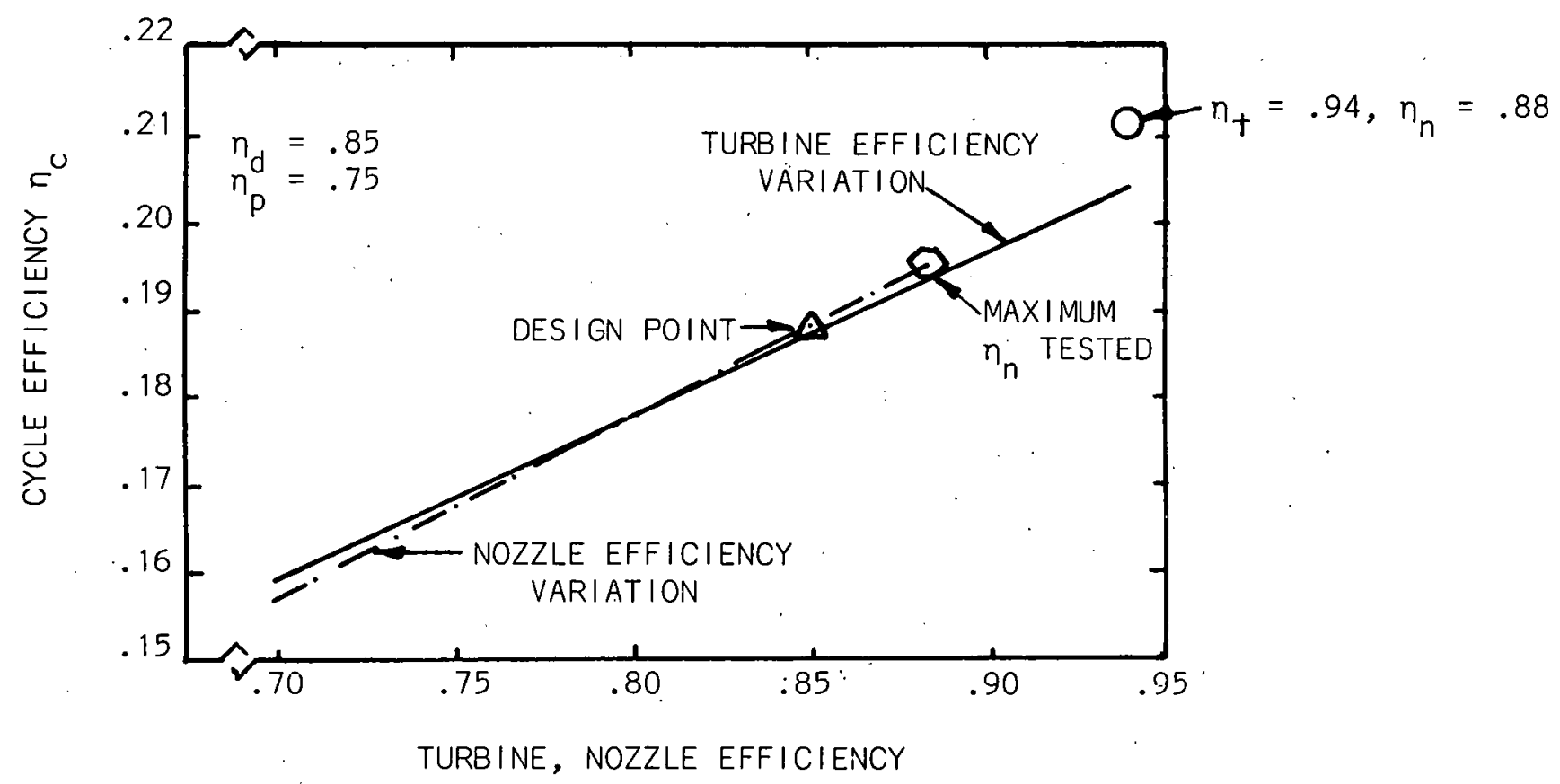

Fig. 16.- Influence of Turbine and Nozzle Efficiencies on Cycle Efficiency $\left(\mathrm{T}_{1}=660^{\circ} \mathrm{F}, \mathrm{T}_{2}=212^{\circ} \mathrm{F}\right)$

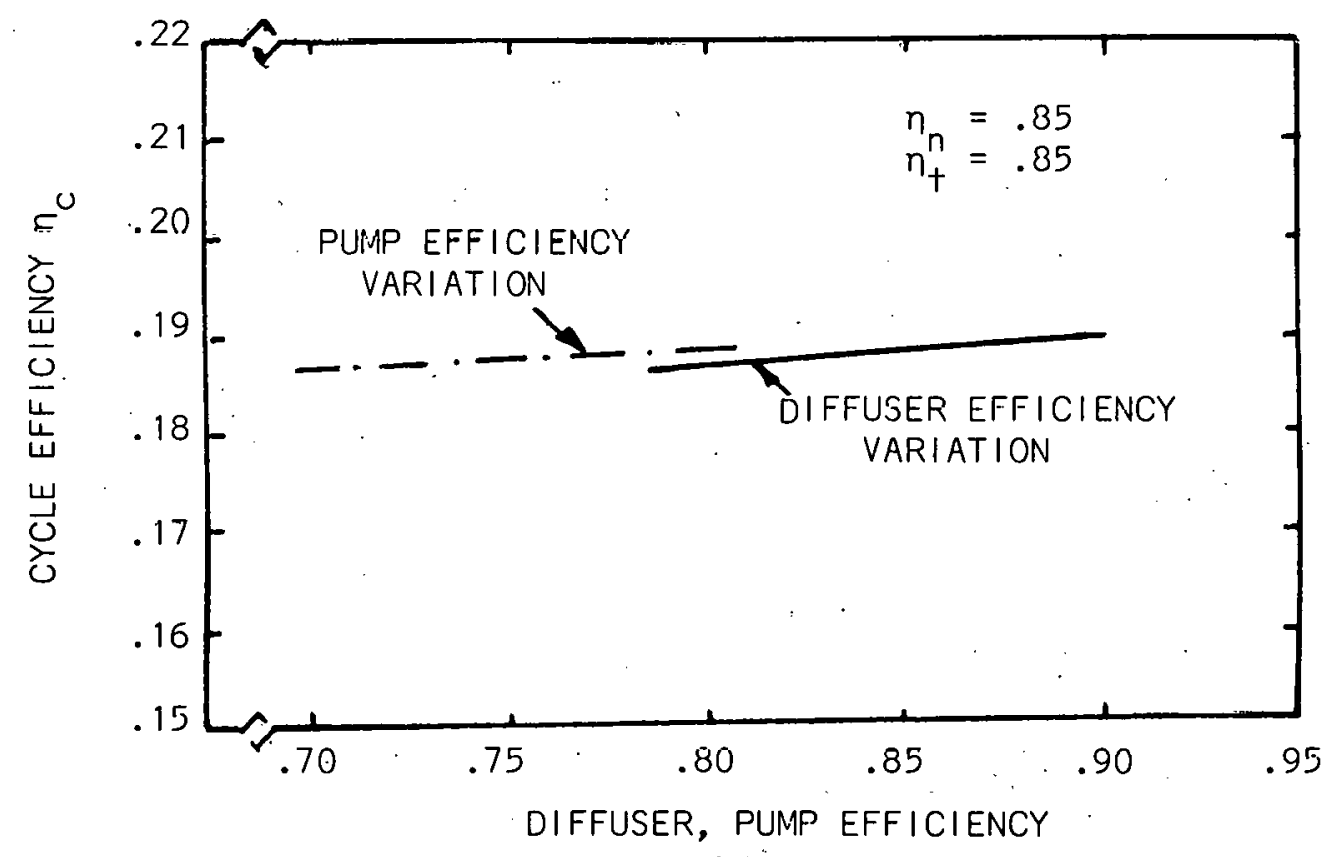

Fig. 11 - Intluence of Diffuser and Pump Efficiencies on Cycle Efficiency $\left(T_{1}=660^{\circ} \mathrm{F}, T_{2}=212^{\circ} \mathrm{F}\right)$ 
$\mathrm{T}_{1}=660^{\circ}$ and $\mathrm{T}_{2}=212^{\circ} \mathrm{F}$. The reference cycle efficiency was about $19 \%$ at this point with the above component efficiencies. As seen in Figure 16, variations in nozzle efficiency or turbine efficiency about the design value of .85 , produce a change of about 1 percentage point in cycle efficiency for every 5 percentage points change in component efficiency. The maximum nozzle efficiency previously measured (.88,

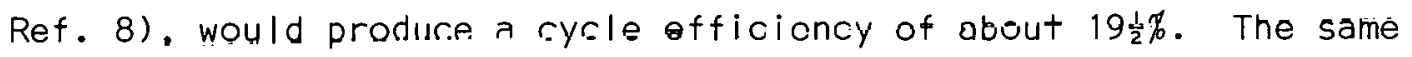
maximum nozzle efficiency with the maximum Pelton wheel efficiency reported (9) would give a cycle efficiency of $21 \%$, a $12 \%$ relative increase above the design point. On the other hand, a nozzle or turbine efficiency of only . 70 would reduce the cycle efficiency to $16 \%$, which would still be a tolerable value.

Figure 17 shows the cycle efficiency to be less dependent on diffuser and pump efficiency. In this chart, the cycle efficiency changes by only about $1 / 10$ percentage point for every 5 percentage points change in pump or diffuser efficiency. This is particularly significant in the case of the diffuser where the ingestion of vapor can cause efficienry losses.

A key problem with a single component water cycle is the high nozzle exit vapor quality, and hence, high spouting velocity. Nozzle spoutIng velocities range from $2,600 \mathrm{ft} / \mathrm{s}$ for $212^{\circ} \mathrm{F}$-condensing temperature, to $3,500 \mathrm{ft} / \mathrm{s}$ for a $90^{\circ} \mathrm{r}$-condensing temperature. These high values negate one of the original advantages of a two-phase cycle - the lower turbine rom. For a two font diameter turbine, on ipiil ldilge of 12,000 to 17,000 would resillt. For a Polton or axial fluw turbine the rela- tive liquid impact velocities in the lower range are within turbine current practice $(1,300-1,400 \mathrm{ft} / \mathrm{s}$, Ref. 10), but extreme erosion could be expected to occur at the upper limit of $1,750 \mathrm{ft} / \mathrm{s}$. Thus, it would appear that a lower velocity, such as could be obtained by staging or the use of two components, would be desirable. 
In' order to determine the benefits of staging, the two stage cycle shown in Figure 10 was analyzed and compared to the single stage version. The maximum temperature was chosen as $680^{\circ} \mathrm{F}$ and the rejection temperature was taken as $90^{\circ} \mathrm{F}$. A single stage system analyzed for these conditions gave an efficiency of $27 \%$ with a nozzle spouting velocity of $3,240 \mathrm{ft} / \mathrm{s}$. For a two foot wheel, this would result in an rpm of 15,500, clearly too high.

Assuming an equal pressure ratio for each stage of the two stage system, with a 10 psi pressure drop between stages, gives an inilet pressure of 40 psia to the second stage. Table 1 summarizes the results of the nozzle calculations using these operating parameters.

\section{TABLE 1}

NOZZLE PARAMETERS OF TWO STAGE, SINGLE COMPONENT SYSTEM Inlet Exit Inlet Exit Spouting

\begin{tabular}{|c|c|c|c|c|c|}
\hline Stage & $\frac{\text { Pressure }}{\text { (psia) }}$ & $\frac{\text { Pressure }}{\text { (psia) }}$ & Qual ity & Quality & $\frac{\text { Velocity }}{(\mathrm{ft} / \mathrm{s})}$ \\
\hline 1 & 2710 & 50 & 0 & .42 & 2250 \\
\hline 2 & 40 & .7 & .27 & .33 & 1915 \\
\hline
\end{tabular}

Using these values, the total cycle efficiency becomes $28 \%$ (the slight increase over the single stage is due to the fact that the second stage nozzle is operating at more nearly constant mass ratio). If the pressure ratios were adjusted slightly, to give equal exit velocities, the resulting spouting velocity for the first and second stages would be $2,090 \mathrm{ft} / \mathrm{s}$. For a two foot diameter turbine, an rpm of 9,980 would result. Thus, the beneficial effect of increasing from a single stage to a two stage system would be reduction of the turbine rpm from 15,500 to 9,980 while increasing the cycle efficiency by approximately one percentage point, from $27 \%$ to $28 \%$. The disadvantage is the addition 
of a second nozzle and turbine. To a first approximation, the rpm is inversely proportional to the square root of the number of stages. Thus, to reduce the rpm from $n_{1}$ to $n_{2}$, a total of $\left(n_{1} / n_{2}\right)^{2}$ stages would be requi red.

TWO COMPONENT - SINGLE STAGE

The nozzle exit velocity can alsu be reduced by the use of a second componert " $B$ ", having a lower sensible heat than the liquid phase of the thermodynamic working fluid "A". In order to retain the advantages of a gas to liquid lied exchanger, the amount of the second compunent must be chosen to give the proper temperature variation in the nozzle and heat exchanger (cf. Appendix B). If too high a flow rate of "B" 'is used, the nozzle and heat exchanger will approach isothermal operation - the same as if "A" were being vaporized in the heat exchanger. This will reduce the cycle efficiency. If too low a flow rate of "B" is used, the liquid to gas mass ratio will be lower than desired - giving a high nozzle spouting velocity (if the hcat source were at a constant temperature, then the mass ratio of " $B$ " to "A" could be freely varien to give the exacl nozzlè spouting valonity and turbinc rpm Jesilrili.

Two-component two-phase bottoming systems were analyzed using water as the thermodynamic working fluid and Dow-Therm $A$ as the linuid somponent. Several combinations were examined but the water--now-Therm combination had the highest ratio of the latent heat of vaporization to sensible heat of those examined. As will be seen later, the nozzle spouting velocities and turbine rpm are higher than desirable. If a higher molecular weight=thermudynamlc working fluid could be found, the turbine rpm could be reduced accordingly.

In order to illustrate the importance of the above parameters, consider a heat source from which it is desired to increase the cycle temperature 
from $T_{2}$ to $T_{1}$ : For an isentropic nozzle expansion we have:

$$
\dot{m}_{a} s_{a_{1}}^{\prime \prime}+\dot{m}_{b} s_{b_{1}}^{\prime \prime}=\dot{m}_{a} s_{a_{2}}^{\prime}+\dot{m}_{b} s_{b_{2}}^{\prime \prime}
$$

$$
\text { where } \begin{aligned}
\dot{m}_{a} & =\text { mass flow rate of component } A \\
\dot{m}_{b} & =\text { mass flow rate of component } B \\
s_{a_{1}}^{\prime \prime} & =\text { entropy of component } A \text { liquid at the nozzle inlet } \\
s_{b_{1}}^{\prime \prime} & =\text { entropy of component } B \text { liquid at the nozzle inlet } \\
s_{a_{2}}^{\prime} & =\text { entropy of component } A \text { vapor at the nozzle exit } \\
s_{b_{2}}^{\prime \prime} & =\text { entropy of component } B \text { liquid at the nozzle exit }
\end{aligned}
$$

$\dot{m}_{b}$ is selected so that component $\dot{A}$ is all vaporized and is at saturated conditions at $T_{2}$. Solving for the mass ratio $r=\dot{m}_{b} / \dot{m}_{a}$ :

$$
r=\frac{s_{a_{2}}^{\prime}-s_{a_{1}}^{\prime \prime}}{s_{b_{1}}^{\prime \prime}-s_{b_{2}}^{\prime \prime}}=\frac{s_{a_{2}}^{\prime}-s_{a_{2}}^{\prime \prime}+s_{a_{2}}^{\prime \prime}-s_{a_{2}}^{\prime \prime}}{s_{b_{1}}^{\prime \prime}-s_{b_{2}}^{\prime \prime}}
$$

or

$$
r=\frac{\frac{L_{v a_{2}}}{T_{2}}+C_{p a}^{\prime \prime} \ln \frac{T_{2}}{T_{1}}}{C_{p b}^{\prime !} \ln \frac{T_{2}}{T_{1}}}
$$

where $s_{a_{2}}^{\prime \prime} \quad=$ entropy of component $A$ liquid at the nozzle exit

$L_{v a 2}=$ latent heat of vaporization of $A$

$\mathrm{C}_{\mathrm{pa}, \mathrm{b}}^{\prime \prime}=$ specific heat of $\mathrm{A}, \mathrm{B}\left(\mathrm{B} / \mathrm{I} \mathrm{b}^{\circ} \mathrm{F}\right)$

Thus, larger $L_{v a}$ and smaller $C_{p b}^{\prime \prime}$ give higher values of mass ratio, which reduces the nozzle velocity.

- The two component cycle using water and Dow-Therm was analyzed for variation of the following parameters:
a. Peak Cycle Temperature
$500^{\circ} \mathrm{F}$ to $700^{\circ} \mathrm{F}$
b. Rejection Temperature $90^{\circ} \mathrm{F}$ to $212^{\circ} \mathrm{F}$
c. Diesel Exhaust Temperature
$520^{\circ} \mathrm{F}$ to, $720^{\circ} \mathrm{F}$
d. Diesel Exhaust Flowrate $15,300 \mathrm{lb} / \mathrm{h}$ to $27,300 \mathrm{lb} / \mathrm{h}$
e. Working Fluids ( $C_{p}$ variation) steam \& Freon thru polyphenyl ether 

f. Liquid/Gas Mass Ratio
3.5 to 23.0
g. Output rpm
5,000 to 12,000

In the case of the mass ratio and output rpm, independent variation was not always possible because of the interrelation of variables.

The effect of the peak cycle temperature is shown in Figure 18. Operation with a condensing pressure of .7 psia $\left(90^{\circ} \mathrm{F}\right)$ and a nozzle exit liquid temperature of $212^{\circ} \mathrm{F}$, gave a peak cycle efficiency of $30 \%$ at a peak temperature of $700^{\circ} \mathrm{F}$. Reduction of the temperature from $700^{\circ} \mathrm{F}$ to $500^{\circ} \mathrm{F}$ (reduction of the peak. pressure from 3,090 psial lu 680 psla) reduced the cycle efficiency by only 6 percentage points (to $24 \%$ ). of course, the reduction is much greater in terms of the available energy if the peak exhaust temperature is constant at $719^{\circ} \mathrm{F}$. The significance of this result is that the part load efficiency can be kept at a high value as the diesel power (exhaust temperature) drops.

The influence of liquid temperature on cycle efficlency for a constant back pressure $(.7 \mathrm{psia})$ and constant peak cycle temperature $\left(660^{\circ} \mathrm{F}\right)$ is shown in Figure 19. Reduction of tho temperatuie fulum $240^{\circ} \mathrm{F}$ to $\mathrm{y}^{\circ} \mathrm{r}$ results in a reduction of the efficiency from $29 \%$ to $25 \%$. This change results from reducing the mass ratio from 6.5 to 3.9. At the higher mass ratio, more energy is transferred into the liquid phase resulting in the higher efficiency.

The nozzle back pressure (condensing temperature) has perhaps the greatest effect on cycle efficiency and turbine rpm. Figure 20 shows the cycle efficlency to increase from $18 \%$ to $29 \%$ as the back pressure is decreased from 14.7 psia to .7 psia. For a constant liquid outlet temperature this results in a simultaneous increase in mass ratio, $r$, and nozzle spouting velocity. The mass ratio increases from 4.7 to 6.5 while the spouting velocity increases from $1,660 \mathrm{ft} / \mathrm{s}$ to $1,920 \mathrm{ft} / \mathrm{s}$. In addition to the disadvantage of higher turbine rpm, decreasing the 


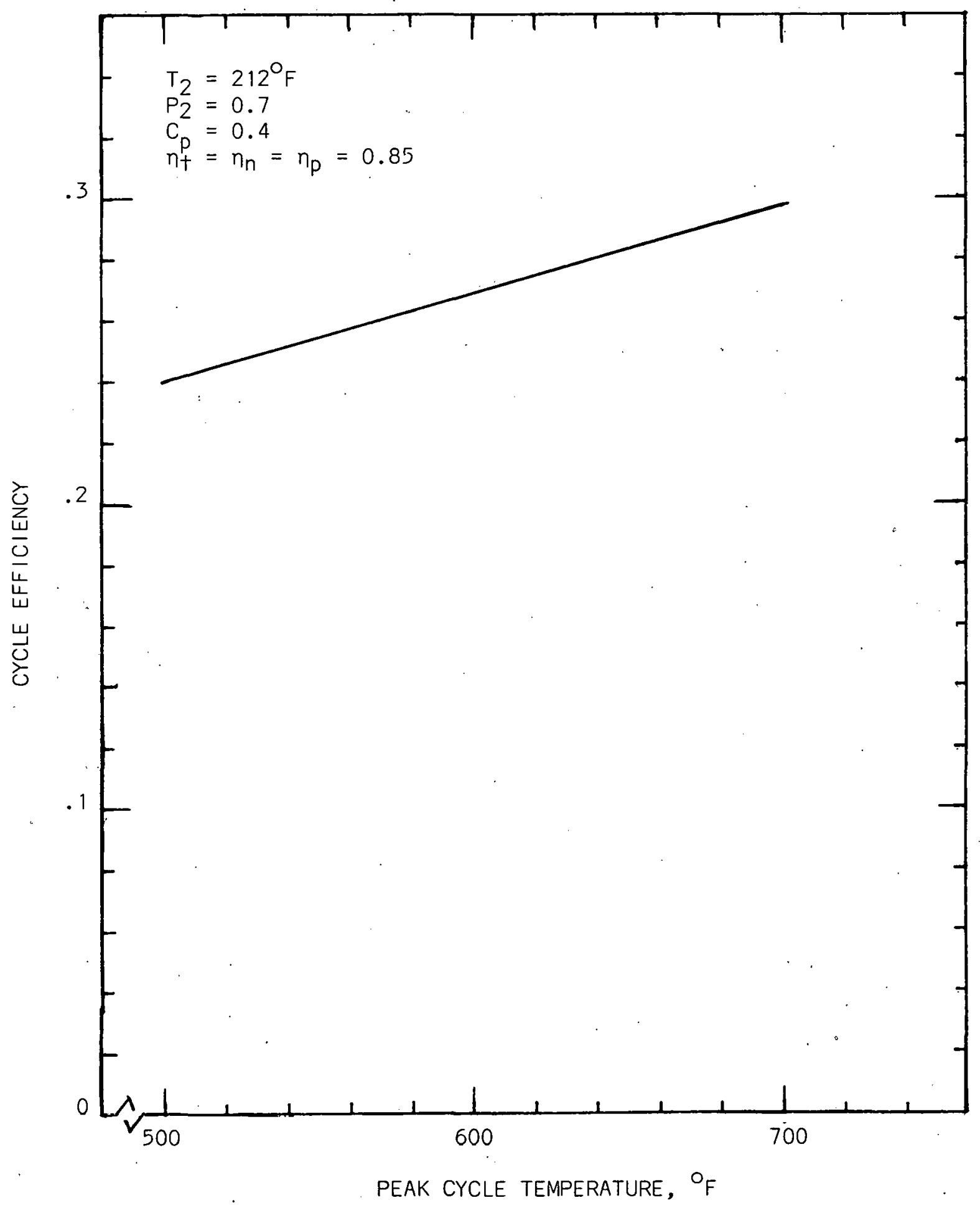

Fig: 18. - Efficlency Versus Peak Cycle Temperature for TwoComponent Bottoming Cycle 


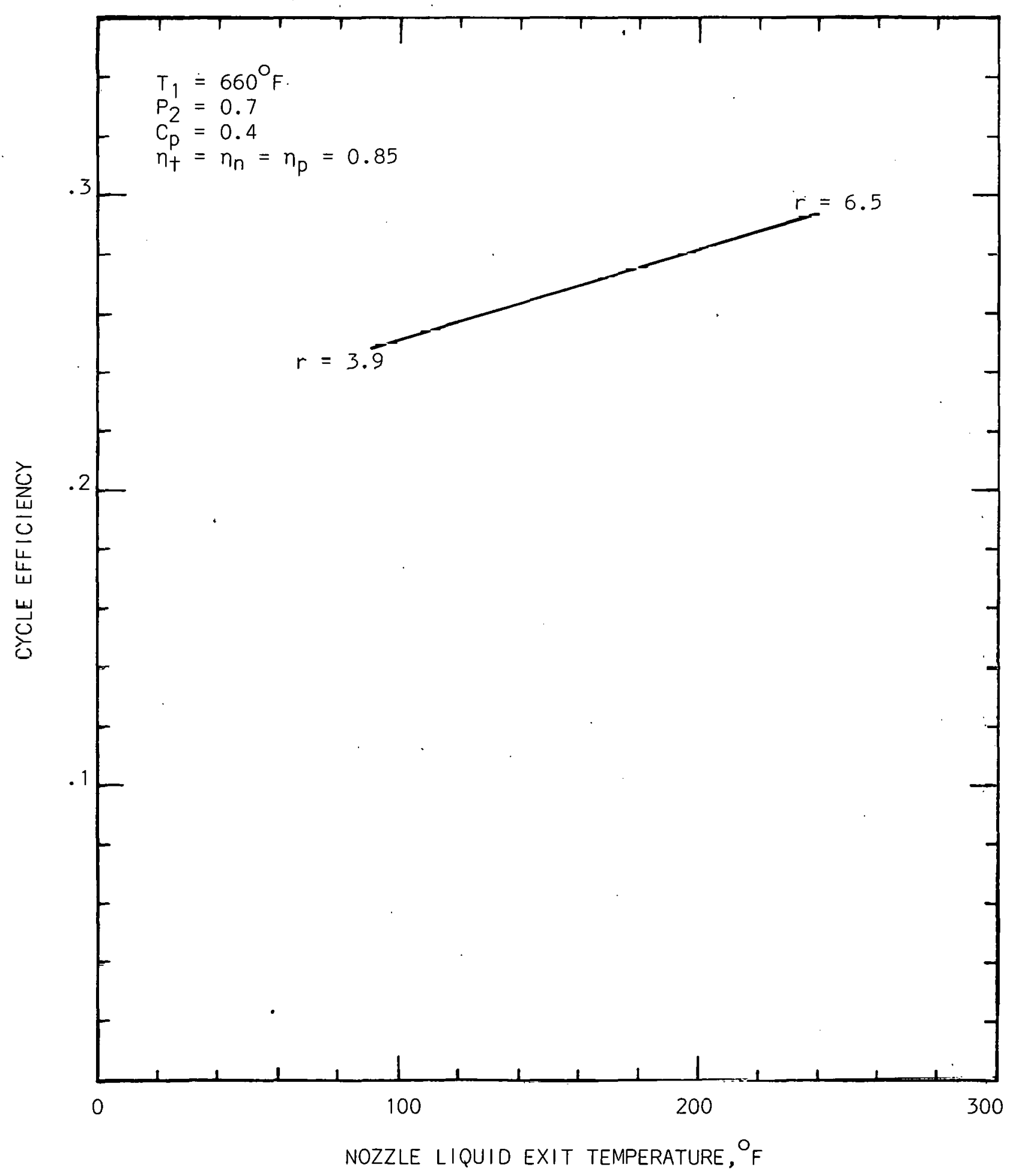

Fig. 19 - Efficiency Versus Nozzle Liquid Exit Temperature for Two-Component Bottoming Cyclé 


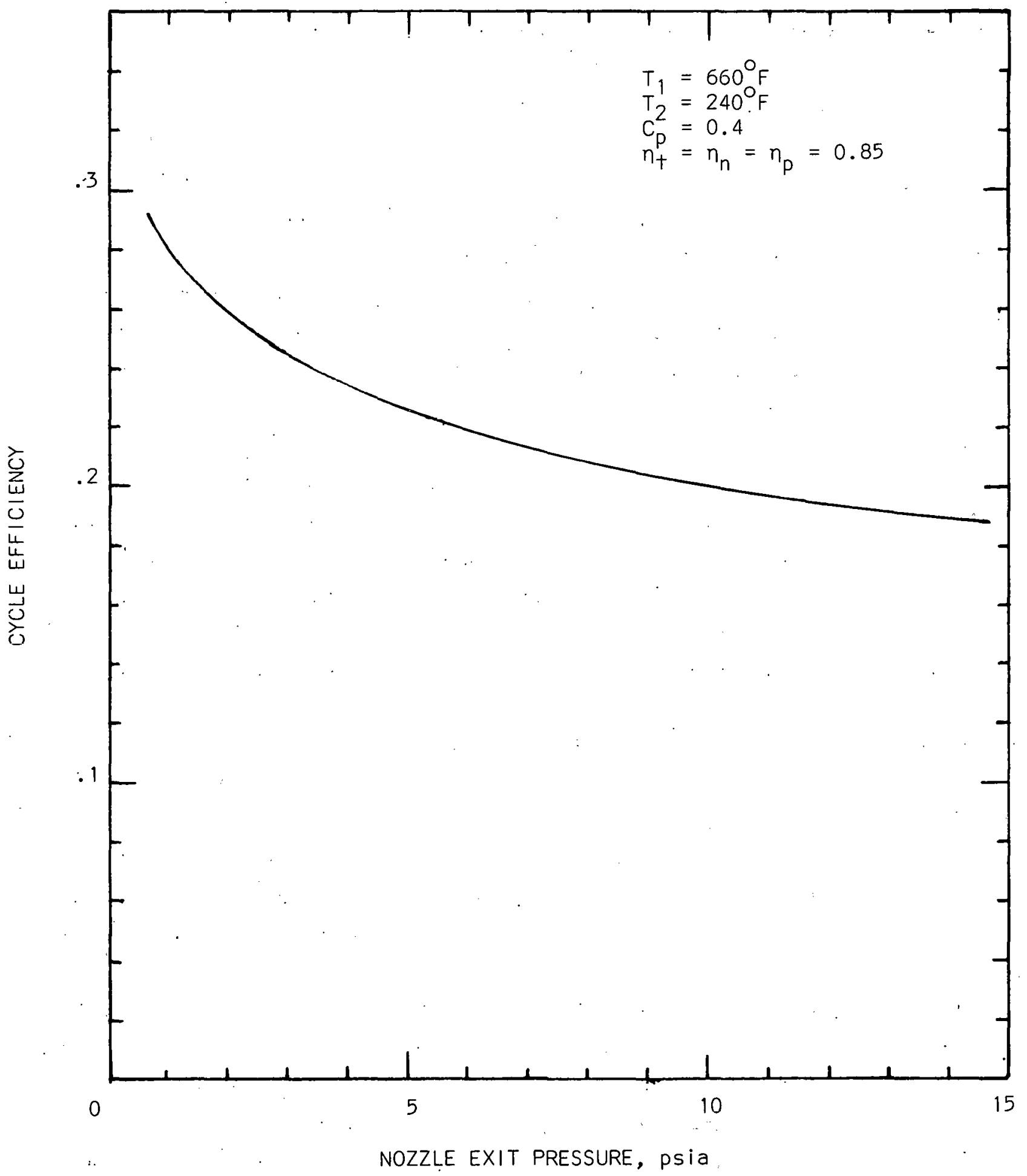

FIg. 20 - Etficiency Versus Nozzlc Exit Pressure (Heat Rejection Temperature) for Two-Component Two-Phase Bottoming Cycle 
back pressure results in a large increase in nozzle exit area which tends to reduce both the nozzle and the turbine efficiency. Thus, the gains reflected in Figure 20. would be somewhat reduced due to decreasing nozzle and turbine efficiency.

The effect of the liquid working fluid can be seen in Figure 21 through the influence of the sensible heat change. The sperific heats of different fluids are indicated on the figure far comparison purpuses. As can be seen, a gradual decrease in cycle efficiency occurs as the heat capacity is decreased. For example, decreasing the sensible heat frum $.6 \mathrm{~B} / 1 \mathrm{~b}^{\mathrm{O} \mathrm{F}}$ to $.2 \mathrm{~B} / 1 \mathrm{~b}^{\circ} \mathrm{F}$ reduces the cycle efficiency from $29 \%$ to $27 \frac{1}{2} \%$. However, the mass ratio increases from 3.9 to 11.7 and the nozzle spouting velocity is reduced from $2,350 \mathrm{ft} / \mathrm{s}$ to $1,520 \mathrm{ft} / \mathrm{s}$. This example best illustrates the transformation possible if the mass ratio of liquid to gas can be increased within the thermodynamic constraints available. The reference cycle finally adopted, is operated at a relatively high nozzle exit pressure to limit the nozzle spouting velocity. Howver, if a suitable fluid with a significantly lower $C_{p}$ than that of Dow-Therm $A$ can be used, considerable efficiency improvement should be obtalnable.

The above results were generated for constant values of nozzle efficiency, turbine efficiency and pump efficiency. The influence of these parameters on cycle efficiency are shown in Figures 22 through 26. In general, the nozzle and turbirle efflciencies have a very strong influence on cycle efficiency, whereas, the pump or diffuser efficlency has a less pronounced effect. For example, increasing the turbine and nnzzle efficiencies from the design value of .85 to .90 would incrense the sycle offlciency lium $.28 \%$ to $31 \%$. Decreasing them both to .70 would reduce the cycle efficiency from $28 \%$ to a little over $20 \%$, which is still a usable value. On the other hand, if the pump efficiency were decreased from .85 to .65, the sycle efficiency would only drop by less than one percentage point (from $28.4 \%$ to $27.5 \%)$. Thus, a considerable range of useful performance exists whether 


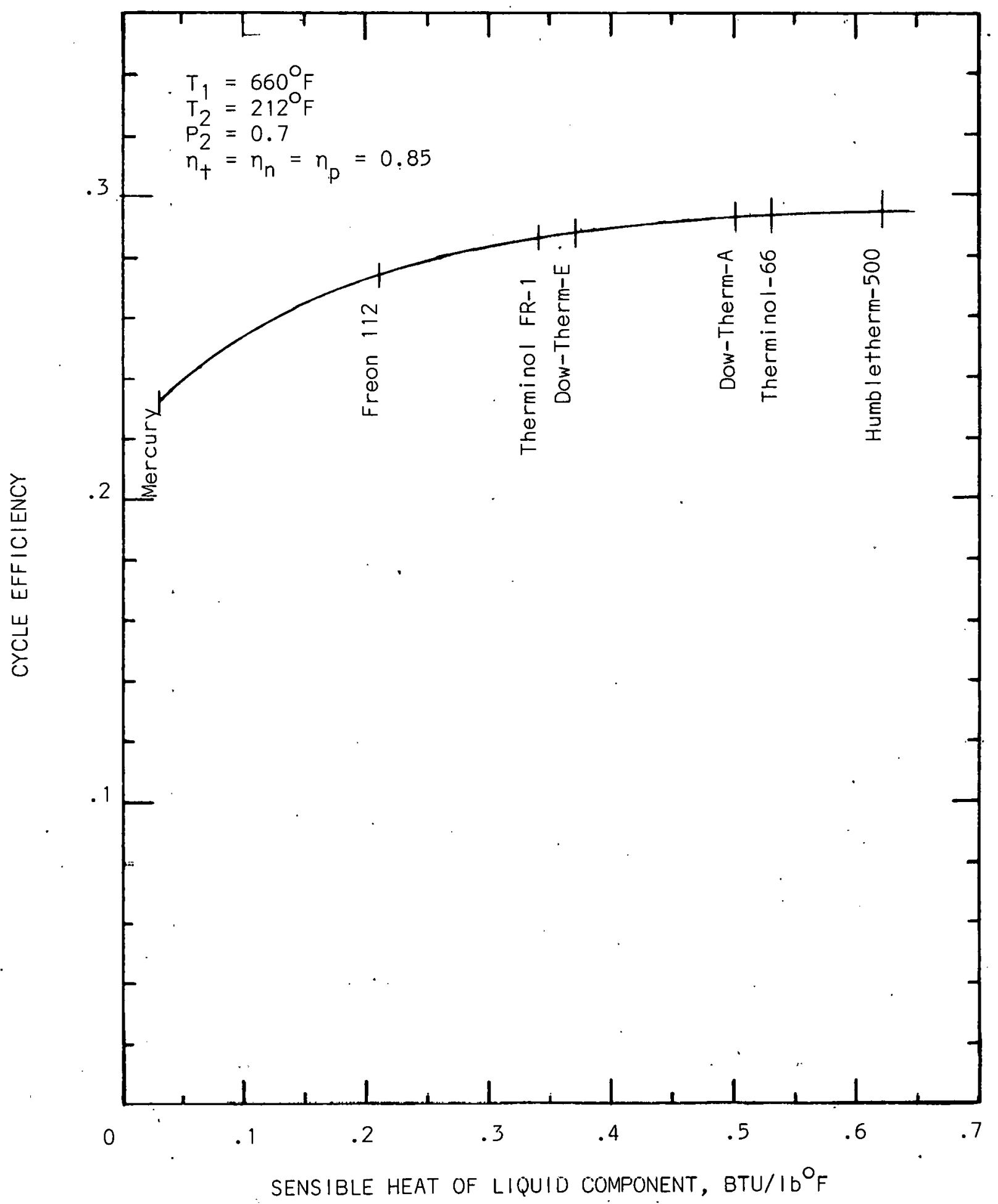

Fig. 2i-Cycle Efficiency Versus Sensible Heat of Liquid Component for Two-Component Two-Phase Bottoming Cycle 


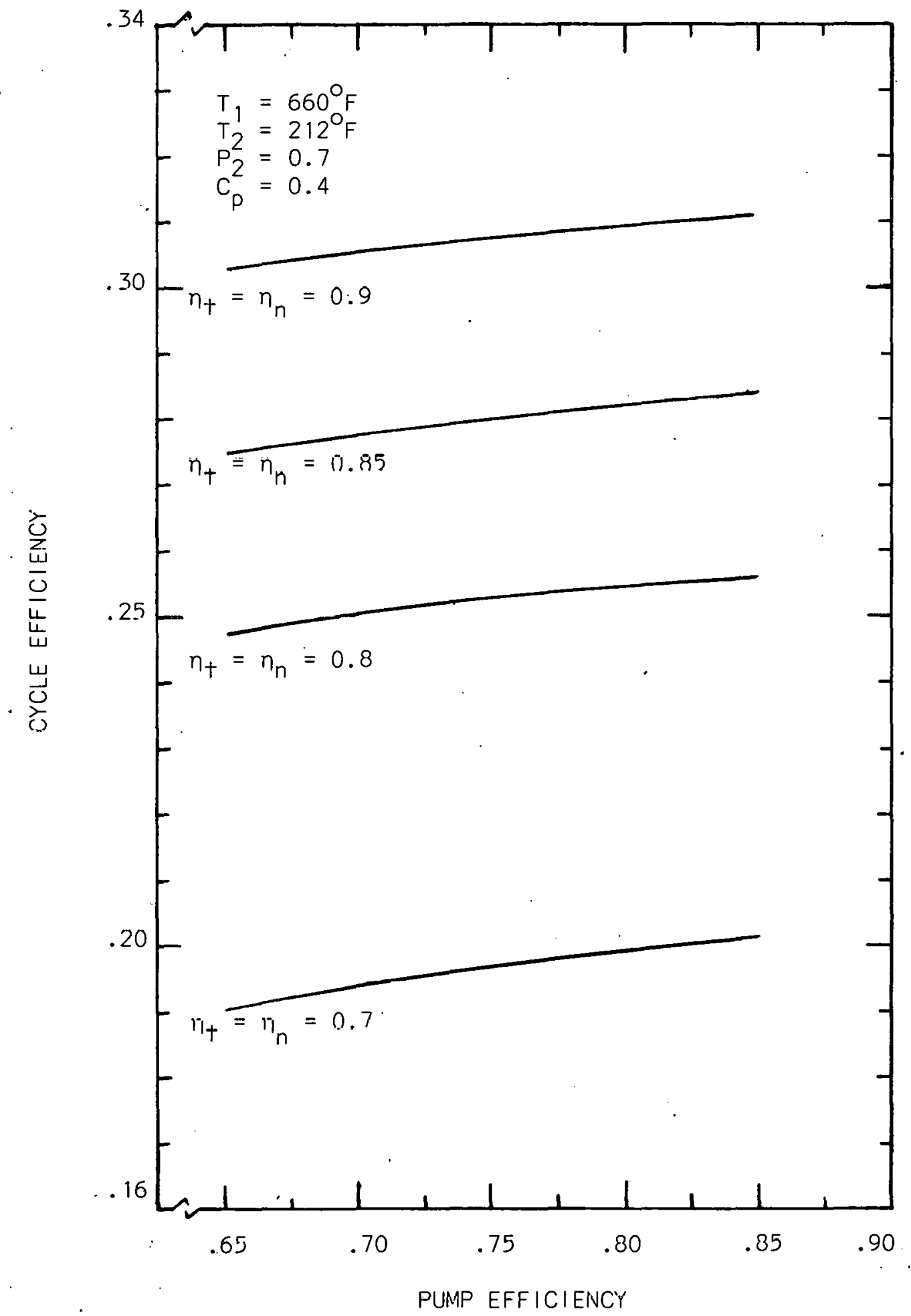

Fig. 22 - Influence of Nozzle, Turbine and Pump Efficiencies on Cycle Efficiency 


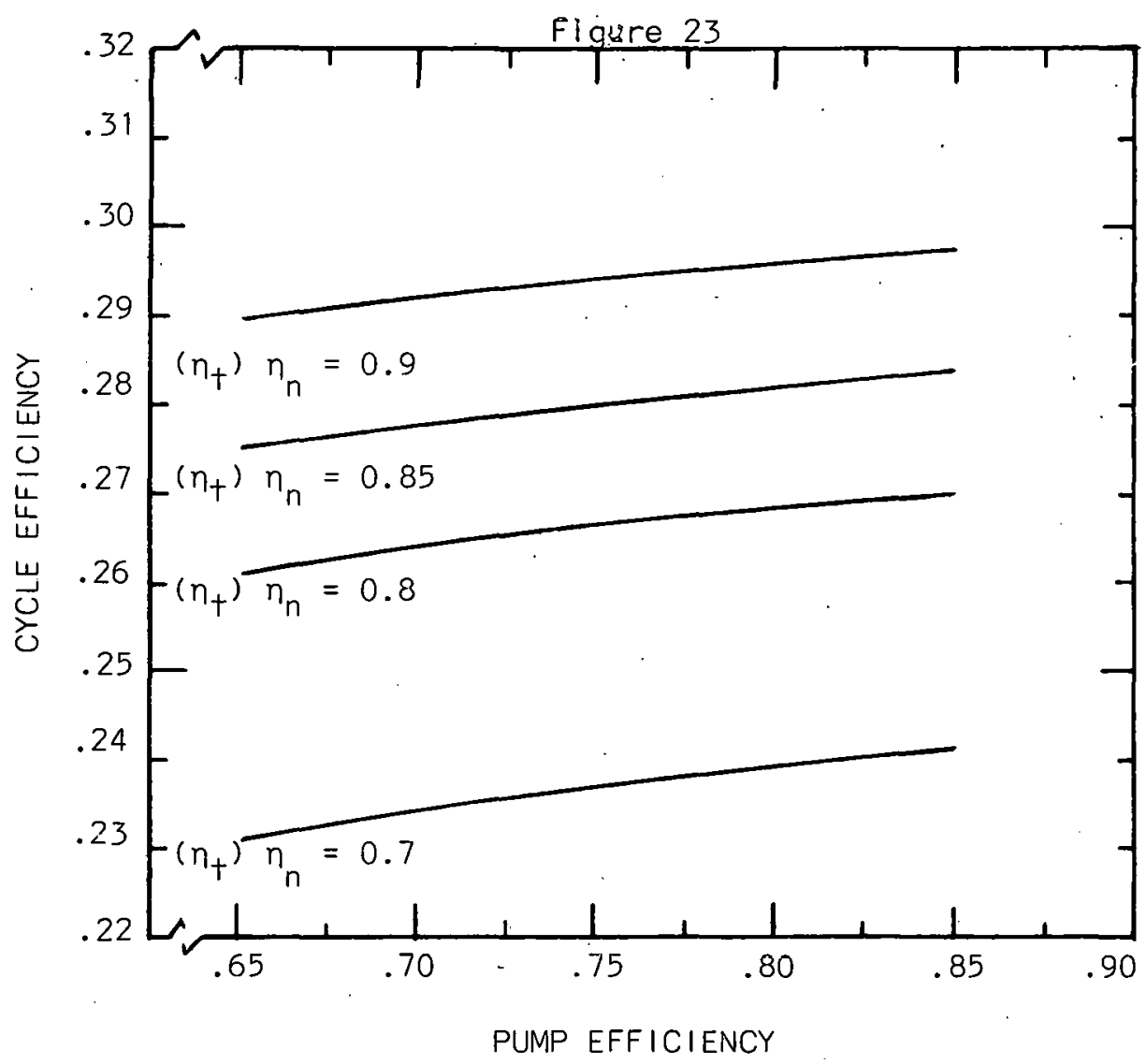

$$
\begin{aligned}
& \mathrm{T}_{1}=660^{\circ} \mathrm{o} F \\
& \mathrm{~T}_{2}=212{ }^{\mathrm{F}} \\
& \mathrm{P}_{2}=0.7 \\
& \mathrm{C}_{\mathrm{p}}=0.4 \\
&\left(n_{n}\right){\eta_{+}}=0.9
\end{aligned}
$$

Figs. 23,24 - Influence of Nozzle, Turbine and Pump Efficiencies on Cycle Efficiency

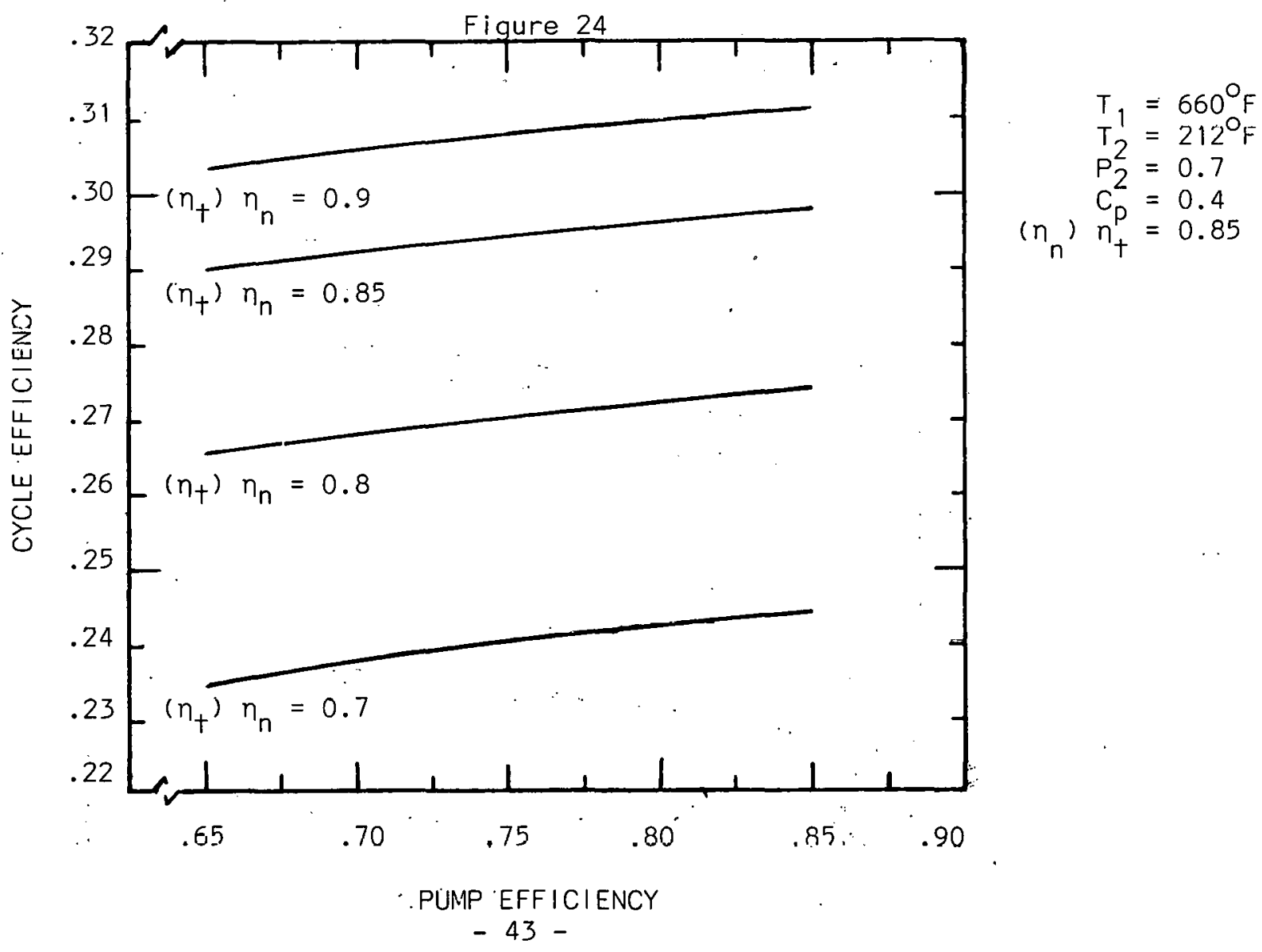




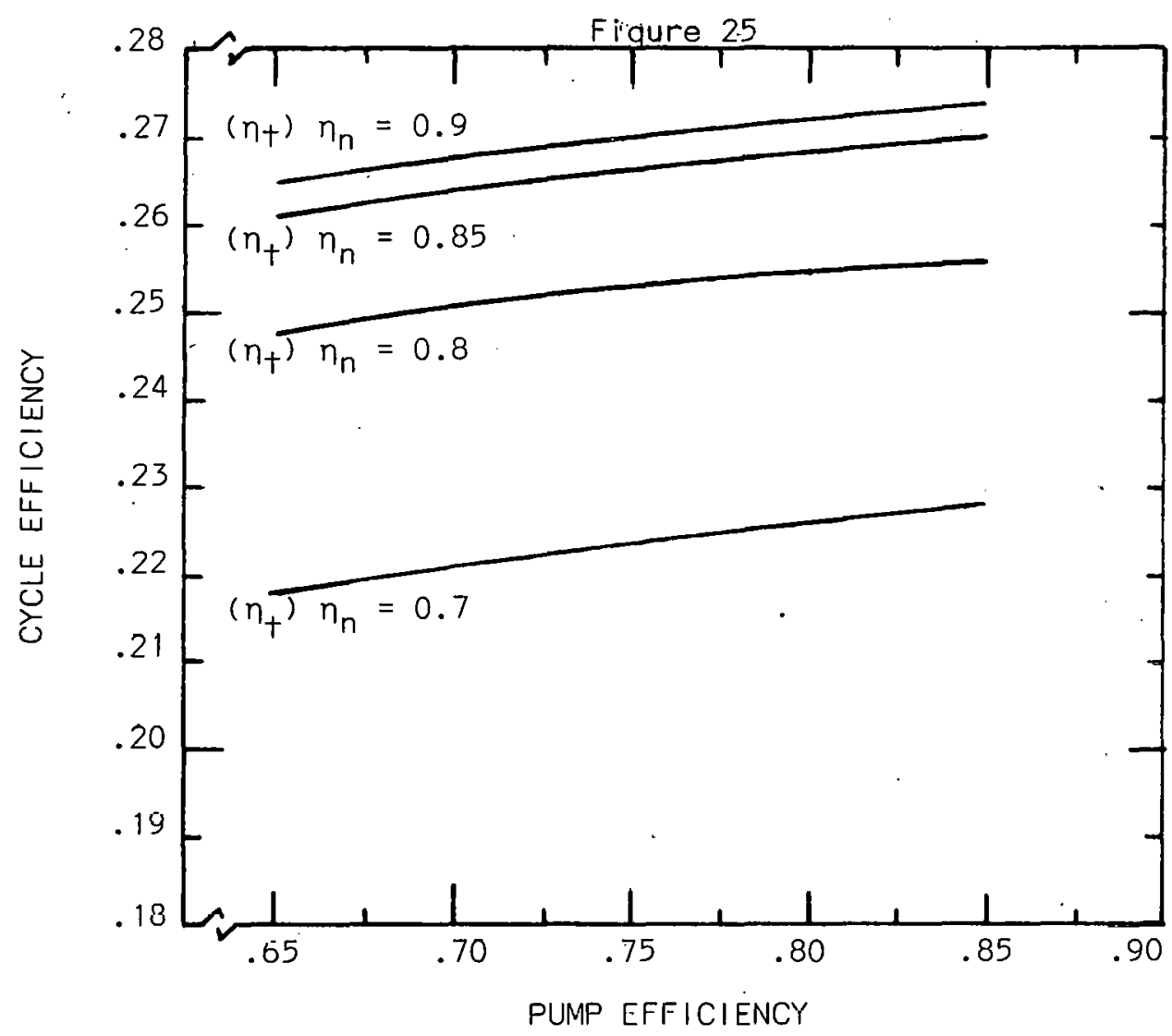

$$
\begin{aligned}
T_{1} & =61 \\
T_{2} & =21<+ \\
P_{2}^{2} & =0.7 \\
C_{p} & =0.4 \\
\left(n_{n}\right) n_{+} & =0.8
\end{aligned}
$$

Figs. 25,26 - Influence of Nozzle, Turbine and Pump Efficiencies on Cycle Efficiency

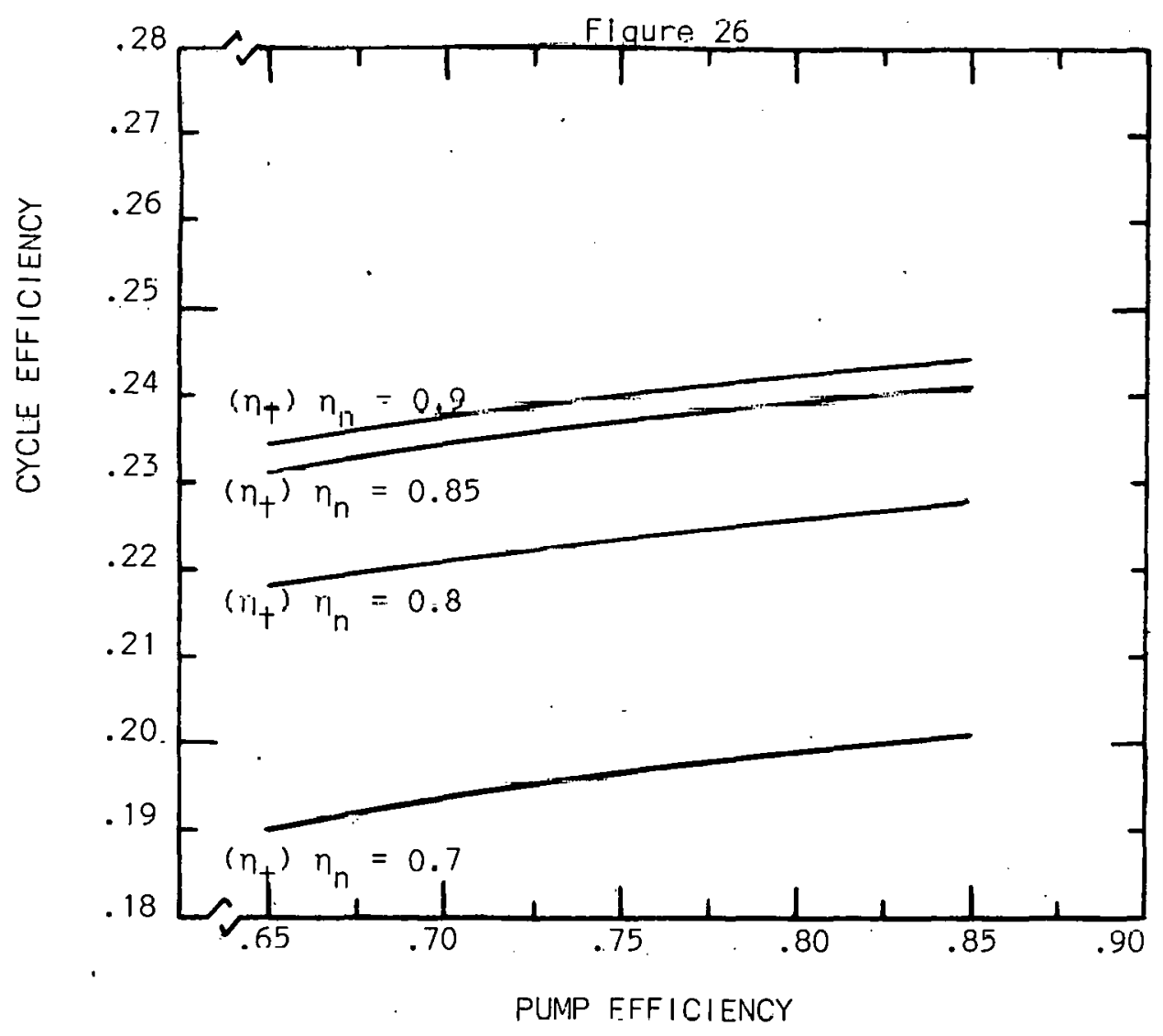

$$
\begin{aligned}
\mathrm{T}_{1} & =660^{\circ} \mathrm{F} \\
\mathrm{T}_{2} & =212^{\circ} \mathrm{F} \\
\mathrm{P}_{2} & =0.7 \\
\mathrm{C}_{\mathrm{p}} & =0.4 \\
\left(n_{n}\right) \eta_{+} & =0.7
\end{aligned}
$$


the nozzle, turbine and diffuser attain the highest values tested or calculated ( $(.9)$ or the lowest values likely ( $(.7)$.

To summarize, the two-component cycle appears to offer substantially lower turbine rpm and somewhat higher efficiencies than a single component system. It was, therefore, chosen to provide the basis for the reference cycle design. Other variations, such as compound cycles or the contact heat exchanger cycle, can offer substantially the same performance as the above variations while possibly achieving other advantages. However, the basic criteria for choice of the reference cycle type and parameters was felt to be simplicity, cost and 'state of the art' components, so a single-stage two-component system was examined. 


\section{REFERENCE CYCLE}

The reference cycle chosen for this design study uses the exhaust from an $1800 \mathrm{HP}$ Colt-Pielstick PC-2 diesel engine to provide heat to the twophase turbine engine. Table 2 (from Ref. 7) summarizes the operating characteristics of the engine over the range of interest. This engine was chosen for the design study because the design power (1800 HP) is large enough to provide a reasonable bottoming cycle efficiency and the engine exhaust temperature $\left(719^{\circ} \mathrm{F}\right)$ is representative of many engines of interest for waste heat recovery. The minimum exhaust temperature $\left(575^{\circ} \mathrm{F}\right)$ was treated in the cycle analysis and the cycle efficiency remained in excess of $20 \%$.

The peak efficiency ( $30 \%$ ) for a bottoming cycle could be obtained by expansion of the two-phase mixture to the lowest possible exhaust pressure (.7 psia for $90^{\circ} \mathrm{F}$ rejection temperature). Use of a liquid component with a low sensible heat would enable operation at this exhaust pressure with a high mass ratio and, therefore, low spouting velocity. However, the lowest sensible heat $\left(\Omega .37 \mathrm{~B} / 1 \mathrm{~b}^{\circ} \mathrm{F}\right.$ ) was found for a 'Therminol' fluid which may have toxicity problems. It was therefore decided to use Dow-Therm i which although having a higher sensible heat ( 2.51 ), is a common heat transfer fluid with no toxicity problems for which commercial equipment is available. With this fluid, the spouting velocity for peak efficiency (29\%) was very high.

In order to limit the rpm to reasonable values ( 8000 ) and to simplify the seals and bearings problems, it was decided to operate the initial system with a nozzle back pressure of one atmosphere. This still produced an acceplably high efficlency (23\%) with a single stage system without any subatmospheric seals. In order to increase the efficiency beyond the normal range for this back pressure (17-18\%), the steam was further expanded (to 1.2 psia) after separation. 
TABLE 2

CPERATING PARAMETERS OF 38TD8-1/8 DIESEL ENGINE

\begin{tabular}{|c|c|c|c|c|c|}
\hline$\%$ of Continuous Rated Power & 110 & 100 & 75 & 50 & 25 \\
\hline BMEP, psi & 139.8 & 127 & 95.3 & 63.5 & 31.8 \\
\hline Input (HHV) & 7117 & 7132 & 7311 & 7861 & 9534 \\
\hline Input (LHV) & 6687 & 6702 & 6871 & .7386 & 8936 \\
\hline Exh. Sensible, Btu/bhphr & 2200 & 2260 & 2460 & 2860 & 3660 \\
\hline Exh. Latent, Btu/bhphr & 430 & 430 & 440 & 475 & 598 \\
\hline Lube Oil, Btu/bhphr & 700 & 702 & 728 & 808 & 1075 \\
\hline AC \& Turbo $\mathrm{H}_{2} \mathrm{O}, \mathrm{Btu} / \mathrm{bhphr}$ & 560 & 512 & 430 & 380 & 349 \\
\hline Cooling $\mathrm{H}_{2} \mathrm{O}$, Btu/bhphr & 460 & 461 & 478 & 530 & 706 \\
\hline Rad. \& Unacc., Btu/bhphr & 222 & 222 & 230 & 263 & 602 \\
\hline Useful Work, Btu/bhphr & 2545 & 2545 & 2545 & 2545 & 2545 \\
\hline Exhaust Temp., ${ }^{\circ} \mathrm{F}$. & 720 & 719 & 701 & 654 & 525 \\
\hline Air Consumption, lb/bhphr & 14.2 & 14.8 & 16.3 & 20.5 & 33.5 \\
\hline Fuel Consumption, $1 \mathrm{~b} / \mathrm{bhphr}$ & 0.368 & 0.369 & 0.378 & 0.406 & 0.492 \\
\hline Exhaust Gas, lb/bhphr & 14.57 & 15.17 & 16.68 & 20.91 & 33.99 \\
\hline$\eta(\mathrm{HHV})$ & 0.358 & 0.357 & 0.348 & 0.324 & 0.267 \\
\hline$\eta(\mathrm{LHV})$ & 0.381 & 0.380 & 0.370 & 0.345 & 0.285 \\
\hline
\end{tabular}


The final state points and flow conditions for the reference cycle are shown in Table 3. The temperatures and pressures are well within the state of the art for steam and Dow-Therm systems. The net power output of $276 \mathrm{HP}$, when added to the diesel output of $1800 \mathrm{HP}$ gives an increase of $15 \%$, or on a per unit fuel basis, the same power for $15 \%$ less fuel. For the $1800 \mathrm{HP}$ size, a $40 \%$ basic diesel efficiency, and a fuel price of $\$ 2.00 /$ million $B$, the annual fuel savings would be $\$ 24,000$ (for an $80 \%$ capacity factor), giving a 3 year payback for about $\$ 300 / \mathrm{kw}$ capital cost of the bottoming system. This cost appears to he a reasonable goal, considering the simplicity.

FLOW CONDITIONS

The flow conditions were chosen to provide a slight degree of superheat at the exit of the nozzle to avoid the Wilson Line during subsequent expansion of the steam in the radial inflow turbine. For inlet conditions of $660^{\circ} \mathrm{F}$ and 2,365 psia and nozzle exit conditions of $230^{\circ} \mathrm{F}$ and 14.7 psia, the following values result:

$$
\begin{aligned}
& s_{a_{1}}^{\prime \prime}=.8987 \mathrm{~B} / 1 \mathrm{~b}^{\circ} \mathrm{F} \\
& s_{a x}^{\prime \prime}=1.7695 \mathrm{~B} / \mathrm{Ib}^{\circ} \mathrm{F} \\
& c_{\mathrm{pb}}^{\prime \prime}-.31 \mathrm{~B} / 1 \mathrm{~b}^{\circ} \mathrm{F} \\
& \mathrm{h}_{a_{1}}^{\prime \prime}=714.2 \mathrm{~B} / \mathrm{lb} \\
& h_{a x}^{\prime}=1159.3 \mathrm{~B} / \mathrm{lb}
\end{aligned}
$$

Substitution in [q. (3) gives:

$$
r=3.50
$$

Substitution of the enthalpy values in Eq. (28) of Appendix B gives:

$$
V_{2 \ell}=1,878 \mathrm{ft}_{\mathrm{s}} \mathrm{s}
$$

A nozzle efficiency of .85 yields:

$$
V_{2}=1,824 \mathrm{ft} / \mathrm{s}
$$

Entry at $15^{\circ}$, with a radius change of .96 from the nozzle center I ine to the separator drum gives a separator liquid velocity of:

$$
v_{s}=(.96)\left(\cos 15^{\circ}\right)(1,824)=1,691 \mathrm{ft} / \mathrm{s}
$$


TABLE 3

STATE POINTS FOR REFERENCE BOTTOMING CYCLE

\begin{tabular}{|c|c|c|c|c|c|}
\hline State Point & $\begin{array}{c}\text { Temperature } \\
(\mathrm{F}) \\
\end{array}$ & $\begin{array}{c}\text { Pressure } \\
\text { (psia) } \\
\end{array}$ & $\begin{array}{l}\text { Flowrate } \\
(\mathrm{lb} / \mathrm{s}) \\
\end{array}$ & $\begin{array}{l}\text { Velocity } \\
(\mathrm{ft} / \mathrm{s}) \\
\end{array}$ & $\begin{array}{l}\text { Liquid/ } \\
\text { Liquid/Gas }\end{array}$ \\
\hline 1 & 660 & 2365 & 2.97 & 30 & $\mathrm{~L}$ \\
\hline 2 & 230 & 14.7 & 2.97 & 1824 & $L+G$ \\
\hline 3 & 230 & 14.7 & 2.31 & 1691 & L \\
\hline 4 & 107 & 1.2 & .66 & 50 & $L+G^{*}$ \\
\hline 5 & 230 & 14.7 & 2.31 & 30 & $L$ \\
\hline 6 & 100 & 1.2 & .66 & 30 & $L$ \\
\hline 7 & 190 & 2465 & 2.97 & 30 & L \\
\hline 8 & .719 & .15 .0 & 7.58 & 50 & G \\
\hline 9 & 242 & 14.7 & 7.58 & 50 & G \\
\hline
\end{tabular}

*Vapor quality $=.96$

POWER OUTPUT - 276 HP @ 8075 RPM

CYCLE EFFICIENCY - . $23 \%$

NET POWER INCREASE - 15\%

AROVF MIFSFI NITPIIT 
For a two foot diameter the separator rpm is:

$$
U_{s}=16,150 \cdot \mathrm{rpm}
$$

Use of a "U-tube" turbine at an rpm one half of the separator rpm gives a turbine rpm of:

$$
W_{t}=8,075 \mathrm{rpm}
$$

The liquid turbine tip speed in $845.5 \mathrm{ft} / \mathrm{s}$. The torque on the turbine due lo momentum change is:

$$
\begin{aligned}
& L_{t m}^{\prime \prime}=2 \dot{m}_{b}\left(V_{s}-V_{t}\right) r_{t} \\
& L_{t m}^{\prime \prime}=121 ; 37 . b f t .
\end{aligned}
$$

The drag on the liquid turbine is given by:

$$
F_{t d}^{\prime \prime}=\frac{c_{d} \rho_{b}^{\prime \prime}\left(v_{s}-v_{t}\right)^{2}}{2} A_{i}
$$

or

$$
F_{t d}^{\prime \prime}=c_{d} \frac{\dot{m}_{\dot{b}}\left(V_{s}-v_{t}\right)}{2}
$$

where $C_{d}=$ the drag coefficient for the liquid pickup

$$
A_{1}-\text { llee lnles area }
$$

$A^{\prime}$ value of $C_{d}=.1$ appears attainable for an inlet with base ventilation ${ }^{(11)}$. Substitution in. Eq. (6) gives:

$$
F_{t d}^{\prime \prime}=3.03 \mathrm{lb}
$$

Since a 1 foot radius is found at this location the drag torque on the inlet is:

$$
L_{t d}^{\prime \prime}=3,03 \mathrm{lbft}
$$

The total torque on the liquid turbine is:

$$
L_{t}^{\prime \prime}=124.32 \mathrm{bft}
$$

The power is therefore:

$$
P_{t}^{\prime \prime}=\frac{(124.3)(845.5)}{(550)}=191 \mathrm{HP}
$$


The power loss due to the drag of the inlet is:

$$
P_{S_{1}}=\frac{(3.03)(1,691)}{(550)}=9.3 \mathrm{HP}
$$

The windage loss of the separator was estimated considering the rim to be a flat plate with the width equal to the separator width and the length equal to the circumference.

The Reynolds Number is:

$$
\operatorname{Re}_{x}=\frac{V_{s} L_{s}}{v_{a}^{\prime}}
$$

For steam at $230^{\circ} \mathrm{F}$ and $14.7 \mathrm{psia}, \nu_{a}^{\prime}=2.3 \times 10^{-4} \mathrm{ft} / \mathrm{s}$

$$
\operatorname{Re}_{x}=\frac{(1,691)(6.28)}{\left(2.3 \times 10^{-4}\right)}=4.55 \times 10^{7}
$$

The friction factor is (12):

$$
f_{p m}=.0024
$$

The drag on the separator is:

$$
F_{s}=f_{p m} \frac{\rho_{a}^{\prime} v_{s}{ }^{2}}{2} L_{s} w_{s}
$$

where $w_{s}=$ separator width

$$
F_{S}=4.04 \mathrm{lb}
$$

The power. loss due to windage is:

$$
P_{S_{2}}=\frac{(4.04)(1,691)}{(550)}=12.4 \mathrm{HP}
$$

Allowing $1.3 \mathrm{HP}$ loss in the bearings and seals, gives a total separator loss of:

$$
P_{S}=23 H P
$$

The net power from the radial inflow turbine obtained by expansion to 1.2 psia is estimated in Appendix $D$ to be:

$$
P_{t}^{i}=1.37 \mathrm{HP}
$$


The pumping power required to return the 1 iquid through the heat exchanger to the nozzle is:

$$
P_{p}=\frac{\left(Q_{a}+Q_{b}\right) \Delta p}{n_{p}}
$$

where $Q_{a}=$ volume flowrate of $A$

$$
\begin{aligned}
Q_{b} & =\text { volume flowrate of } B \\
\Delta p & =\text { pressure rise }=2,450 \mathrm{psi}
\end{aligned}
$$$$
\|_{p}=\text { pump efflclency }=.75
$$

$$
P_{p}=8.9 .4 H
$$

The net power is given by:

$$
P_{n}=P_{t}^{\prime}+P_{t}^{\prime \prime}-P_{s}-P_{P}
$$

Substitution of the above values gives:

$$
P_{n}=137+191-23-29=276 \mathrm{HP}
$$

The heat rejection is:

$$
n_{c}=\dot{m}_{a} l_{v a} a^{x} v a
$$

where $\times_{v a}=$ the exit quality from the steam turbine Substitution of the appropriate values gives:

$$
Q_{C}=654.4 \mathrm{~B} / \mathrm{s}
$$

The cycle efficiency is:

$$
n_{c}=\frac{P_{n}}{P_{n}+Q_{c}}
$$

or

$$
n_{c}=.23
$$


OPERATION

The schematic diagram of Figure 27 shows a configuration of the reference cycle where the exhaust from the diesel is passed through a jacket to preheat the inventory. Startup is then achieved by a ramp injection of the hot charge downstream of a check valve. This type of startup technique was successfully used in a similar two-phase cycle ${ }^{(13)}$ where the power was extracted in a magneto-hydrodynamic generator instead of a turbine. In that case, steady state operation with a flow of $150 \mathrm{lb} / \mathrm{s}$ of Nak was achieved in 2-3 seconds. 


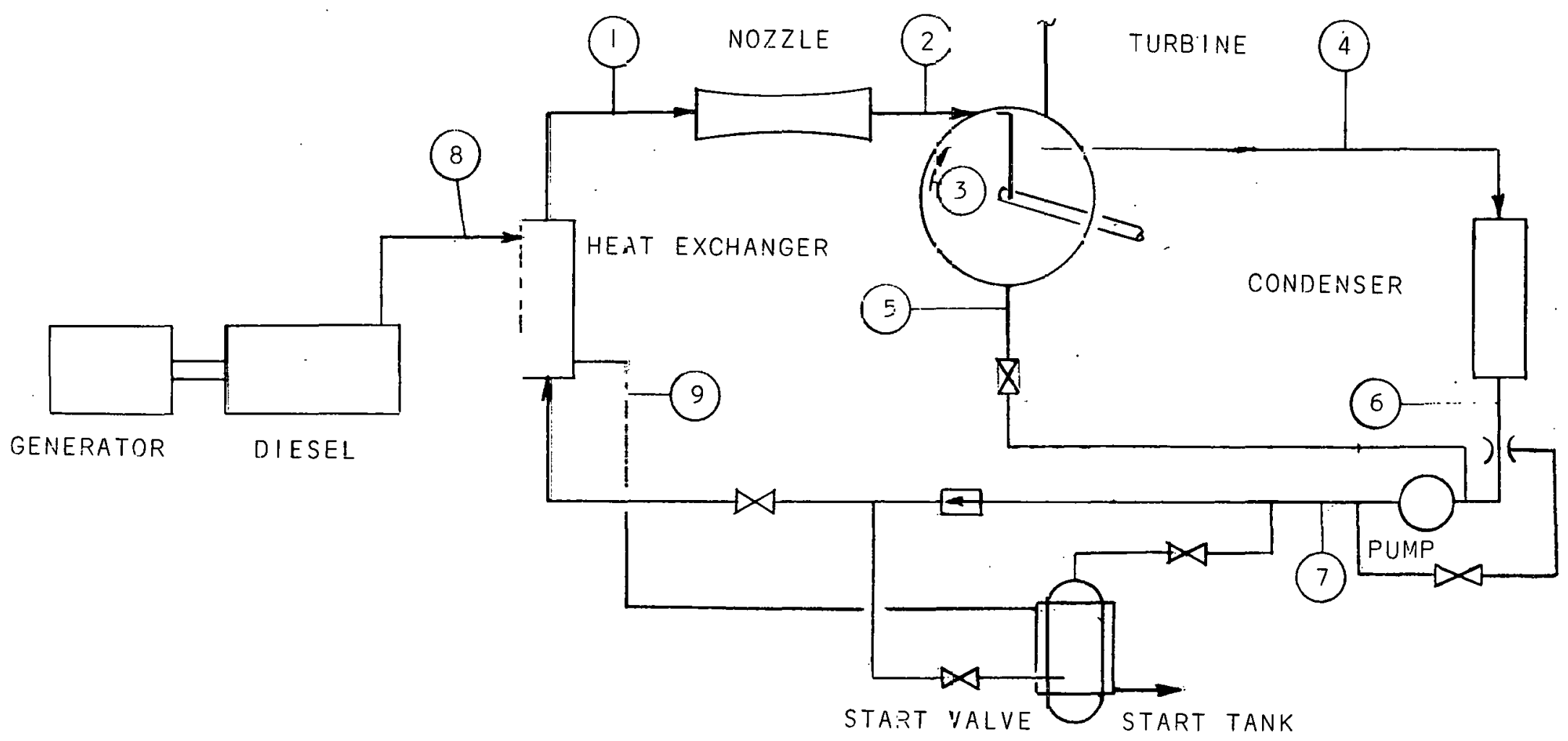

Fig. 27-Schematiz of Reierence System 


\section{TURBINE DESIGN}

The design configuration of the two-phase turbine resulting from the analysis for the reference bottoming application summarized in section IV, is given in Figures 28 and 29. The basic procedures used in the mechanical design are summarized in Appendix C. The steam turbine design is described in Appendix D.

The turbine has a single stage expansion of the two-phase mixture in the 12 inch nozzles. The mixture impinges on the inside surface of the free wheeling drum, forming a liquid layer traveling at 1,691 ft/s. The layer drives a liquid turbine to $845 \mathrm{ft} / \mathrm{s}(8,075 \mathrm{rpm})$ for the "U-tube" version shown in Figure 28. The discharge from the U-tube is collected in an annular tube and exits from the hot well of the turbine. The separator drum free wheels on the turbine shaft and is held in place by clips and retainers as shown. The separator drum and turbine are overhung from the $35 \mathrm{~mm}$ shaft. The bearings are standard grease packed double seal bearings. A simple mechanical sliding seal is used to isolate the low temperature $\left(230^{\circ} \mathrm{F}\right.$ ) steam at atmospheric pressure from ambient.

The separated steam flows radially inward from the drum through a twostage turbine to the exhaust pressure of 1.2 psia. The radial inflow turbine is keyed to the same shaft as the liquid turbine and thus has the same rpm, 8,075. As summarized in Appendix D, a total of $137 \mathrm{HP}$ is added by the steam turbine to the liquid turbine output of $191 \mathrm{HP}$. Expansion of the total two-phase mixture to the lower pressure would result in a greater fraction of the power being available in the liquid - phase. The turbine blading is conventional radial design and could probably be cast in quantity for $\$ 75-100$.

Figure 29 shows the nozzle detail and the detail of a counter-balanced radial inflow liquid turbine. The nozzle is built up of two conical sections and a throat, in accordance with past design practice ${ }^{(14)}$. 


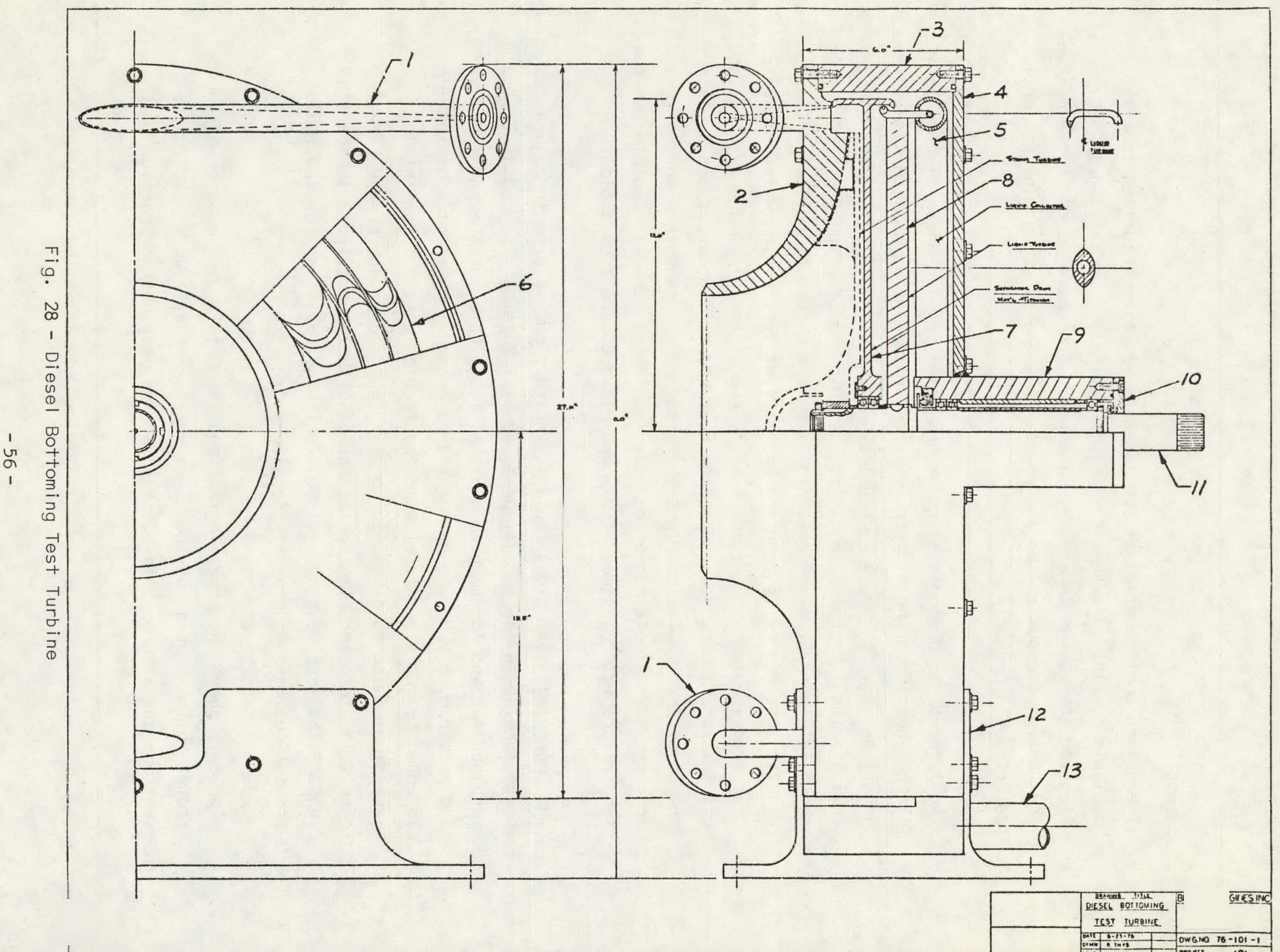




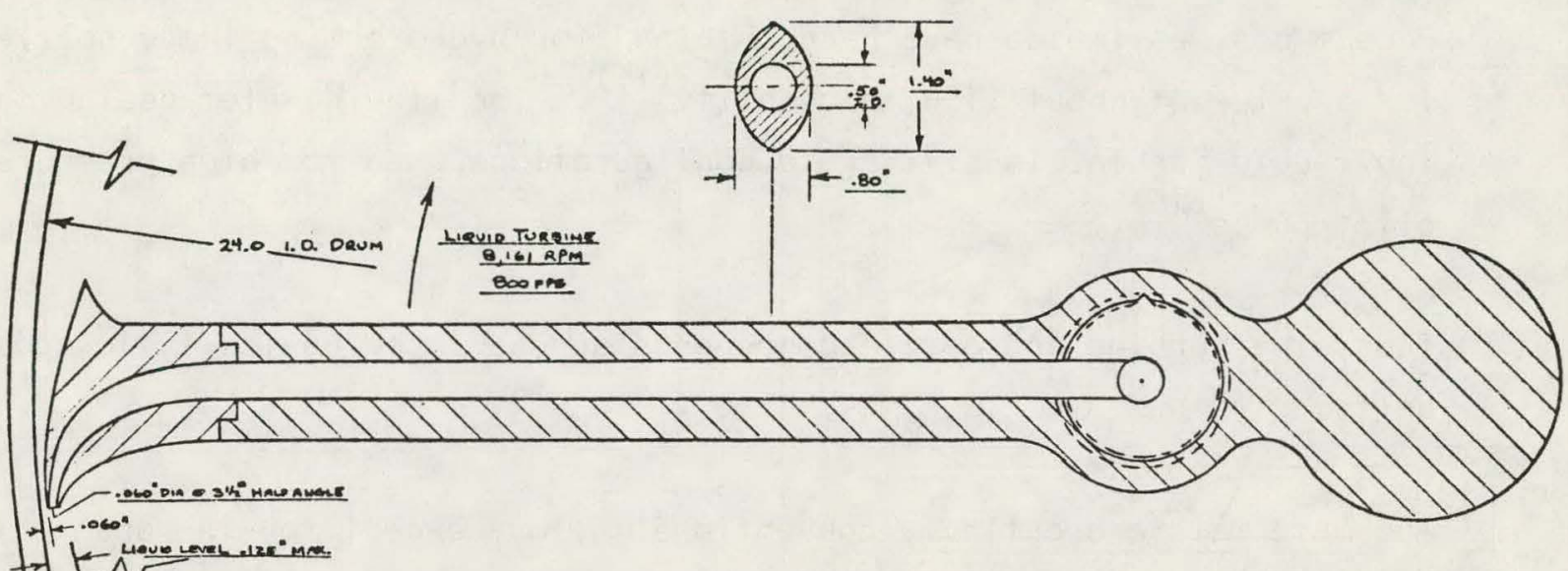

Liquid Turbine Details

(WITM SHART Discmanate 2400 paie)

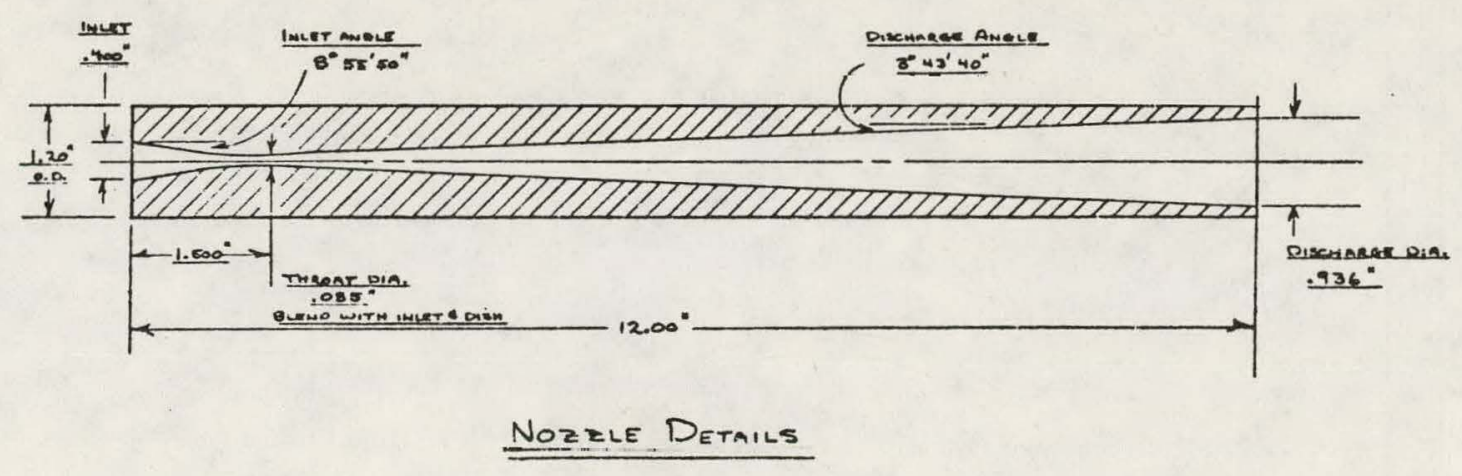

Fig. 29 - Nozzle and Liquid Turbine Design Details 
Recent cost estimates have been obtained for hydroforming these nozzles for a price of about $\$ 150$ in quantity ${ }^{(15)}$. The liquid inlet design on the liquid turbine is similar to configurations used for high pressure, pitot pumps ${ }^{(16)}$.

Thus, the turbine and nozzle components appear to be basically low cost units.

The materials are entirely conventional alloys except for the drum which is titanium for this design. Table 1 summarizos the materials for major components of the assembly.

To summarize, the nozzle and turbine assembly is a simple, low cost design which can be mass produced for much less than a multi-stage axial flow gas turbine with high speed bearings and seals. Increases in the mass ratio, made possible through using a liquid with lower sensible heat would enable a lower separator drum rpm and the use of low carbon steel. Staging the nozzle expansion would have a similar influence but with an increase in the total number of components. 
TABLE 4

MATERIALS LIST FOR MAJOR TURBINE COMPONENTS

\begin{tabular}{|c|c|c|c|c|c|c|c|}
\hline Dash No. & Part & - & & Mater & -ial & & \\
\hline-1 & Nozzle (2) & ASTM & A $148-58$ & GRADE & $150-125$ & (Steel & ( Casting) \\
\hline-2 & Casing, Front & ASTM & $A 105-55 T$ & & & (Stee) & ( Forging) \\
\hline-3 & Casing, Side & ASTM & A105-55T & & 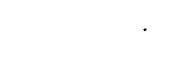 & (steel & ( Forging) \\
\hline-4 & Casing, Back & ASTM & A105-55T & & & (stee) & ( Forging) \\
\hline-5 & Liquid Collector & ASTM & A106 & & & (steel & (Pipe) \\
\hline-6 & Steam Turbine & ASTM & A148-58 & GRADE & $150-125$ & (steel & Casting) \\
\hline-7 & Separator Drum & AMS & $4969(\mathrm{Ti}$ & $-5 A !-$ & $-1.5 \mathrm{Fe}$ & $-1.4 \mathrm{C}$ & $\mathrm{Cr}-1.2 \mathrm{Mu})$ \\
\hline-8 & Liquid Turbine & ASTM & A $148-58$ & GRADE & $150-125$ & $\begin{array}{r}\text { (Steel } \\
\text { Stell }\end{array}$ & $\begin{array}{l}\text { Casting with } \\
\text { ite tip) }\end{array}$ \\
\hline & - & & & & & . & \\
\hline-9 & Bearing Housing & ASTM & A $106-55 T$ & $r$ & $\cdot$ & (Steel & ( Pipe) \\
\hline $\begin{array}{c}-10 \\
.\end{array}$ & End Plate & ASTM & A105-55T & & & (steel & Forging) \\
\hline-11 & Shaft & ASTM & A105-55T & & & (steel & ( Forging) \\
\hline-12 & Base & ASTM & A $105-55 T$ & & & (steel & Forging) \\
\hline-13 & Outlet Pipe & ASTM & $A 106$ & & & (Steel & (Pipe) \\
\hline
\end{tabular}




\section{SYSTEM SPECIFICATIONS}

Components of the two-phase turbine cycle chosen for this application are all well within the state of the art. Common fluids were chosen for the first system (water and Dow-Therm A). The temperatures for the pumps and valves are in the range of $90-250^{\circ} \mathrm{F}$. The peak temperature for the exhaust gas-liquid heat exchanger is that of the diesel exhaust, $719^{\circ} \mathrm{F}$. The pressures required are high $(2,500$ psia, maximum) but are within normal practice for both steam and hydraulic systems. The only "exotic" materials roquircd arc stellite tip on the inlet of the liquid turbiue lu minimi<e erosion and, for the initial system, a titanium drum for the separator. Use uf a llyulu with a lower specliflc heat than Uow-Therm would reduce the separator and turbine rpm, simplifying the bearing and seal requirements further. However, the values for the reference cycle (16,150 and 8,075 rpm) are within the range of commercially available seals and bearings. In order to enable preliminary assessments to be made of the system cost and complexity, specifications for the major components are given below:

\section{PRIMARY HEAT EXCHANGER}

$\begin{array}{lc}\text { Mesign - tube-fin construction, heliarc welded joints } \\ \text { Material - ASTM Al05-55T, Al06-55T (carbon steel) } \\ \text { Inlet I iquid temperature (tube side) } & 190^{\circ} \mathrm{F} \\ \text { Inlet I iquid pressure } & 2,465 \mathrm{psia} \\ \text { Inlet gas temperature (fin side). } & 719^{\circ} \mathrm{F} \\ \text { Outlet I iquid temperature } & 660^{\circ} \mathrm{F} \\ \text { Outlet I iquid pressure } & 2,365 \mathrm{psia} \\ \text { Outlet gas temperature } & 242^{\circ} \mathrm{F} \\ \text { Gas pressure drop } & 10^{\prime \prime} \mathrm{H} / \mathrm{O} \\ \text { Liquid flowrate } & 2.97 \mathrm{lb} / \mathrm{s} \\ \text { Gas flowrate } & 7.58 \mathrm{lb} / \mathrm{s} \\ \text { Heat transfer rate } & 654 \mathrm{~B} / \mathrm{s} \text { (net) }\end{array}$


The type of construction to be used can be very similar to the unit shown in Fig. 30. Some decrease in construction costs relative to a vapor generator should be realized because of the smaller flow area (hence, tube size) required by the liquid.

\section{CONDENSER}

$\begin{array}{ll}\text { Design - tube-shell construction } \\ \text { Material - ASTM Al05-55T, ASTM Al06-55T (carbon steel) } \\ \text { Inlet temperature } & 107^{\circ} \mathrm{F} \\ \text { Inlet pressure } & 1.2 \mathrm{psia} \\ \text { Outlet temperature } & 100^{\circ} \mathrm{F} \\ \text { Outlet pressure } & 1.1 \mathrm{psia} \\ \text { Flowrate } & .66 \mathrm{lb} / \mathrm{s}, \text { steam } \\ \text { Heat transfer rate } & 504 \mathrm{~B} / \mathrm{s}\end{array}$

Figure 31 is a isometric drawing of a condenser used in a diesel bottoming application. A smaller surface area would be possible for the two-phase bottoming cycle because of the higher condensing coefficients of the steam (relative to organic vapor).

START AND DUMP TANK

$$
\begin{array}{lc}
\text { Design - welded construction } \\
\text { Material - ASTM Al05-55T } \\
\text { Pressure (maximum) } & 2,500 \mathrm{psia} \\
\text { Tomperature (maximum) } & 500^{\circ} \mathrm{C} \\
\text { Volume } & 4 \mathrm{ft}^{3}
\end{array}
$$

PUMP

$\begin{array}{lr}\text { Pressure rise } & 2,500 \text { psia } \\ \text { Flowrate } & 3 \mathrm{lb} / \mathrm{s}, \text { water - Dow-Therm A mixture } \\ \text { Efficiency } & .75\end{array}$



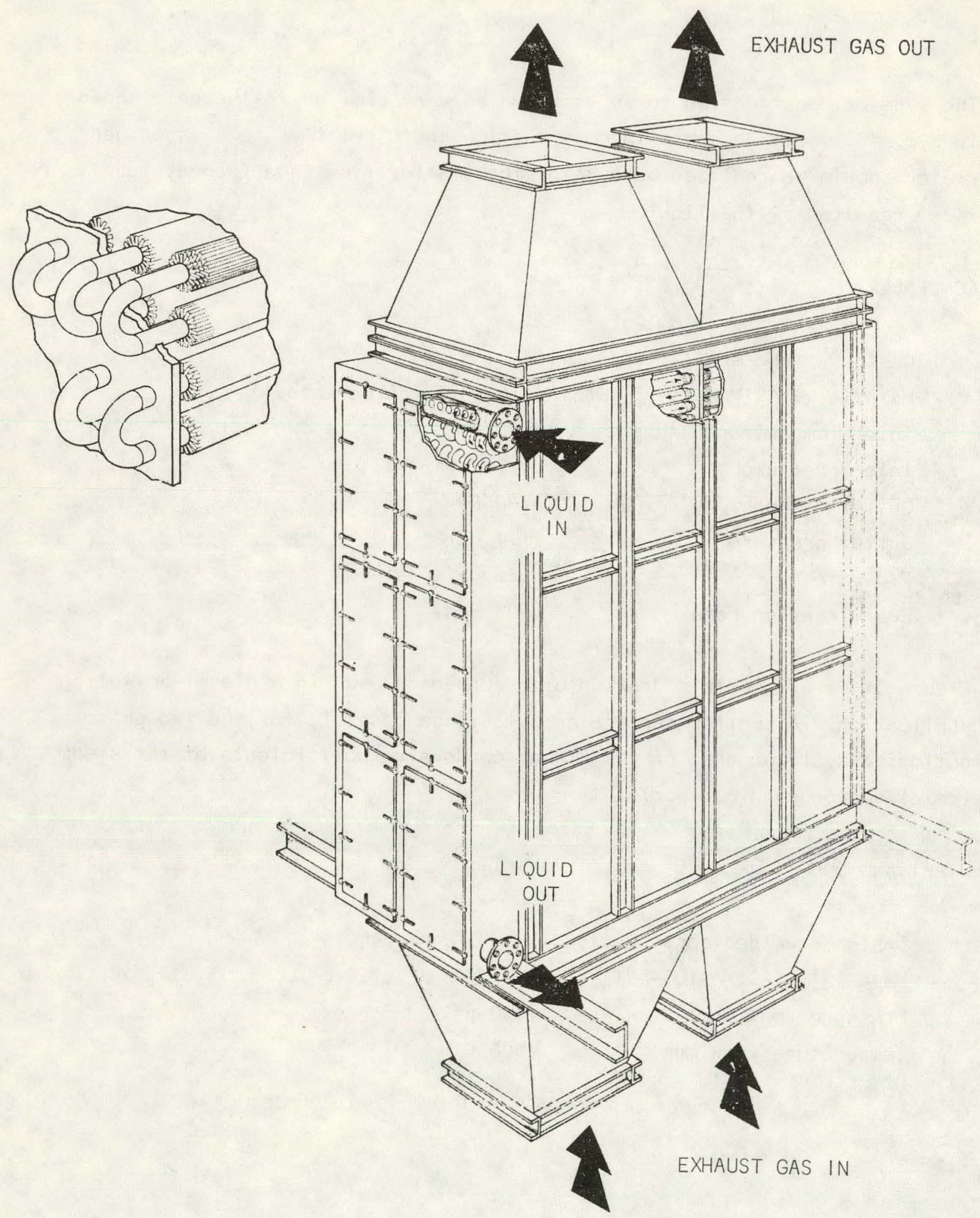

Fig. 30 - Isometric IIIustration of a Typical

Exhaust Gas Heat Exchanger

(After Ref. 7) 


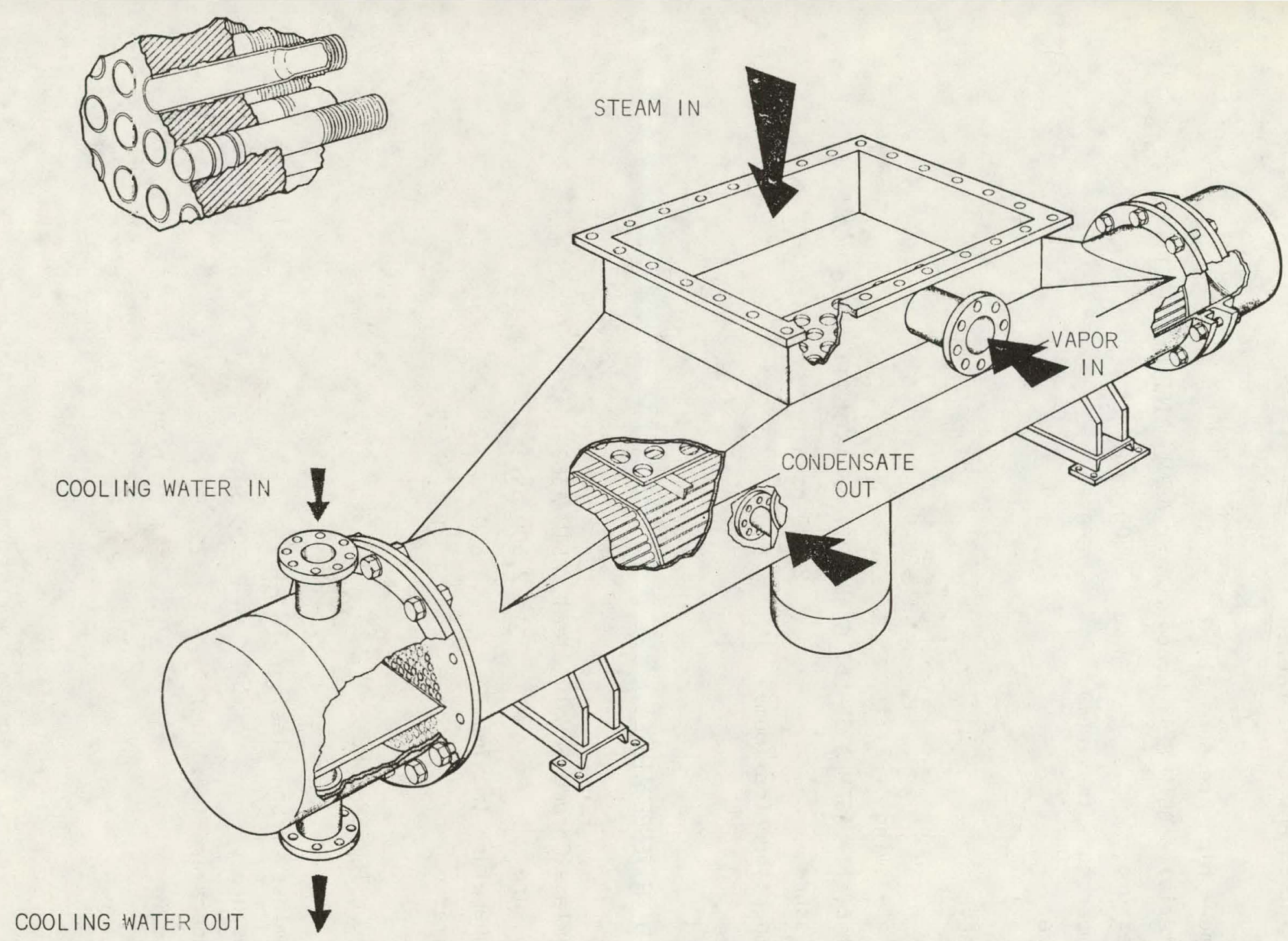

Fig. ż1 - Isometric IIIustration of a Typical Condenser (After Ref. 7) 
CONTROL VALVES AND START VALVE

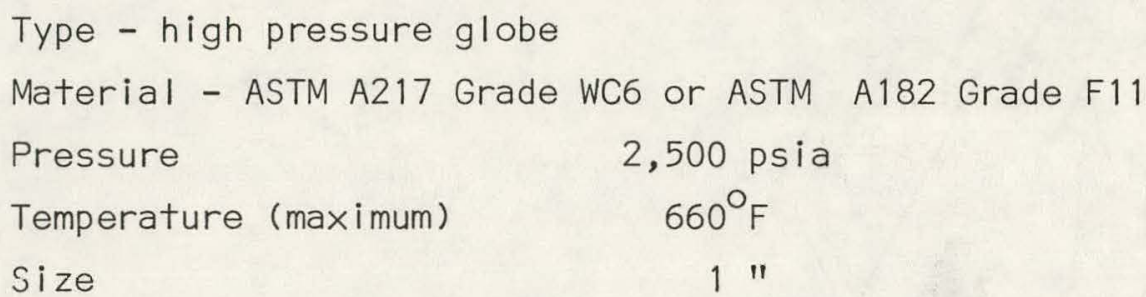

CHECK VALVE

Typo - swing or Iift

Material - ASTM A335-55T Grade P11 or ASTM 217 Grade WC6

Pressure

2,500 psia

Temperature (maximum)

$660^{\circ} \mathrm{F}$

size

$1 "$

PIPING, HIGH TEMPERATURE

Seamless Chrome - Moly Steel, ASTM A369

Pressure

?, $50 \cap$ rsia

Temperature (maximum)

$660^{\circ} \mathrm{F}$

Diameter

$1 ", 1 / 2 "$

PIPING, LOW TEMPERATURE

Seamless Carbon Steel, ASTM A106

Pressure

2,500 usia

Temperature (maximum)

$250^{\circ} \mathrm{F}$

Diameter

$1 ", 1 / 2 ", 1^{\prime}$ 
BEARINGS

\author{
Bore - $35 \mathrm{~mm}$ \\ Grease Packed \\ e.g. Fafnir Medium 2MM307 WI Single and 2 MM307. DB Double
}

SEALS

Carbon Face Seal, Bellows Loading

(Design Equivalent to Chicago Rawhide Manf. Co. No. B33-90 66 T1) 


\section{CYCLE PERFORMANCE WITH CONTACT HEAT EXCHANGER}

Since the cost of tube and fin exchanger is as much as $50 \%$ of the system and resistances like fouling and scaling cause reduction in effective heat transfer the feasibility of replacing tube and fin was analyzed. Because heat transfer occurs from gas to liquid, the two-phase cycle offers the possibility of using a direct contact heat exchanger. A detailed cycle analysis using the contact heat exchanger was performed. Calculations were done for parametric variation of nozzle efficiency, turbine efficiency, liquid temperature, nozzle exit temperature and pressure. The equations used are summarized in Appendix E.

The cycle analysis were done using water as the thermodynamic working fluid and Therminol 66 as the liquid component. They were analyzed for the following parametric variation:

$$
\begin{array}{lr}
\text { Liquid outlet temperature } & 680^{\circ} \mathrm{F}-500^{\circ} \mathrm{F} \\
\text { Nozzle exit temperature } & 90^{\circ} \mathrm{F}-230^{\circ} \mathrm{F} \\
\text { Nozzle exit pressure } & 14.7-0.7 \text { psia }
\end{array}
$$

The flow conditions were chosen to provide a slight degree of superheat at nozzle exit to avoid Wilson line if there is any further expansion of the vapor alone.

The effect of the liquid outlet temperature on the cycle is shown in Figure 32. As it is seen from the figure that at nozzle exit pressure of 0.7 psia and temperature of $230^{\circ} \bar{F}$ a peak cycle efficiency 0.27 was reached at $640^{\circ} \mathrm{F}$. By using a tube and $f$ in exchanger a maximum efficiency of 0.3 was achieved at peak cycle temperature of $700^{\circ} \mathrm{F}$. But in this case regenerative heating was used after tho condonscr. The dccrcasc in cycle efficiency above $640^{\circ}$. is due to the energy input required to heat the subcooled liquid to the higher nozzle inlet temperatures.

Reduction of temperature of Therminol from $640^{\circ} \mathrm{F}$ to $500^{\circ} \mathrm{F}$ reduced the cycile efficiency by 3 percentage points (to $24 \%$ ) and in the case of tube and fin 


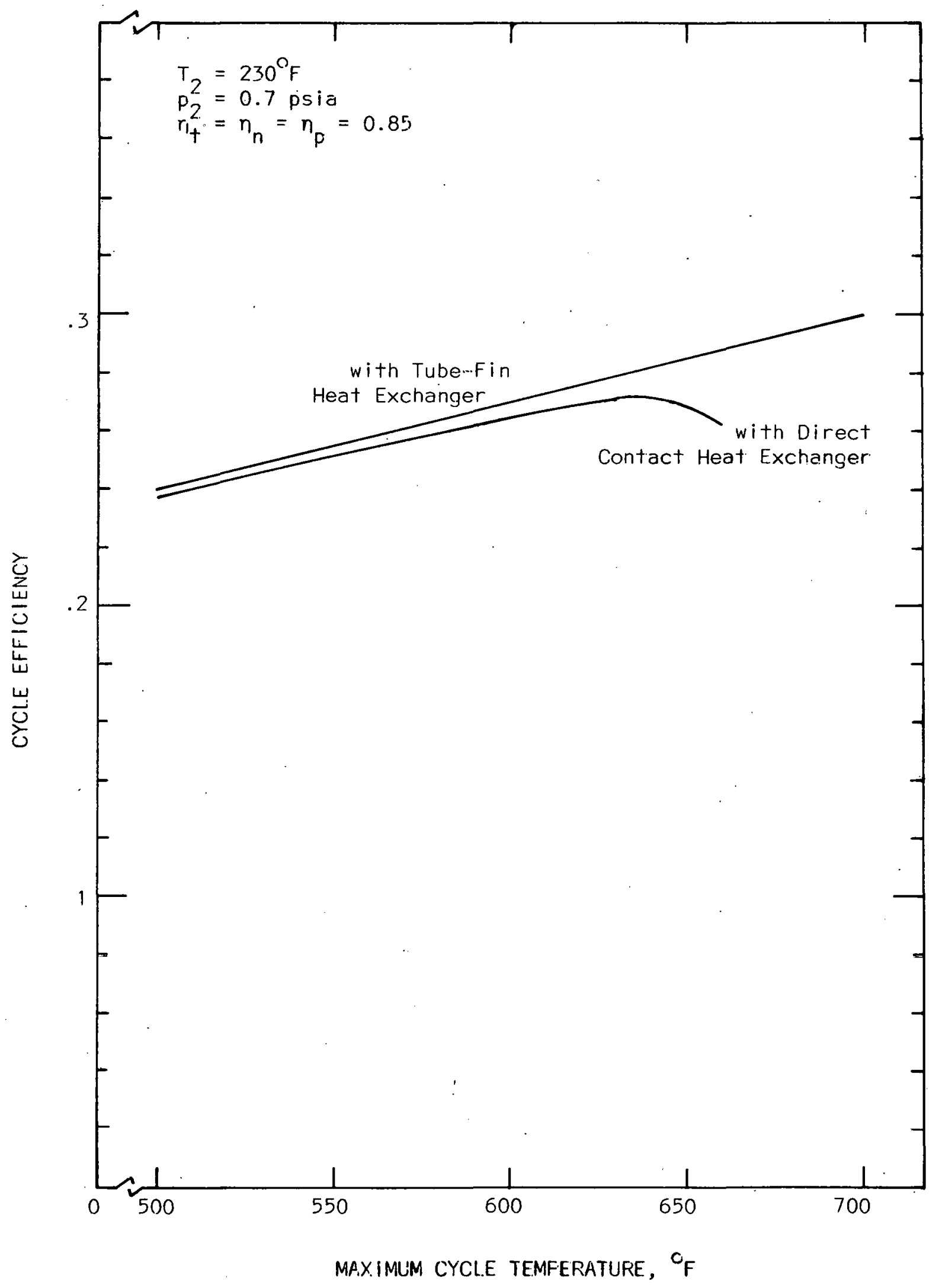

Fig. 32 - Comparison of Contact Heat Exchanger Cycle Efficiency and Tube-Fin Heat Exchanger Cycle Efficiency. Variation with Maximum Cycle Temperature.

$-67-$ 
exchanger 4 perenctage points were noticed for the same temperature drop (from $28 \%$ to $24 \%$ ). The significance of this is that the part load efficiency can be kept at a high level as diesel exhaust temperature drops.

The influence of nozzle exit temperature for a constant back pressure ( $0.7 \mathrm{psia}$ ) and constant cycle temperature $\left(660^{\circ} \mathrm{F}\right)$ by using both direct contact and tube-fin exchanger is shown in Figure 33.

Reduction in temperature from $230^{\circ} \mathrm{F}$ to $90^{\circ} \mathrm{F}$ reduces cycle efficiency from $26 \%$ to $23 \%$ and $30 \%$ to $24 \%$ respectively.

This results from the reduction in mass ratio. Nozzle back pressure has perhaps the greatest effect on cycle efficiency. Figure 34 shows the cycle efficiency to change from $18 \%$ to $29^{\circ}$ (using tube-fin exchanger) and $17^{\%}$ to 26\% (direct contact exchanger) as the back pressure is decreased from 14.7 to 0.7 psia. For a contact liquid outlet temperature this results in a simultaneous increase in mass ratio, $r$, and nozzle spouting velocity. The mass ratio increases from 4.7 to 6.5 and 5.79 to 7.36 while the spouting velocity changes from $1660 \mathrm{ft} / \mathrm{s}$ to $1920 \mathrm{ft} / \mathrm{s}$ and 1560 to $1879 \mathrm{ft} / \mathrm{s}$ respectively.

The above results were generated for constant values of nozzle efficiency, turbine efficiency and pump efficiency. As shown in Figures 35 through 37 , the nozzle and turbine efficiency have a greater influence on cycle efficloncy. For cxample, reducing turbine elliciency 0.9 to $0.7 \%$, the cycle efficiency would be reduced from $24 \%$ to $18 \%$. And decreasing the nozzle efficiency from 0.85 to 0.7 drops cycle efficiency from $21 \%$ to $17 \%$.

To summarize, it appears that the possible cost advantages of a direct contact heat exchanger could be gained without sacrificing a great deal in efficiency (27\% compared to. $30 \%$ of tube-fin exchanger). 


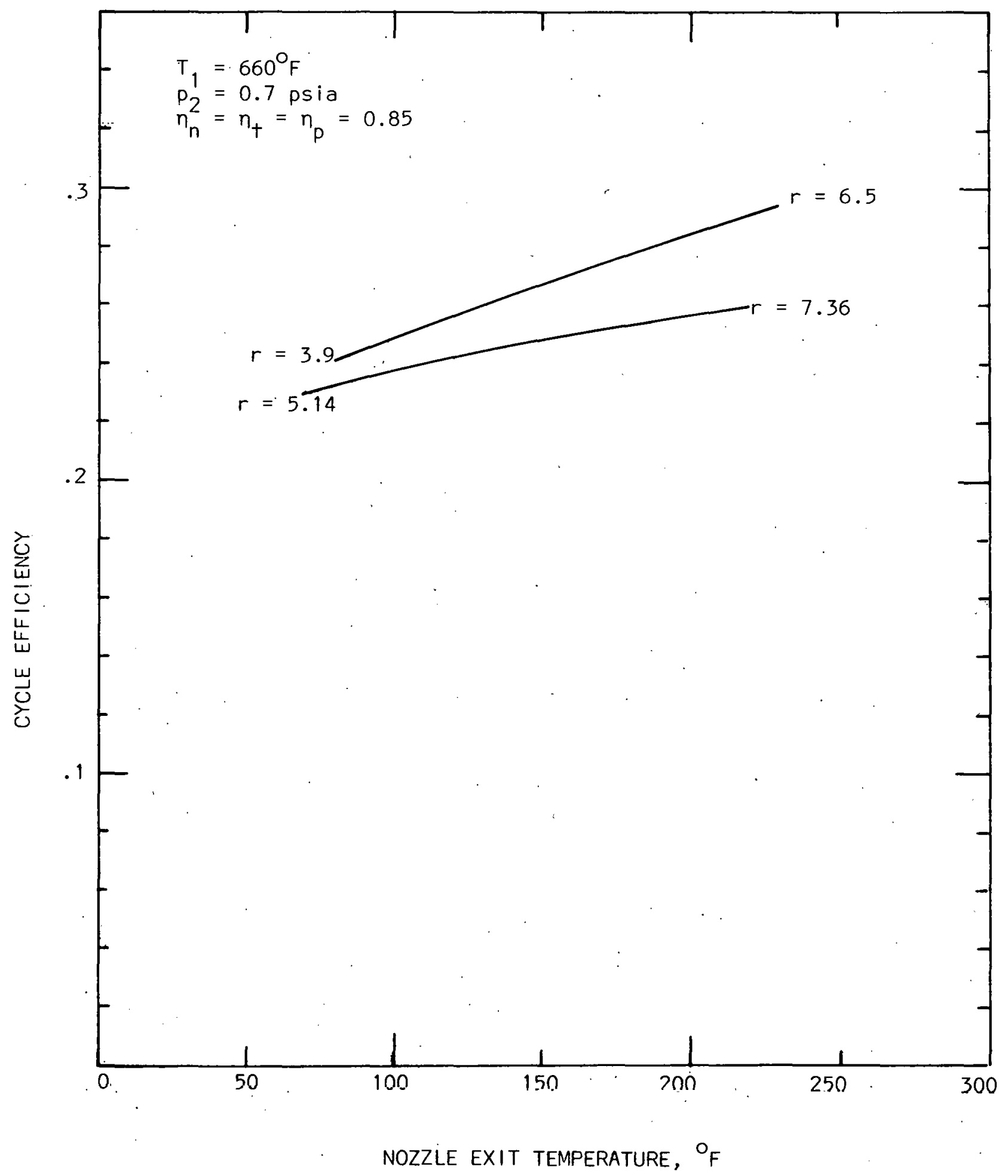

Fig. 33 - Comparison of Contact Heat Exchanger Cycle Efficiency and Tube-Fin Heat Exchanger Cycle Efficiency. Variation with Nozzle Exit?Temperature. 


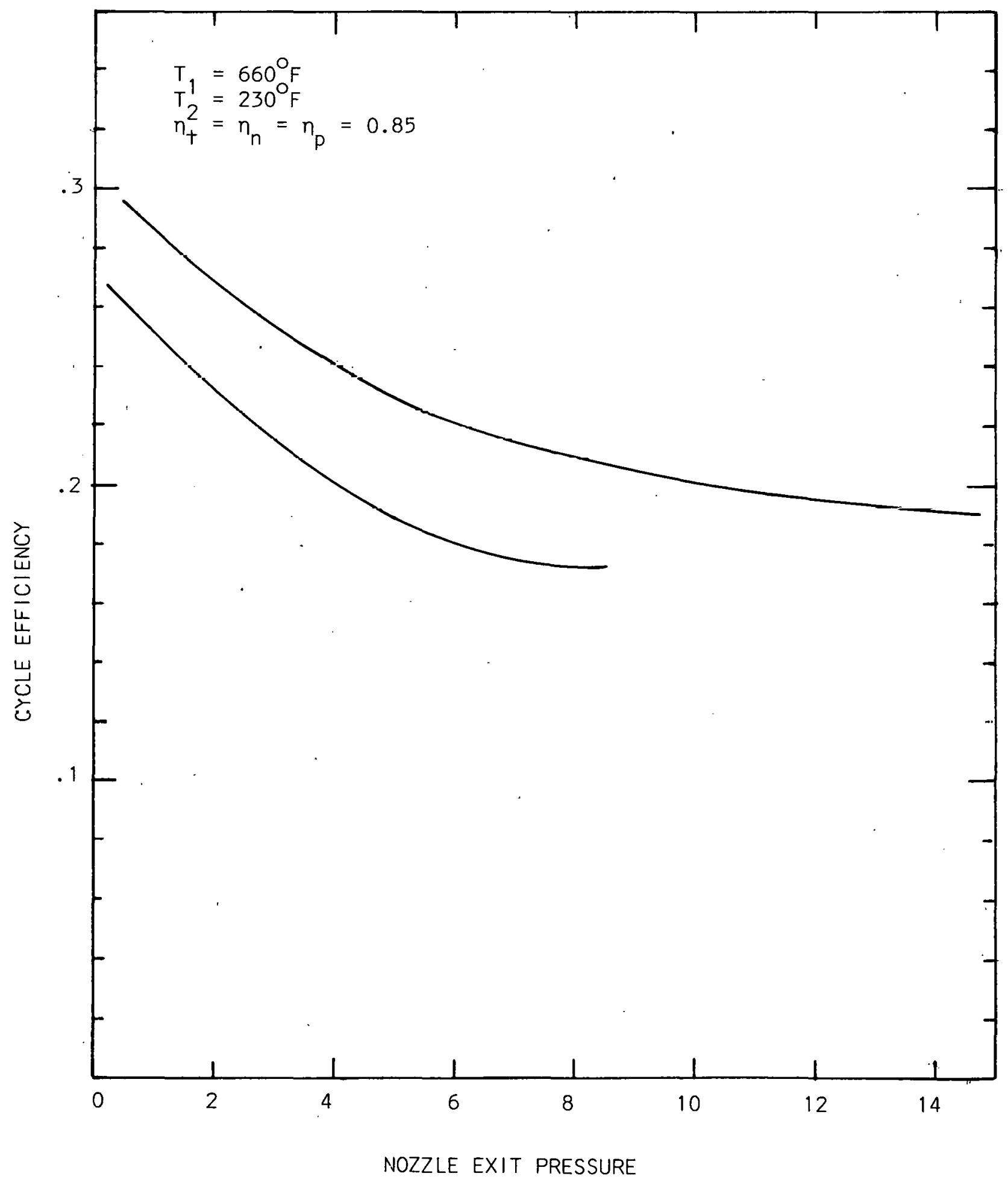

Fig. 34 - Comparison of Contact Heat Exchanger Cycle Efficiency and Tube-Fin Heat Exchanger Cycle Efficiency. Variation with Nozzle Exit Pressure. 


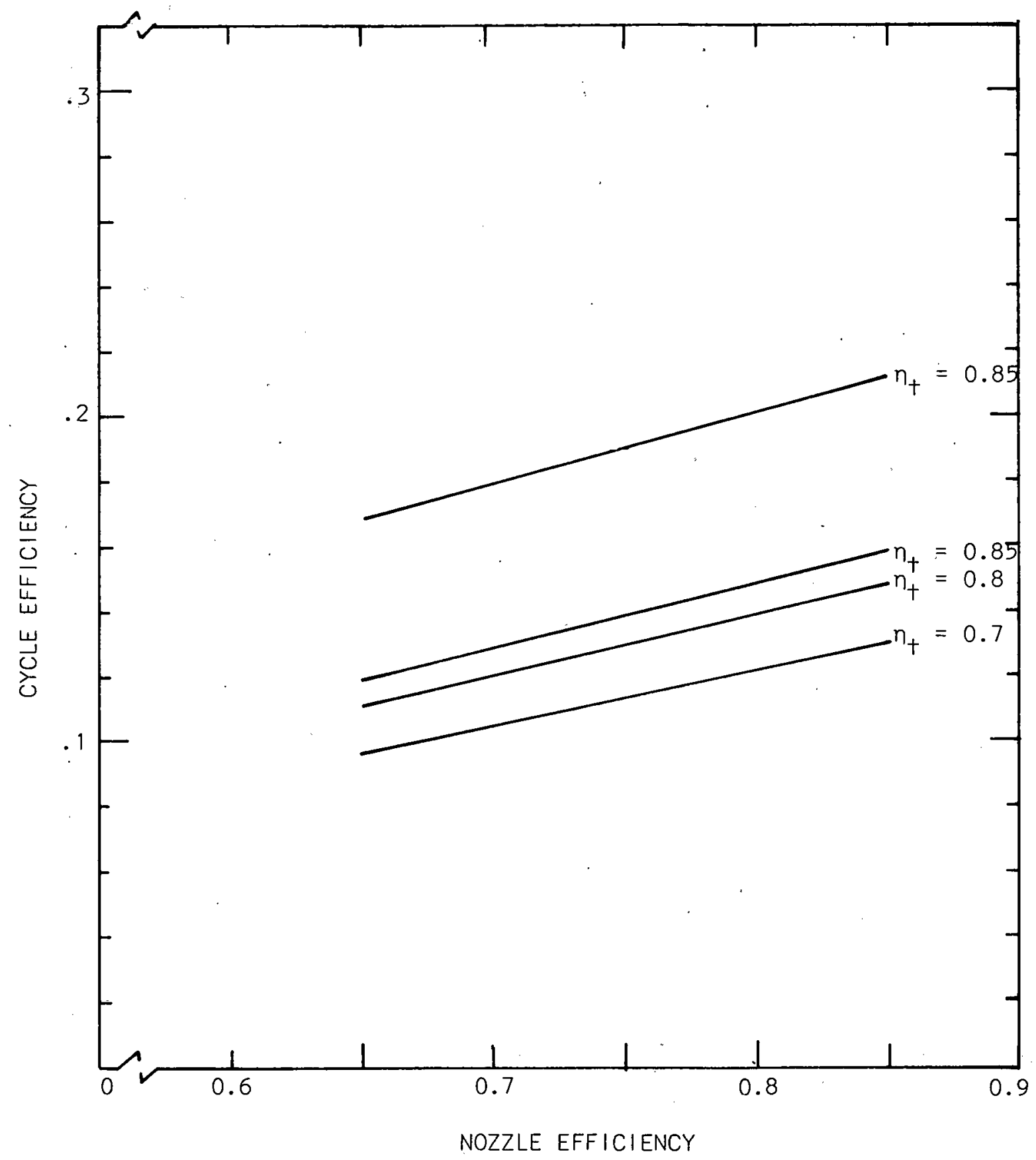

Fig.' 35 - Influence of Nozzle Efficiency on Efficiency of a Biphase Turbine Bottoming System with a Contact Heat Exchanger 


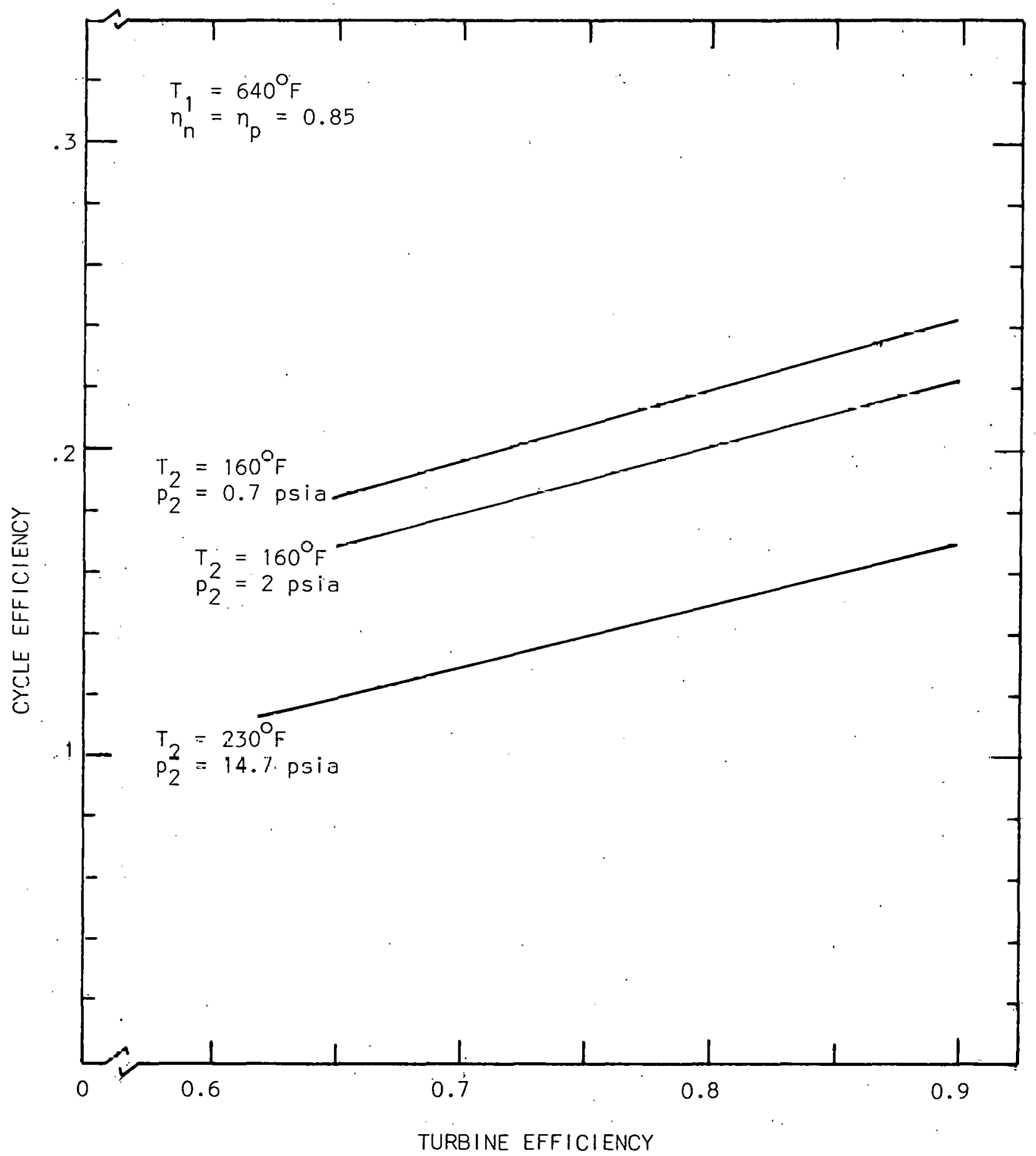

Fig. 36 - Efficiency of Biphase. Turbine Bottoming System with Contact Heat Exchanger Effect of Turbine Efficiency 


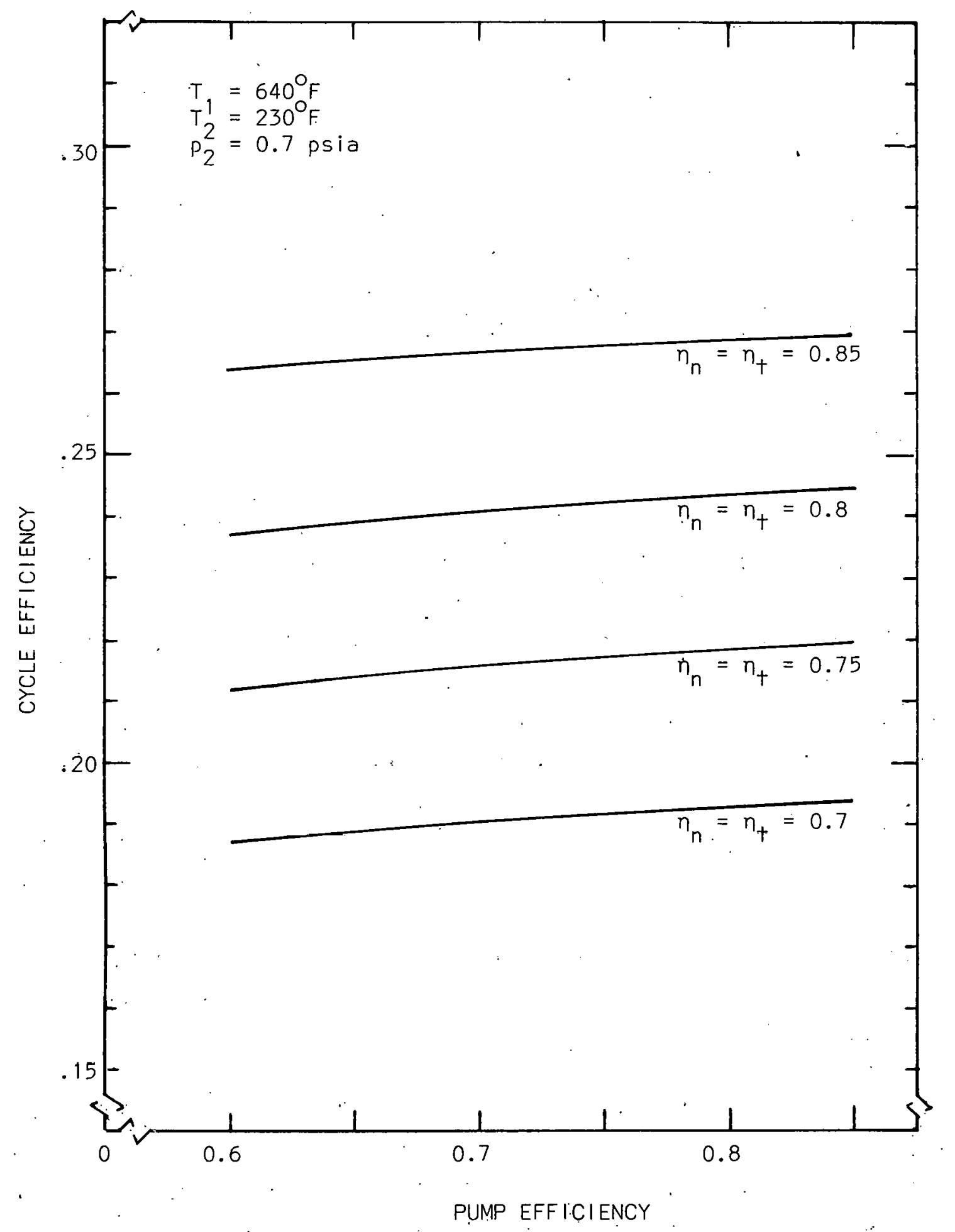

Fig. 37-Efficiency of a Biphase Turbine Bottoming System with Contact Heat Exchanger Influence of Pump Efficiency. 
The parametric cycle analyses of several cycles which were conducted showed a maximum two-phase bottoming cycle efficiency of about $30 \%$ for a $719^{\circ} \mathrm{F}$ diesel exhaust temperature and a rejection temperature of $90^{\circ} \mathrm{F}$ (.7 psia). Limitations on working fluid choice and the desire for simplicity and moderate rpm led to the specification of an atmospheric exhaust pressure from the two-phase nozzle for the reference design cycle. Since the cost of tube and fin exchanger is as much as 50\% of the system, and resistances like fouling and scaling cause reduction in effective heat transfer, the feasibility of replacing tube-fin heat exchanger with a contact heat exchanger. was evaluated.

Direct contact between fluids makes heat exchanger between them effective; the greater intimacy of the direct contact fluids usually permits the attainment of greater heat transfer co-efficient than is possible in tubular exchangers. In tubular equipment, the tube limits the intimacy of contact and serves as a surface upon which resistances accumulate as fouling and scale. One of the principal reasons for employing tubes is to prevent mixing of either gas or liquid which may be of concern if the two phases are not mutually soluble.

\section{TYPES OF CONTACT HEAT EXCHANGERS}

Several types of heat exchangers are available for direct contact heat transfer:
1) 'spray tower
2) Packed or plate column
3) Baffls plats or shower deck column

Spray towers have large contact area and relatively inexpensive operation and equipment cost. However, the spray tower operates with a high degree of back mixing of the phases, thus limiting the operation to not more than two contacting stages. A further weakness in the fundamental approach to estimating spray performance is deviation from counter-current flow. 
A baffle column or shower deck is often used for contacting gases with liquid containing solids. Baffle plates have a lower efficiency and are not suitable for operating at high heat transfer rates, because the column is much larger.

Packed beds are one of the most efficient systems for direct contact heat exchanger between two immiscible fluids. They are presently being used in variety of transfer systems. The control of thermal emissions and the waste heat recovery from this process favor the use of a packed column because of lower transfer resistance, cost, and applicability to more contacting stages.

Based on the information available and on the compatibility of packed columns for a higher number of contacting stages, the decision was made to use a packed column for our operation. Design of these units depends greatly on the heat transfer capacity and pressure drop characteristic of the packing material being considered.

A number of packings were considered for a range of sizes:

1) Intalox saddles (ceramic)

2) Berl saddles (ceramic)

3) Metal pall rings

4) Metal ballast rings

5) Brush esp packing

Cost comparison and evaluation of packing characteristics were made for different packings. Ceramic palll rings were selected for design analysis.

WORKING FLUIDS

Berause of the importance of the working fluid in determining the size of the heat exchanger and the exhaust scrubbing requirements, a more extensive survey of available working fluids was performed. The fluids considered were: 
1) Therminol group of heat transfer liquids:

Therminol 88, Therminol 66, Therminol 60, Terminol 55, Therminol 44

2) Dowtherm $A$ and Dowtherm $G$

3) Mobiltherm 600

4) Chevron Teknifax

5) Arco Rubilene

6) Dow Corning group of silicone and fluorosllicone fluids

7) Calgon refrigeration oil

8) Dupont's Freon goup

9). Animal oil (fish oil)

A comparison of physical and thermal properties were made. A summary of the results is given in Appendix F.

After careful review of the properties of the fluids, Therminol 66 was selected for our system from the viewpoint of low vapor pressure, low sensible heat, insolubility in water and thermal stability.

SIZING OF DIRECT CONTACT EXCHANGER

A comprehensive design would incorporated an evaluation of the evaporation and condensation effects, which occur simultaneously with heat transfer in the direct contact heat exchanger. The present design effort doesmnt ronsider evaporation or condensation in the analysis instead allowing a $10 \%$ size increase to account for this effect.

Design Equation - The heat exchanger requirements are indicated on Fig. 38. On the assumption that the mass evaporated in negligible, a heat balance across column element is:

$$
G\left(C_{P}\right)_{G}\left(-d T_{G}\right)=G^{\prime}\left(C_{P}\right)_{G}\left(-d T_{G}\right)=U a\left(T_{G}-T_{L}^{\prime}\right) d Z
$$




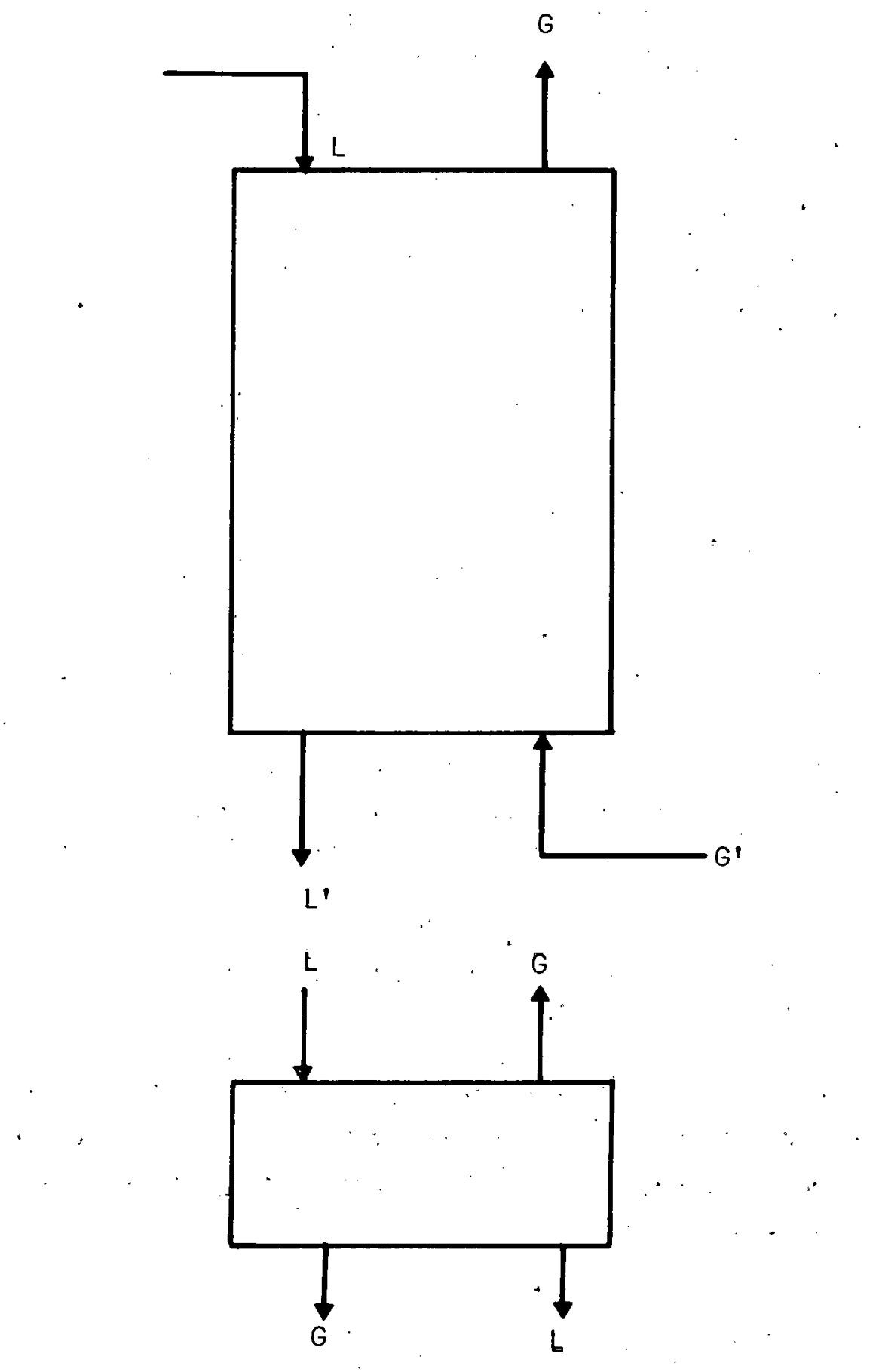

Fig. 38 - Schematic of Direct Contact Heat Exchanger 
where

$$
\begin{aligned}
& G=\text { total gas mass flow rate }\left(\mathrm{lb} / \mathrm{hr} \mathrm{ft}^{2}\right) \\
& G^{\prime}=\text { noncondensible gas mass flow rate }\left(\mathrm{lb} / \mathrm{hr} \mathrm{ft}^{2}\right) \\
& \left(C_{P}\right)_{G}=\text { heat capacity of gas phase }\left(B T U / / b{ }^{\circ} F\right. \text { ) } \\
& T_{G}=\text { gas phase temperature }{ }^{\circ} \mathrm{F} \\
& T_{L}=1 \text { iquid phase temperature }{ }^{\circ} F \\
& U=\text { overai i heat transter co-efticient (Blu/hr t+ }{ }^{2} n_{t} \text { ) } \\
& a=\text { heat transfer surface per volume of packing }\left(f t^{2} / f t^{3}\right) \\
& 7=\text { helght nf trower (ft) }
\end{aligned}
$$

Rearranglng

$$
d Z=\frac{G^{\prime}\left(C_{P}\right)_{G}}{U a} \times \frac{-d T_{G}}{\left(T_{G}-T_{L}\right)}
$$

In many calculations, the group $G^{\prime}\left(C_{F}\right) /$ Na will remain nearly constant even though individual components of the product may vary. When this occurs, the height of a transfer unit $\left(\mathrm{H}_{\mathrm{SG}}\right)$ and the number of transfer units may be defined so that height of the required packed section can be determined from:

$$
\int_{Z_{i}}^{Z_{2}} d Z=H_{O G} \int_{T_{G_{1}}}^{T_{G_{2}}} \frac{\left(-d T_{G}\right)}{\left(T_{C^{-T}}-T_{L}\right)}=H_{O G}{ }^{N_{O G}}
$$

Tower cross sectional area must be determined first, using the generalized pressure drop correlation available from Eckert. The Eckert correlation is a recent development generally used for predicting the tower diameter based on a definite pressure drop:

$$
\frac{L}{G}\left(\frac{\rho_{g}}{\rho_{\ell}-\rho_{g}}\right)^{0.5} \text { vs. } \frac{G^{2} F \mu}{\rho_{g}\left(\rho_{\ell}-\rho_{g}\right) g_{C}}
$$


where

$$
\begin{aligned}
& L=1 \text { iquid rate }\left(1 \mathrm{~b} / \mathrm{sec} / f t^{2}\right) \\
& G=\text { gas rate }\left(1 \mathrm{~b} / \mathrm{sec} / \mathrm{ft}^{2}\right) \\
& \rho_{\ell}=1 \text { iquid density }\left(\mathrm{lb} / \mathrm{ft}^{3}\right) \\
& \left.\rho_{g}=\text { gas density..(1b/ft+ } t^{3}\right) \\
& \mu=\text { liquid viscosity (cps) } \\
& F=\text { packing factor }
\end{aligned}
$$

\section{HEAT TRANSFER CO-EFFICIENTS}

The data for the calculation of heat transfer process in direct contact exchangers are not sufficiently represented in technical literature. It is usually evaluated based on a heat balance and necessary flow rates. If the individual mass transfer co-efficients $k_{g}$ and $k_{1}$ can be determined for the specific column operating conditions, the film heat transfer co-efficients $h_{G}$ and $h_{L}$ can be estimated by heat and mass transfer analogies. Then the overall heat transfer co-efficient can be obtained.

$$
\frac{1}{U}=\frac{1}{h_{G}}+\frac{1}{h_{L}}
$$

The most successful correlation of individual gas and. liquid phase co-efficients for packed towers is that of Onda where:

$$
\begin{gathered}
K_{L}\left[\frac{\rho_{L}}{\mu_{L} G}\right]=0.0051\left[\frac{L}{a_{w} \mu_{L}}\right]^{\frac{2}{3}}\left[\frac{\mu_{L}}{\rho_{L} D_{L}}\right]^{-0: 5}\left(a_{+} D_{p}\right)^{0.4} \\
\frac{K_{G} R T}{a_{+} D_{G}}=5.23\left[\frac{G}{a_{+} \mu_{G}}\right]^{0.7} \cdot\left[\frac{\mu_{G}}{\rho_{G} D_{G}}\right]^{\frac{1}{3}}\left(a_{t} D_{p}\right)^{-2.0} .
\end{gathered}
$$

$h_{L}$ and $h_{G}$ can be found from:

$$
h_{G}=K_{G} P_{B M} C_{P}\left[\frac{S c}{P r}\right]^{0.67}
$$


and

$$
h_{L}=K_{L} C_{P}\left[\frac{S c}{P r}\right]^{0.67} .
$$

Diffusion co-efficients in the above relations were estimated by using the following equation:

$$
\frac{D_{L}}{T}=7.4 \times 10^{-8} \frac{(X M)^{0.5}}{V_{h} 0.6}
$$

. where

$$
\begin{aligned}
& M=\text { molecular weight of components } \\
& X=\text { association parameter }
\end{aligned}
$$

The gas phase diffusion co-efficient can be found from:

$$
\frac{B T^{\frac{3}{2}} \sqrt{\frac{1}{M_{1}+\frac{1}{M_{2}}}}}{\operatorname{Pr}_{12}{ }^{\prime} I_{D}}
$$

$P_{B M}$ is assumed to be 1.0 as evaporation and condensation are neglected. Then:

$$
H_{O G}=\frac{\cdot^{G\left(C_{P}\right)}}{U_{A V^{a}}}
$$

The result's of the design calculation for the contact heat exchanger with metal pall rings and ceramic saddles are presented in Appendix $G$.

The tower cross sectional area was determined first by using Eckert's correlalion. The total available pressure drop was 0.3 psia, so that the pressure drop through the packed bed must be less than 10 inches of water. Choosing a pressure drop of 0.5 inch of $\mathrm{H}_{2} \mathrm{O}$ per $\mathrm{ft}$ ( $\mathrm{Fig} .39$ ) of packed bed with 3 inch ceramic saddles and $L / G$ ratio of 0.39 , the gas rate $G$ is $1315 \mathrm{lb} / \mathrm{hr} \mathrm{ft}^{2}$. 


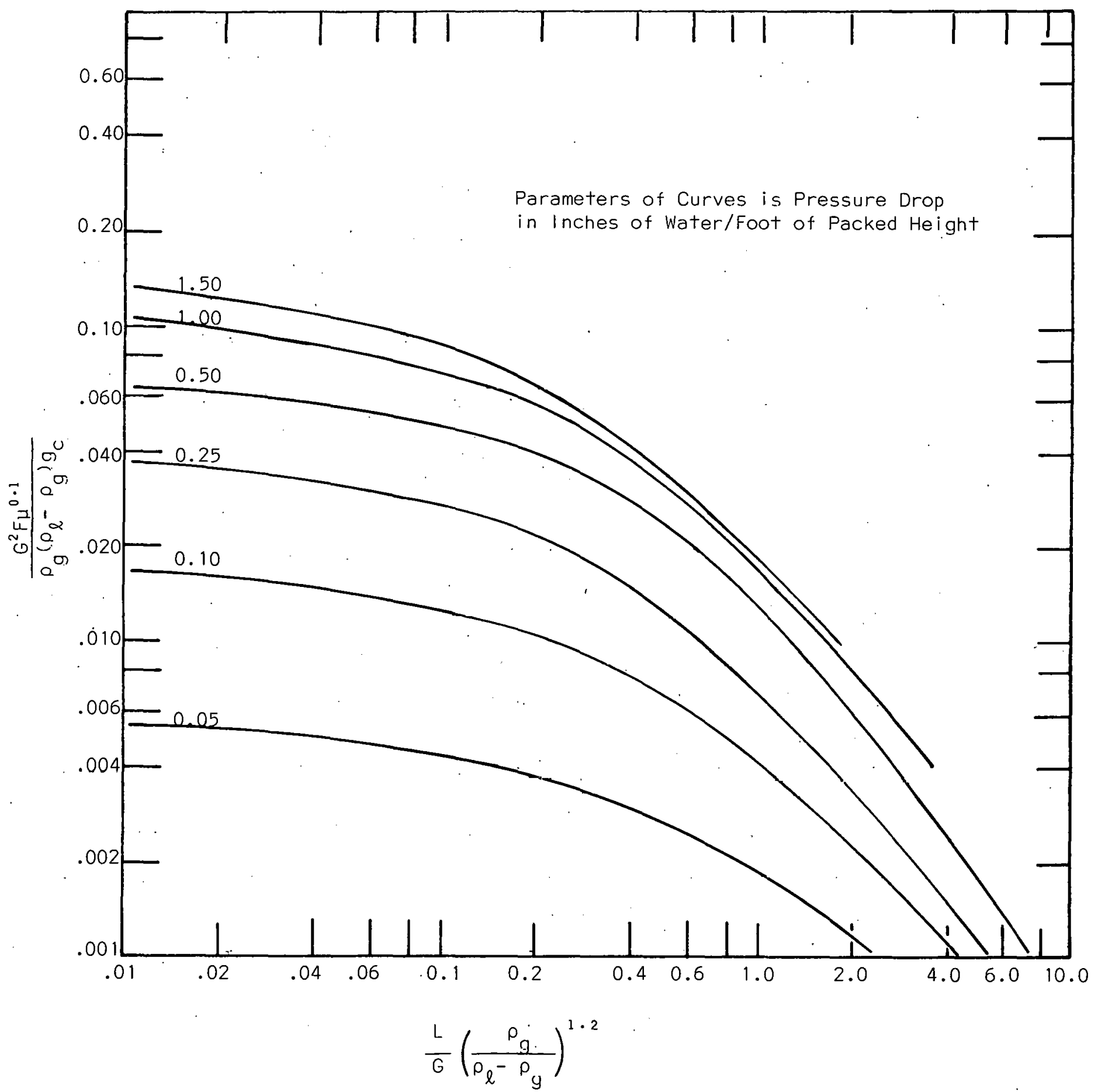

Fig: 39 - Packed Tower Design Parameters 
The liquid rate $\mathrm{L}$ is $513 \mathrm{lb} / \mathrm{hr} \mathrm{ft}^{2}$ which depending upon the type of column packing chosen, is close to minimum liquid rate required for properly wetting the packing, corresponding heat transfer co-efficient and overall co-efficient are shown in Appendix $B$.

The total height of the tower required is $16 \mathrm{ft}$ and a diameter of $5.5 \mathrm{ft}$ with 3 inch ceramic saddles. The requirement of good contact between the liquid and. gas is hard to meet especially in a larger tower. The liquid once distributed over the top of the packing, ideally flows in thin films over the entire packing surface all the way down the tower. Actually, the films tend to get thlcker in some places and thinner in others and collects into small rivulets and flows along. localized paths through the packing. Especially at low liquid rates, much of the packing surface may be dry or best be covered by a stagnent film of liquid. This effect is known as channeling and is the main reason for poor performance of large towers. Because a comparatively large tower and liquid rate close to minimum resulted from the use of 3 inch ceramic packings, there is a possibility of channeling.

This can be either avoided by adding an intermediate liquid distributor which will resist the flow towards the wall, or by selecting some other packing size or material whose characteristic will make it possible to design a comparatively smaller tower and high liquid rate. Design analys is was further performed with 2 inch metal pall rings and 2 inch ceramic saddles. With 2 inch pall rings the diameter of the tower is $4.65 \mathrm{ft}$ and total height $10 \mathrm{ft}$. The liquid and gas rates are respectively $641 \mathrm{lb} / \mathrm{hr} \mathrm{ft^{2 }}$ and $1625 \mathrm{lb} . \mathrm{hr} \mathrm{ft}^{2}$ and this should enable proper wetting of the column and a better tower performance. With 2 inch saddles a tower height of $9.5 \mathrm{ft}$ and a diameter of $5.5 \mathrm{ft}$ were obtained. Thus a relatively compact vessel can be used with either 2 inch metal or ceramic packing. Column design for the case where hoth heat and mass transfer occur requires a stepwise iterative calculation.

COMPOSITION OF DIESEL EXHAUST EMISSION

Most diesel engines emit visible smoke, unburnt hydorcarbon, nitric oxide, 
sulfur compound, oxygenated hydrocarbon and other particulates:

1) The unburnt hydrocarbon in the diesel. exhaust consist of either original or decomposed fuel molecule or recombined intermediate compound. A small portion may originate from lubricating oil.

2) Carbon monoxide is formed during intermediate combustion stages of hydrocarbon fuel and proceeds through oxidation. If these reactions are incomplete due to lack of oxidant or low temperature, carbon monoxide is left out.

3) Soot or black smoke is emitted as a product of incomplete combustion at maximum load. It.consists of irregularly shaped, agglomerated fine carbon particles.

4) Nitric oxide is formed during the combustion process.

Other particulates emitted from diesel engine include polynucleur, aromatic, phenols, aldehydes and odor. However, these emissions are functions of operating variables and engine design and may vary. Emissions from a typical diesel engine are given in Table 5. One of the secondary benefits of the direct contact heat exchanger is the scrubbing action of the heat transfer fluid on the exhaust. Particulate emissions will be eliminated and particle absorption of gaseous compounds accomplished. 
CONIPARISON BETWEEN ERAKE SPECIFIC EMISSION OF DIFFERENT TYPES OF DIESEL

ENGINES, OVER A MOD!FIED 13 MODE TEST CYCLE

\& Code 10

A

$B$

C

D

$1 \quad E$

$\stackrel{\infty}{P} \quad F$
Power, bhp

34.5

53.6

57.1

58.1

68.1

73.1

77.1

85.7

46.7
4 Cycle, Naturally aspirited 0.1.

Emissions, g/bhp-hr

Nitric Oxide Hydrocarbcn Aldehydes Particulates Odor (as $\mathrm{NO}_{2}$ ) (as $\mathrm{CH}_{2}$ )

(as $\mathrm{HCHO}$ )

0.5

0.6

4.5

$6.7 \quad 3.1$

19.8

3.0

0.4

0.6

3.6

C. 4

.0 .1

4.0

$16.7 \quad 3.1$

9.5

2.3

6.9

0.6

4 Cycle Turbocharged, D.I.

3.9

17.8

3.1

$1 i .7$

2.6

2 cycle, D.I.

14.7

0.7

6.1

3.3 


\section{MIST SEPARATOR}

In order to avoid any liquid or solid entrainment with the gas stream it was decided to use a mist separator at the outlet of gas stream. Several types of mechanisms are available to separate the mist from gases. Among them wire mesh impingement type separator: consists of 4 to 6 .inches deep bed of knotted mesh pad with a high free volume of $97 \%$ to $99 \%$. Usually it is installed horizontally between a bottom support and top hold down grid. It is almost $100 \%$ efficient for particles $8 \mu$ and larger. To improve collection efficiency on finer particles two mesh pads are used in series a high density mesh in the bottom and a low density mesh in the top. Fabric mist eliminators are often used for particle sized $3 \mu$ and smaller, they have a very high collection efficiency $(99.98 \%)$. But they require a larger space and have a high pressure drop, which makes them incompatible for the system.

Moreover, one of the advantages of using a contact heat exchanger (packed bed type) is that it will wash away the coarser particles $10 \mu$ and larger with the liquid stream. Subsequent filtration at the heat exchanger outlet or nozzle inlet will separate these particles.

However, gases must be sampled in order to determine the particle sizes and evaluate equipment performance. Liquid also should be tested to determine the chemical stability and degradation if any. 


\section{ECONOMIC COMPARISON BETWEEN CONTACT AND TUBE-FIN HEAT EXCHANGERS}

\section{DESCRIPTION OF DIRECT CONTACT EXCHANGER}

The direct contact exchanger consists of a cylindrical shell filled with randomly oriented packing material, but in some cases the packing may be carefully positioned. The design drawings of the heat exchanger are shown in Figure 40 and Figure 41. A support plate is provided at the bottom of the column for supporting the packing material and a liquid distribution device designed to provide effective irrigation of the packing at the top. The unlt is of flanger rongtrilistion and with an inspertion manhole tor easy disassembly and maintenance. The material of construction is 304 stainless steel.

\section{TUBE-FIN EXCHANGER}

The tube and fin exchangers are discussed in detail in Section VI. Figure 30 shows an isometric view of the tube-fin exchanger.

A cost comparison of $\mathrm{fin}$ and tube with direct contact heat exchanger was made. The cost of the contact heat exchanger consisted of actual fabricotion quotations based on the design drawings and November 1976 catalog prices for the packing material. The cost of the tube-fin heat exchanger was obtained from Ref. 7 which was published in November 1974. No inflation in price was considered nor were economics of size (the exchanger of Ref. 7 was for a $1000 \mathrm{~kW}_{\mathrm{e}}$ system whereas contact heat exchanger is designed for a $200 \mathrm{~kW} e$ system).

Table 6 furnishes a breadkdown of the cost estimated for both the contact heat exchanger and tube-fin exchanger. The final cost show the contact heat exchanger cost to bc $\$ 52 / \mathrm{kW}$ versus $\$ 97 / \mathrm{kW}$ for the tube-fin heat exchanger. The cost advantage should be much greater if carbon steel was used instead of stainless steel for the tube-fin exchanger. 


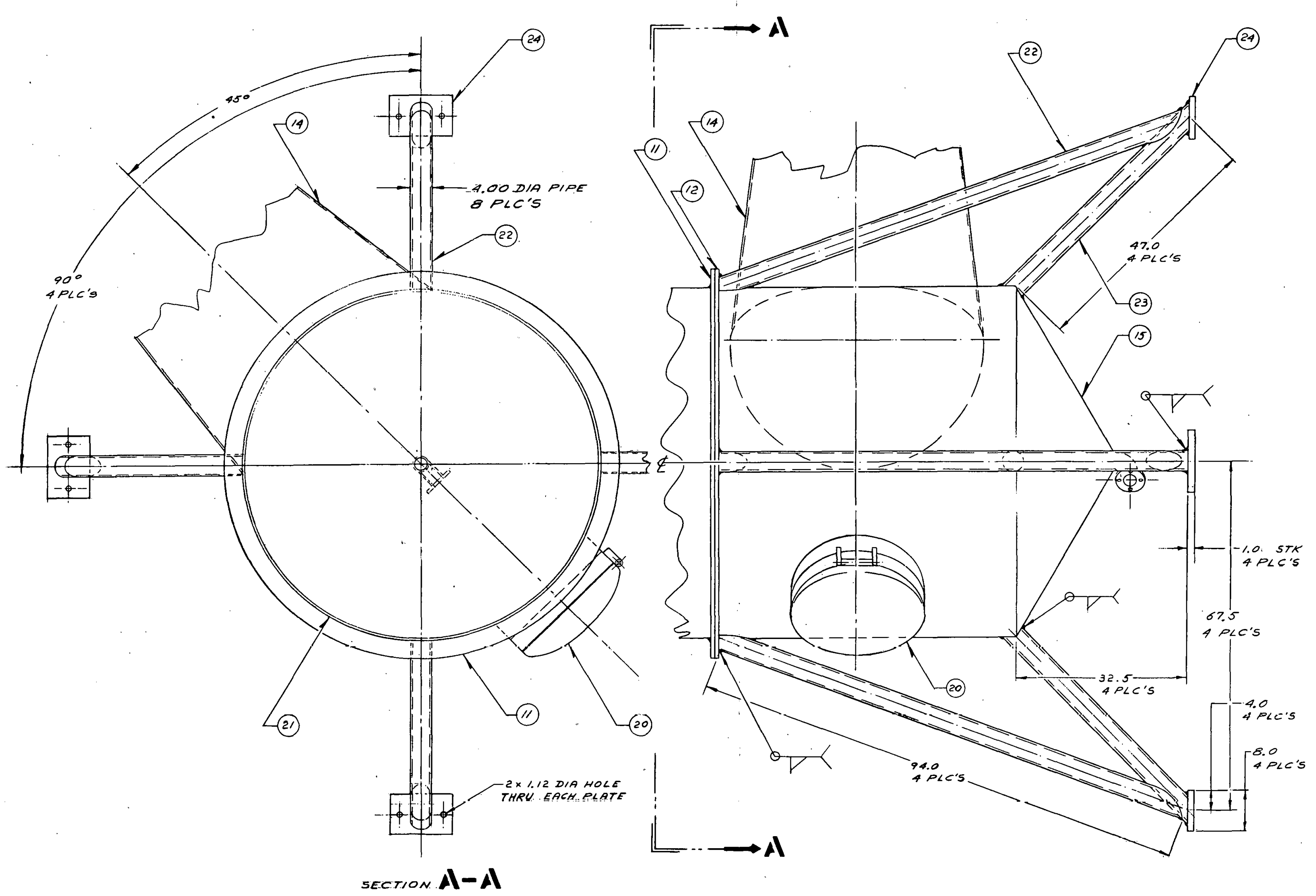




\section{TABLE 6}

COMPARISON OF COST OF CONTACT HEAT EXCHANGER WITH

TUBE-FIN HEAT EXCHANGER

Cost for Direct Heat Exchanger

A. Tower $5.5 \mathrm{ft}$ diameter and $15 \mathrm{ft}$ cylinder length standard removable top and fixed bottom head, with manhole, gas, liquid inlet and outlet, flanges and other fittings (drawing).

Material of construction - stainless steel 304 wall thickness - $\frac{1}{4} "$

B. 2" ceramic saddles packing

$5.5 \mathrm{dia}$. and $10 \mathrm{ft}$ packed length, $\$ 7.35 / \mathrm{cft}$

$\$ 7,000.00$ for fabrication and materials

$\$ 1,745.00$

C. Support plate for packing

200.00

D. Liquid distributor

200.00

E. Mist eliminator, wire mesh impingement type,

6" wire mesh including top and bottom

900.00

support grid

F. Insulation 3" calcium silicate, material cost

725.00

TOTAL COST $=A+B+C+D+E+F=$

$\$ 10,000.00$

Power generated $205.9 \mathrm{~kW}$

Cost $\$ 52.30 / \mathrm{kW}$

Cost for Tube-Fin Exchanger

A. Fin tube, tube o.d. $3 / 4$ inch with a wall thickness of 0.083 inch

Material for tubing ASTM-A-179, low carbon steel

Serrated fins, 6/inch

Height of fins, 0.375 inch

Thickness, $\quad 0.012$ inch

Material- ASTM-A-366-66T, Mod. C

0.10 max. carbon steel with fins spot welded to tube

Total fin tubing length, 10,000 ft @\$3/ft $30,000.00$ 


\section{TABLE $6-$ CONT'D $^{\prime}$}

B. Cost for Assembly, Shroud, Insulation, etc.

I. Tube pitch: Longitudinal 3 inch

Transverse 2.75 inch

Material for headers and U-bends - ASTM-A-372 grade 1 steel heliarc welded

$\$ 38,500.00$

11. Shroud: Material - carbon steel

Insulation: mineral wool board $21,500.00$

11.1. Welding and testing of tube bundle: 8,000.00

TOTAL COST - A $+B$

$=30,000.00+38,500.00+21,500.00+8,000.00$

$=98,000.00$

Power generated $1,009 \mathrm{~kW}$

Cost $\$ 97.25 / \mathrm{kW}$ 


\section{$X$. TURBINE. TEST SYSTEM}

In order to provide performance testing of two-phase nozzles and turbines (c.f. Section XI) a blowdown test system was designed, using available components where possible. The objective of this system is to provide short duration test runs"for conditions of interest to diesel bottoming and other waste heat recovery appi ications. The design conditions for the test loop are summarized in Table 7. A schematic of the test system is shown in Figure 42 .

Dowtherm $A$ and Water are heated to the nozzle inlet. temperature in separate spherical vessels $(1,2)$. The maximum temperature and pressure for the Dowtherm $A$ is $700^{\circ} \mathrm{F}$ and $1200 \mathrm{psia}$. The water vessel (2) has a maximum pressure rating of 3000 psia but the water would be only heated to $560^{\circ} \mathrm{F}$ to remain liquid at the 1200 psia pressure of the Dowtherm: The pressure is maintained on the working fluids by a:nitrogen blanket provided by high pressure bottles and regulator. The heat to the vessels is supplied by fiberglass insulated heating jackets. The Dowtherm and water flow through turbine flow meters and throttling valves to the test nozzle (3) wherein they are mixed. The water vaporizes during expansion in the nozzle and drives the liquid Dowtherm to a high exit velocity. The two-phase mixture is impinged on a thrust target (4) to measure the performance of the nozzle.

The Dowtherm falls to the bottom of the receiver tank (11) and is pressurized by a Kobe positive displacement pump and returned to the Dowtherm vessel (1). It may be returned continuously, in which case the temperature of the Dowtherm.will gradually drop, or it may be returned at the end of each test run. The steam separated from the Dowtherm is discharged through a vent (10) to atmosphere or through a water bath to atmosphere.

Makeup water for the high temperature vessel (2) is: provided by a centrifugal pump (12) which draws water from a boiler feed water treating unit. 


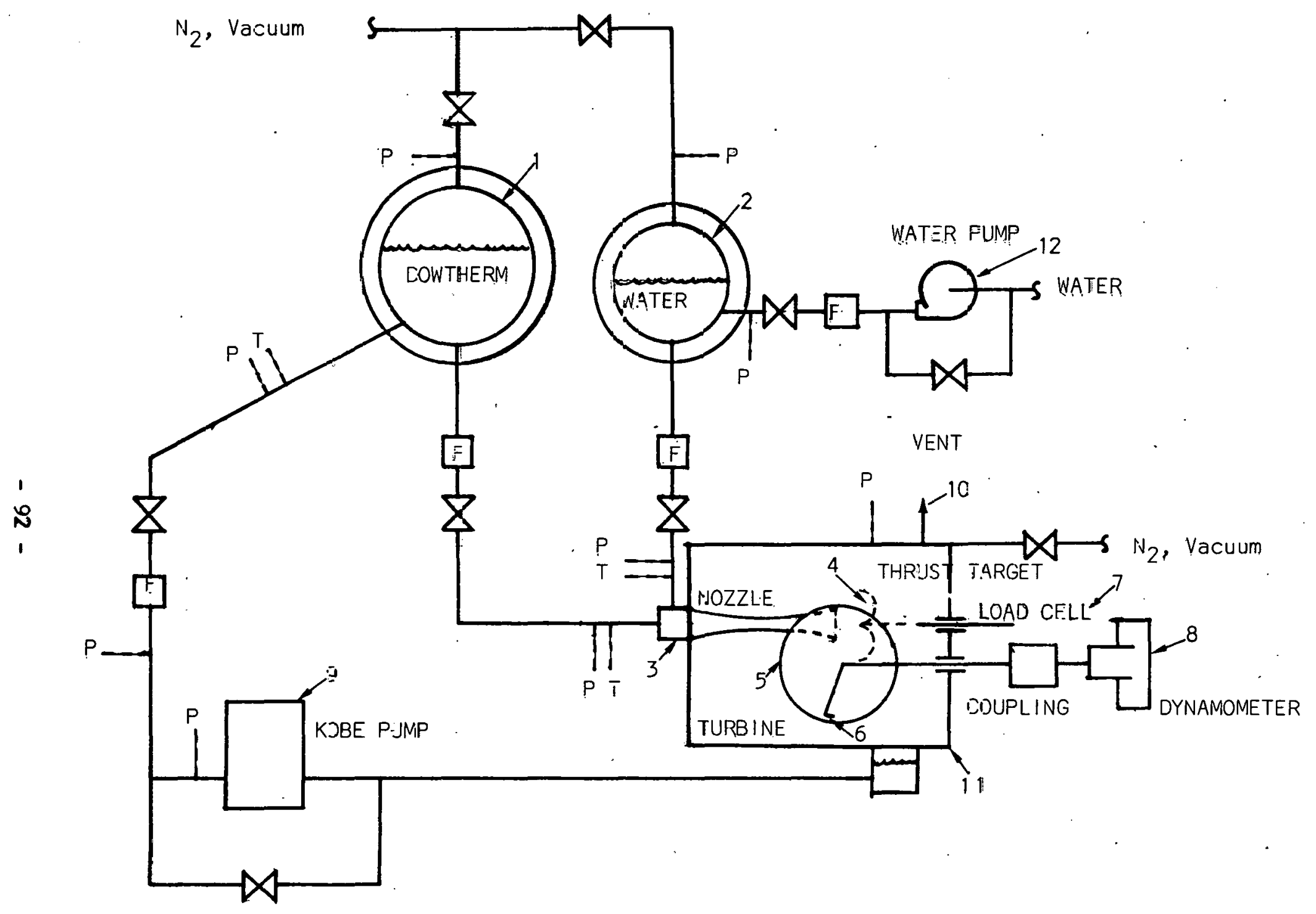

Fig. 42 - Two-Phase Nozzle and Turbine Test Systam 
After measurement of the performance of the two-phase nozzle, tests would be conducted with a two-phase turbine $(5,6)$ installed in the receiver vessel. The receiver vessel incorporates view ports for flow visualization of the two-phase turbine during operation. The output shaft drives a dynamometer (8) through a rotary seal in the receiver vessel.

TABLE 7. DESIGN POINT PARAMETERS FOR THE TEST SYSTEM

$\begin{array}{lc}\text { Dowtherm Temperature } & 660^{\circ} \mathrm{F} \\ \text { Water Temperature } & 560^{\circ} \mathrm{F} \\ \text { Dowtherm Pressure } & 1200 \mathrm{psia} \\ \text { Water Pressure } & 1200 \mathrm{psia} \\ \text { Dowtherm Flow Rate } & 1.5 \mathrm{lb} / \mathrm{s} \\ \text { Water Flow Rate } & 0.3 \mathrm{lb} / \mathrm{s} \\ \text { Turbine Power Output } & 50 \mathrm{HP} \\ \text { Maximum Run Duration } & 10 \mathrm{~min}\end{array}$

The engineering layout for the blowdown test system is shown in Figure 43. A modular approach was used to maximize existing structure and components. The Dowtherm and water vessels are existing components which are mounted in the locations shown on an integral frame. Although the basic tests will be conducted in a blowdown operational mode an existing heat exchanger (condenser) and high pressure water pump are included in the basic equipment layout to enable eventual continuous operation. Other major components which are existing units are the two high pressure Kobe pumps, heat exchanger, control valves and all instrumentation. Table 8 is a component and material list for the test system. Existing items are indicated by asterisks.

The turbine test unit for the blowdown system is shown in Figure 44 . The design output of this unit is $50 \mathrm{HP}$ at $3600 \mathrm{rpm}$. The single inlet nozzle 

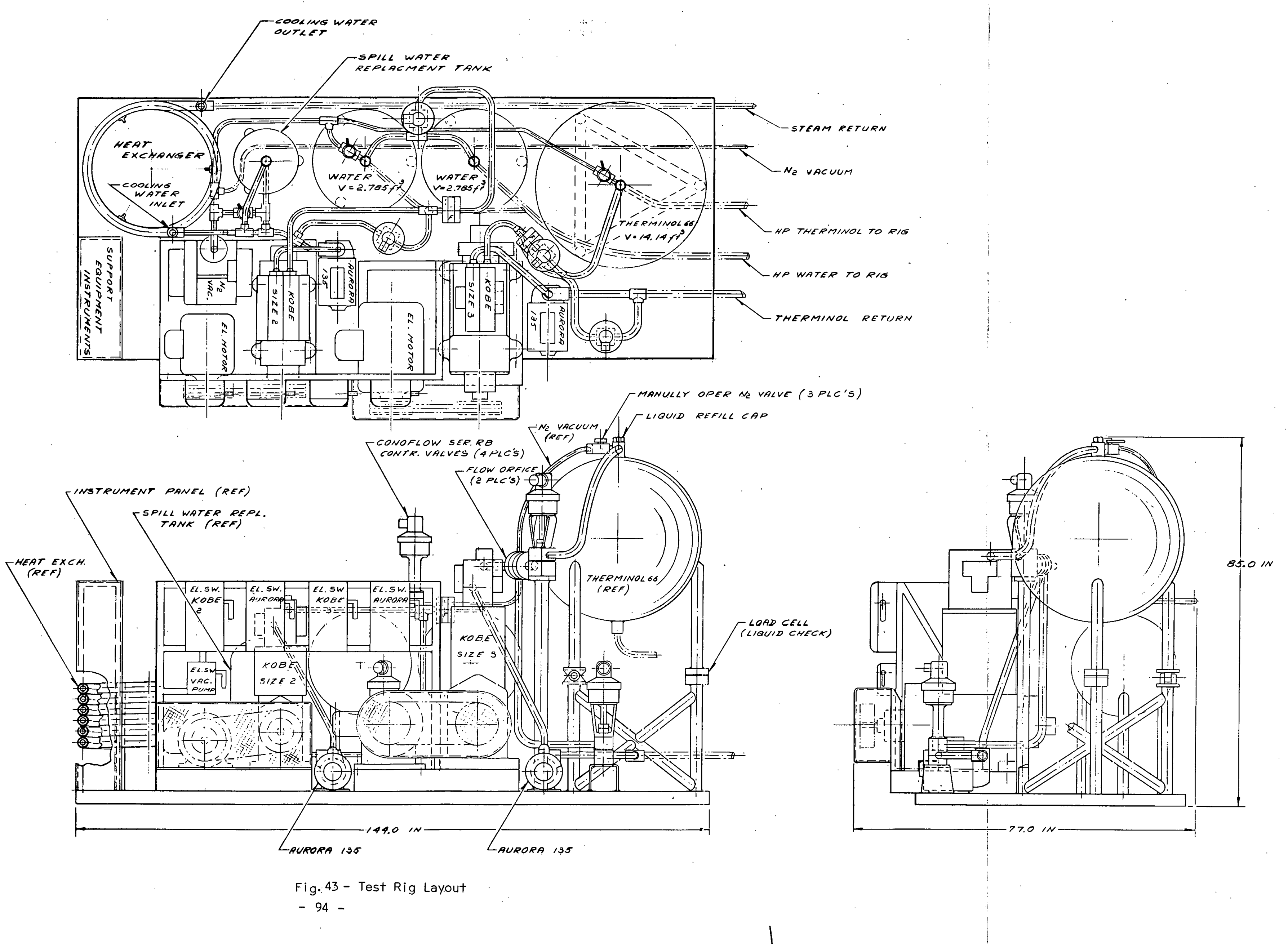
TABLE 8. COMPONENTS FOR BLOWDOWN TURBINE TEST RIG

\begin{tabular}{|c|c|c|c|c|}
\hline ITEMS & REQUIRED & DESCRIPTION & SERIAL & VENDOR \\
\hline 1 & 1 & $\begin{array}{l}\text { Therminol Tank* } \\
\text { Cap. } 14.14 \mathrm{cu} f+ \\
\text { Max. W.P. }=1200 \text { psi }\end{array}$ & 9457 & $\begin{array}{l}\text { Southwest Welding Mfg. Co. } \\
\text { Mat'I Cres. }\end{array}$ \\
\hline 2 & 2 & $\begin{array}{l}\text { Water Tank* } \\
\text { Cap. } 2.785 \text { cu ft each } \\
\text { Max.W.P. }=3000 \text { psi }\end{array}$ & $\begin{array}{l}9458 \\
9459\end{array}$ & $\begin{array}{l}\text { Southwest Welding Mfg. Co. } \\
\text { Mat'I Cres. }\end{array}$ \\
\hline 3 & 1 & $\begin{array}{l}\text { Kobe HP Pump Assy.* } \\
\text { Size } 3 \text { Type F }\end{array}$ & $C-5331$ & $\begin{array}{l}\text { Kobe Pump Co. } \\
(25 \text { HP Mot.) }\end{array}$ \\
\hline 4 & 1 & Kobe HP Pump Assy.* & $B-3693$ & $\begin{array}{l}\text { Kobe Pump Co. } \\
\text { (15 HP Mot.) }\end{array}$ \\
\hline 5 & 4 & $\begin{array}{l}\text { HP Rem. Contr. Valve* } \\
\text { ConoFlow RB-52 }\end{array}$ & & $\begin{array}{l}\text { ConoFlow Corp. } \\
\text { Blackwood; New Jersey } 08012\end{array}$ \\
\hline 6 & 3 & $\begin{array}{l}\text { HP Manually Contr.* } \\
\text { Valve } 4500 \text { CWP }\end{array}$ & & $\begin{array}{l}\text { Jamesbury Corp. } \\
\text { Worcester, Mass. }\end{array}$ \\
\hline 7 & 1 & $\begin{array}{l}\text { L.P. Turbo Pump } \\
\text { Aurora } 135-\mathrm{F} 05 \\
\text { Frame } 56,2 \mathrm{HP} \text {, } \\
9.8 \mathrm{Ga} \text {. Min. (Therminol) }\end{array}$ & . & $\begin{array}{l}\text { Aurora Pumps and Systems } \\
\text { North Aurora, } 111.60542\end{array}$ \\
\hline 8 & 1 & $\begin{array}{l}\text { L.P. Turbo Pump } \\
\text { Aurora } 135-J 05 \\
\text { Frame } 184 \mathrm{~T}, 7.5 \mathrm{HP} \\
32.8 \mathrm{Gal} \text {. Min. (Water) }\end{array}$ & & $\begin{array}{l}\text { Aurora Pumps and Systems } \\
\text { North Aurora, } 111.60542\end{array}$ \\
\hline 9 & As Requ'd. & Instrumentation* & & - \\
\hline 10 & 1 & Flow Orfice & & As required, Mat'l Cres. \\
\hline 11 & 1 & Flow Orfice & & As required, Mat'l Cres. \\
\hline 12 & 1 & $\begin{array}{l}\text { Spill Water Repl. Tank. } \\
\text { Cap. } 2.3 \text { cu ft }\end{array}$ & & $\begin{array}{l}\text { Pressure Støel Tank, } 60 \\
\text { Milwaukee, Wisc. }\end{array}$ \\
\hline 13 & 1 & Condensator* Coil & 73519 & $\begin{array}{l}\text { The Whitlooks Mfg. } \\
\text { West Hartford, Conn. }\end{array}$ \\
\hline 14 & 1 & $\begin{array}{l}\text { Kinney Vacuum Pump } \\
\text { Model KC- } 8 \mathrm{C}\end{array}$ & $2035 P$ & $\begin{array}{l}\text { Kinney Vacuum Pumps } \\
\text { Div. of New York Air Brake Co. } \\
\text { Boston, Mass. }\end{array}$ \\
\hline 15 & 1 & $\begin{array}{l}\text { Load Cell* } \\
\text { Model E354-3 }\end{array}$ & 6178 & Sensor Hydraulic Diaphragm \\
\hline 16 & As Requ'd. & $\begin{array}{l}\mathrm{N}_{2} \text { Vacuum I ine } \\
\frac{1}{4} \text { in Tubing, } \\
.088 \text { Wall Thickness }\end{array}$ & & $\begin{array}{l}\text { Ducommun Metal Co. } \\
\text { Mat'I Cres. } 304\end{array}$ \\
\hline 17 & As Requ'd. & $\begin{array}{l}\text { Steam return line } \\
3 / 4 \text { in Tubing } \\
.113 \text { Wall Thickness }\end{array}$ & & $\begin{array}{l}\text { Ducommun Metal Co. } \\
\text { Mat'l Cres. } 304\end{array}$ \\
\hline
\end{tabular}


TABLE 8. COMPONENTS FOR BLOWDOWN TURBINE TEST RIG (CONT'D)

\begin{tabular}{|c|c|c|c|c|}
\hline ITEMS & REQU IRED & DESCRIPTION & SERIAL & VENDOR \\
\hline 18 & As Requ'd. & $\begin{array}{l}\text { HP Therminol to Rig. } \\
1 \frac{1}{4} \text { in Tubing } \\
.140 \text { Wall Thickness } \\
\end{array}$ & & $\begin{array}{l}\text { Ducommun Metal Co. } \\
\text { Mat'I Cres. } 304\end{array}$ \\
\hline 19 & As Requ'd. & $\begin{array}{l}\text { HP Water to Rig. } \\
\frac{1}{2} \text { in Tubing } \\
.109 \text { Wall Thickness }\end{array}$ & & $\begin{array}{l}\text { Ducommun Metal Co. } \\
\text { Mat'I Cres. } 304\end{array}$ \\
\hline 20 & As Requ'd. & $\begin{array}{l}\text { Therminol return line } \\
1 \frac{1}{\pi} \text { in Tubing } \\
.140 \text { Wall Thickness }\end{array}$ & & $\begin{array}{l}\text { Ducommun Metal Co. } \\
\text { Mat'l Cres. } 304\end{array}$ \\
\hline 21 & As $\operatorname{Requ}^{\dagger} \mathrm{d}$. & $\begin{array}{l}\text { Therminol return bypass } \\
\text { line. } 1 \frac{1}{4} \text { in Tubing } \\
.140 \text { Wall Thickness }\end{array}$ & & $\begin{array}{l}\text { Ducommum Metal Co. } \\
\text { Mat'I Cres. } 304\end{array}$ \\
\hline 22 & As Requ'd. & $\begin{array}{l}\text { Therminol return via HP } \\
\text { pump line. } 1 \frac{1}{4} \text { in Tubing } \\
.140 \text { Wall Thickness }\end{array}$ & & $\begin{array}{l}\text { Ducommun Metal Co. } \\
\text { Mat'I Cres. } 304\end{array}$ \\
\hline 23 & As Requ'd. & $\begin{array}{l}\text { Therminol return to tank } \\
1 \frac{1}{4} \text { in Tubing } \\
.140 \text { Wall Thickness }\end{array}$ & & $\begin{array}{l}\text { Ducommun Metal Co. } \\
\text { Mat'I Cres. } 304\end{array}$ \\
\hline 24 & As Requ'd. & $\begin{array}{l}\text { HP Water return to tank } \\
\frac{1}{2} \text { in Tubing } \\
.109 \text { Wall Thickness } \\
\end{array}$ & & $\begin{array}{l}\text { Ducommun Metal Co. } \\
\text { Mat'I Cres. } 304\end{array}$ \\
\hline 25 & As Requ'd. & $\begin{array}{l}\text { HP Water return distribu- } \\
\text { tor I ine. } \frac{1}{2} \text { in Tubing } \\
.109 \text { Wall Thicknoss }\end{array}$ & & $\begin{array}{l}\text { Ducommun Metal Co. } \\
\text { Mat'I Cres. } 304\end{array}$ \\
\hline 26 & As Requ'd. & $\begin{array}{l}\text { Water return bypass line } \\
\frac{1}{2} \text { in Tubing } \\
.109 \text { Wall Thickness }\end{array}$ & & $\begin{array}{l}\text { Ducommun Metal Co. } \\
\text { Mat'I Cres. } 304\end{array}$ \\
\hline 27 & As Requ'd. & $\begin{array}{l}\text { Water return from } \mathrm{HP} \text { pump } \\
\text { line. } \frac{1}{2} \text { in Tubing } \\
.109 \mathrm{Wali} \text { Thickness }\end{array}$ & & $\begin{array}{l}\text { Ducommun Metal Co. } \\
\text { Mat'/ Cres. } 304\end{array}$ \\
\hline 28 & As Requ'd. & $\begin{array}{l}\text { Water return via HP } \\
\text { pump line. } \frac{1}{2} \text { in Tubing } \\
.109 \text { Wall Thickness } \\
\end{array}$ & & $\begin{array}{l}\text { Ducommun Metal Co. } \\
\text { Mat'I Cres. } 304\end{array}$ \\
\hline 29 & As Requ'd. & $\begin{array}{l}\text { Water line to spill tank } \\
3 / 8 \text { in Tubing } \\
.091 \text { Wall Thickness }\end{array}$ & & $\begin{array}{l}\text { Ducommun Metal Co. } \\
\text { Mat'I Cres. } 304\end{array}$ \\
\hline 30 & As Requ'd. & $\begin{array}{l}\text { Water line return from } \\
\text { condensator. } \frac{1}{2} \text { in Tublng } \\
.109 \text { Wall Thickness }\end{array}$ & & $\begin{array}{l}\text { Ducommun Metal Co. } \\
\text { Mat'l Cres. } 304\end{array}$ \\
\hline 31 & 1 & $\begin{array}{l}\text { El. switch, vacuum* } \\
\text { Pump motor } 11 \mathrm{CB} 3 \mathrm{E}\end{array}$ & & $\begin{array}{l}\text { Furnas Electric Comp. } \\
\text { Batavia, } 111.60510\end{array}$ \\
\hline 32 & 1 & $\begin{array}{l}\text { El. switch, Kobe } 2^{*} \\
\text { Pump motor } 14 \text { GB } 32 \text { EC } \\
11\end{array}$ & & $\begin{array}{l}\text { Furnas Electric Comp. } \\
\text { Batavia, } 111.60510\end{array}$ \\
\hline
\end{tabular}


TABLE 8. COMPONENTS FOR BLOWDOWN TURBINE TEST RIG (CONT'D)

\begin{tabular}{c|c|l|c|l}
\hline ITEMS & REQUIRED & \multicolumn{1}{|c|}{ DESCRIPTION } & SERIAL & \multicolumn{1}{|c}{ VENDOR } \\
\hline 33 & 1 & $\begin{array}{l}\text { El. Switch, L.P.* } \\
\text { Aurora water pump } \\
14 \text { DF 32 EC }\end{array}$ & $\begin{array}{l}\text { Furnas Electric Comp. } \\
\text { Batavia, 111.60510 }\end{array}$ \\
\hline 34 & 1 & $\begin{array}{l}\text { El. Switch, Kobe 3* } \\
\text { Pump motor 14 HB 32 ECj1 }\end{array}$ & $\begin{array}{l}\text { Furnas Electric Comp. } \\
\text { Batavia, IIl, 60510 }\end{array}$ \\
\hline 35 & 1 & $\begin{array}{l}\text { El. Switch, L.P.* } \\
\text { Aurora Therm. Pump } \\
14 \text { CF 32 EC }\end{array}$ & $\begin{array}{l}\text { Furnas Electric Comp. } \\
\text { Batavia, 111.60510 }\end{array}$ \\
\hline
\end{tabular}




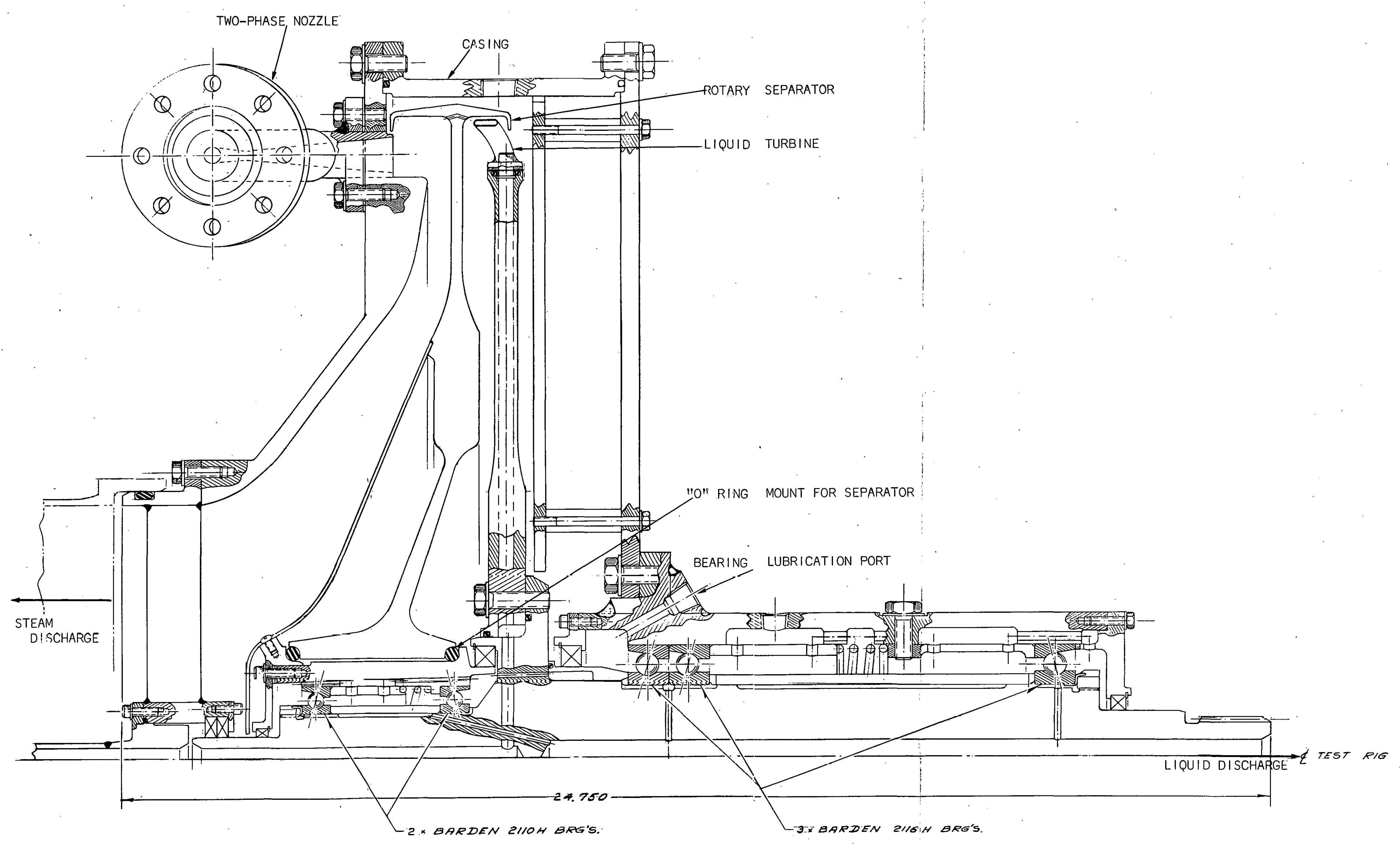

Fig. 44- Test Rig Turbine Assembly 
discharges tangentially to the drum, forming a high velocity liquid layer. The liquid flows through the holes in the drum to the opposite side of the support membrane. The liquid subsequently drives the liquid turbine flowing through an interval diffuser to the shaft. It is subsequently discharged through the back end of the hollow shaft. A splined end is provided to couple to the dynamometer shaft. The liquid turbine inlet is detachable from the tube body so that the shape and approach angle can be varied to maximize the energy conversion. The separator drum is soft mounted on "O" rings to accomodate varying degrees of imbalance resulting from different drum flow conditions and spatial distribution. The turbine is designed for liquid kinetic energy recovery only since this involves the application of the least conventional technology. However, the unit is designed to permit easy modification of the vapor passages to incorporate a radial inflow turbine in the future to extract the maximum energy from the two-phase flow. The casing is also designed to accomodate an impulse turbine or Pelton wheel type of unit should that be desired.

The test loop end turbine designed will provide an inexpensive and versatile means to substantiate two-phase nozzle and turbine performance for waste heat recovery applications. 


\section{X.I. PROGRAM PLAN}

A program culminating in the demonstration of a two-phase bottoming system was developed for the reference design cycle. The main objective of the plan is to demonstrate the technology of two-phase turbine bottoming systems in sufficient depth to provide a firm basis for commercial applications. The time required, 3 years, and the estimated cost, 1.3 million dollars, are very reasonable values for demonstration of a new technology which has the potentially large industrial impact of the two-phase turbine.

The first year's program is summarized in Figure 45. The basic objective of the first year is to demonstrate performance of the nozzle and turbine for the actual flow conditions of the bottoming system. A simple blowdown test will be conducted with steam alone and with a mixture of steam and a second fiuid. The major portion of the blowdown test facility will be available from capital equipment and government furnished equipment. The system is sized to provide $50 \mathrm{HP}$ output power for a 10 minute duration. The testing of both steam alone and s.team and oil, will provide sufficient data for either single component or two-component systems. The end of the first year provides a convenient, low cost $(\$ 230 \mathrm{~K})$, decision point for continuing the effort. The level of performance attainable will have been demonstrated for the fluids and temperatures of interest. Performance and economic analyses based on the actual test performance will have been completed.

The second year's program will demonstrate performance of the complete two-

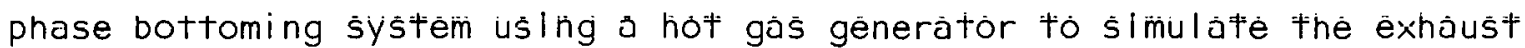
from a diesel engine. The estimated schedule is summarized in Figure 46 . The power output from the system will be in excess of $200 \mathrm{HP}$ on a continuous basis. The bottoming system will he designed fonr eventulal Inng term nperation to verify reliability. 
MONTHS AFTER INCEPTION OF CONTRACT

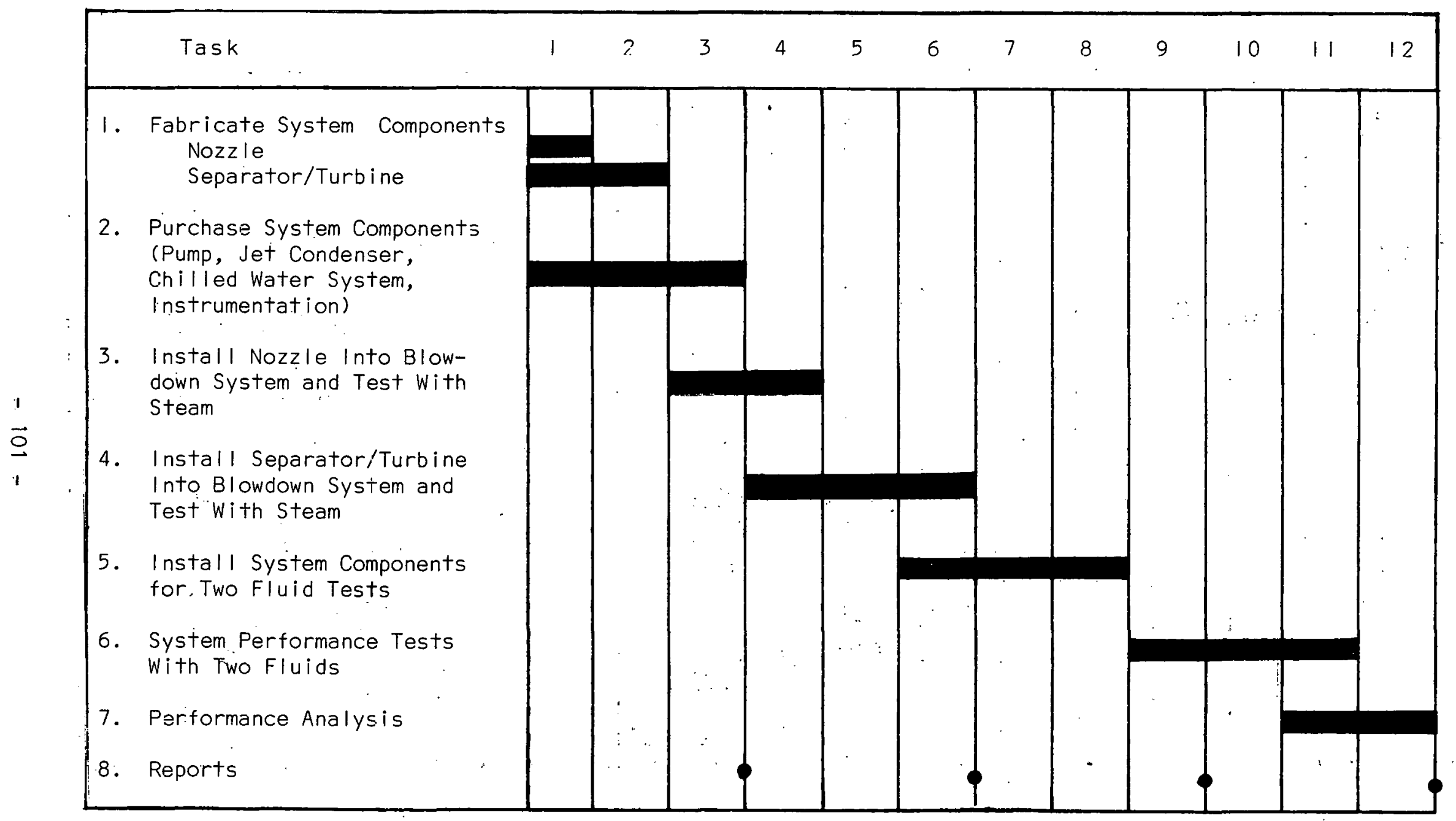

Fig. 45 - Schedule for Demonstration of a Biphase Eottoming Cycle - Year 1 
MONTHS AFTER INCEPTION OF CONTRACT

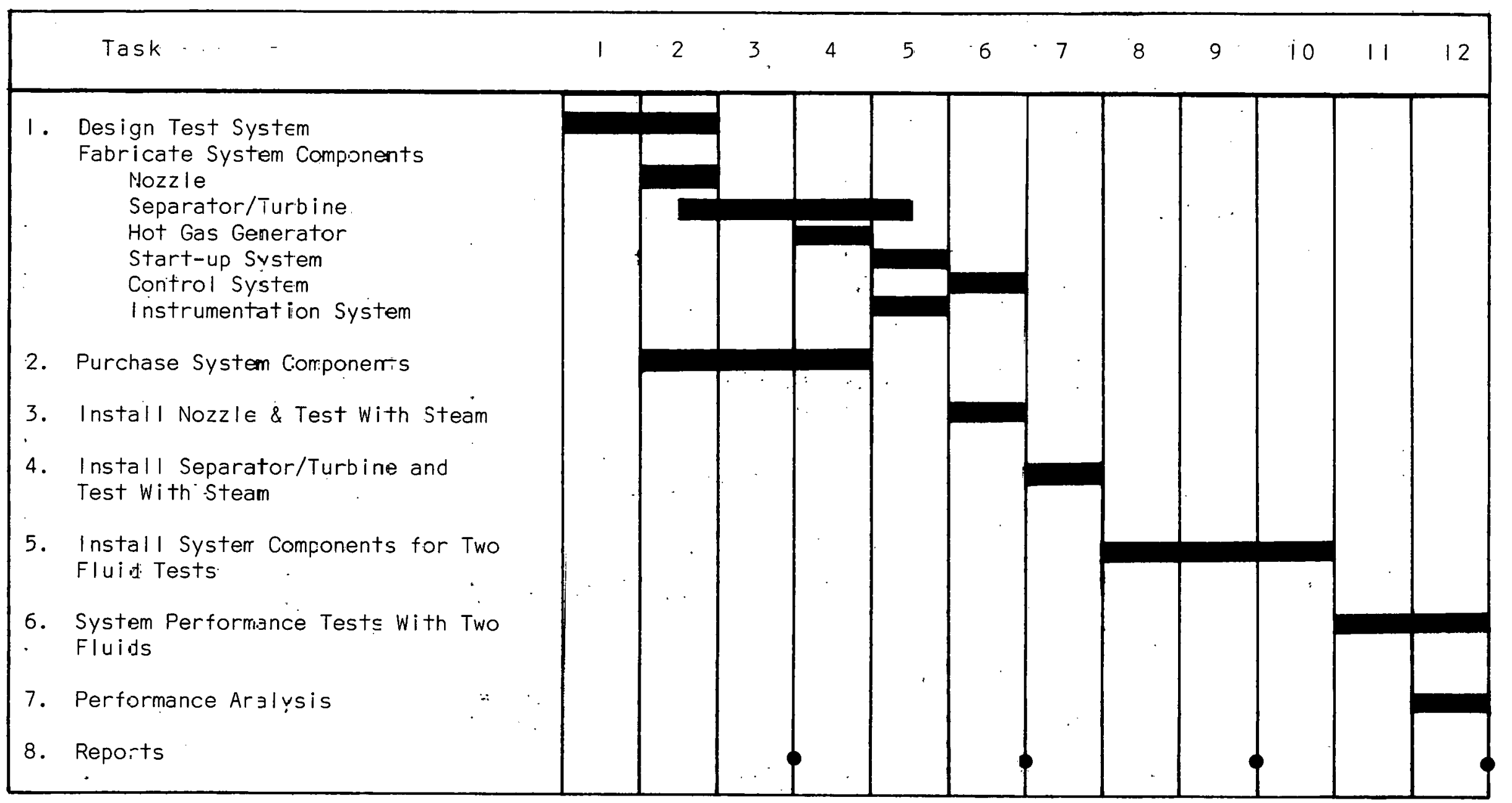

Fig. 46 - Schedule for Demonstration of a Biphase Bottoming Cycle - Year 2 
The third year's program, shown in Figure 47, will consist of endurance testing of the hot gas laboratory system and field testing of the final two-phase bottoming system. Thus, reliability of the rotating unit and performance of the complete system will both be demonstrated. The power level of the final field test unit will depend upon the available diesel engine for the demonstration. The program plan assumes availability of a large industrial diesel or spark ignition engine in the Southern California area. Likely candidates that have such engines are the Southern California Gas Company, Lomita Gas Company, the seven major refineries, Southern California Edison and the Los Angeles Department of Water and Power.

A cost breakdown for the 1.3 million dollar demonstration program is shown in Tables 9, 10 and 11 . The costs are based on 1976 dollars with an expected annual salary increase of $10 \%$ and an overhead increase of five percentage points per year. 


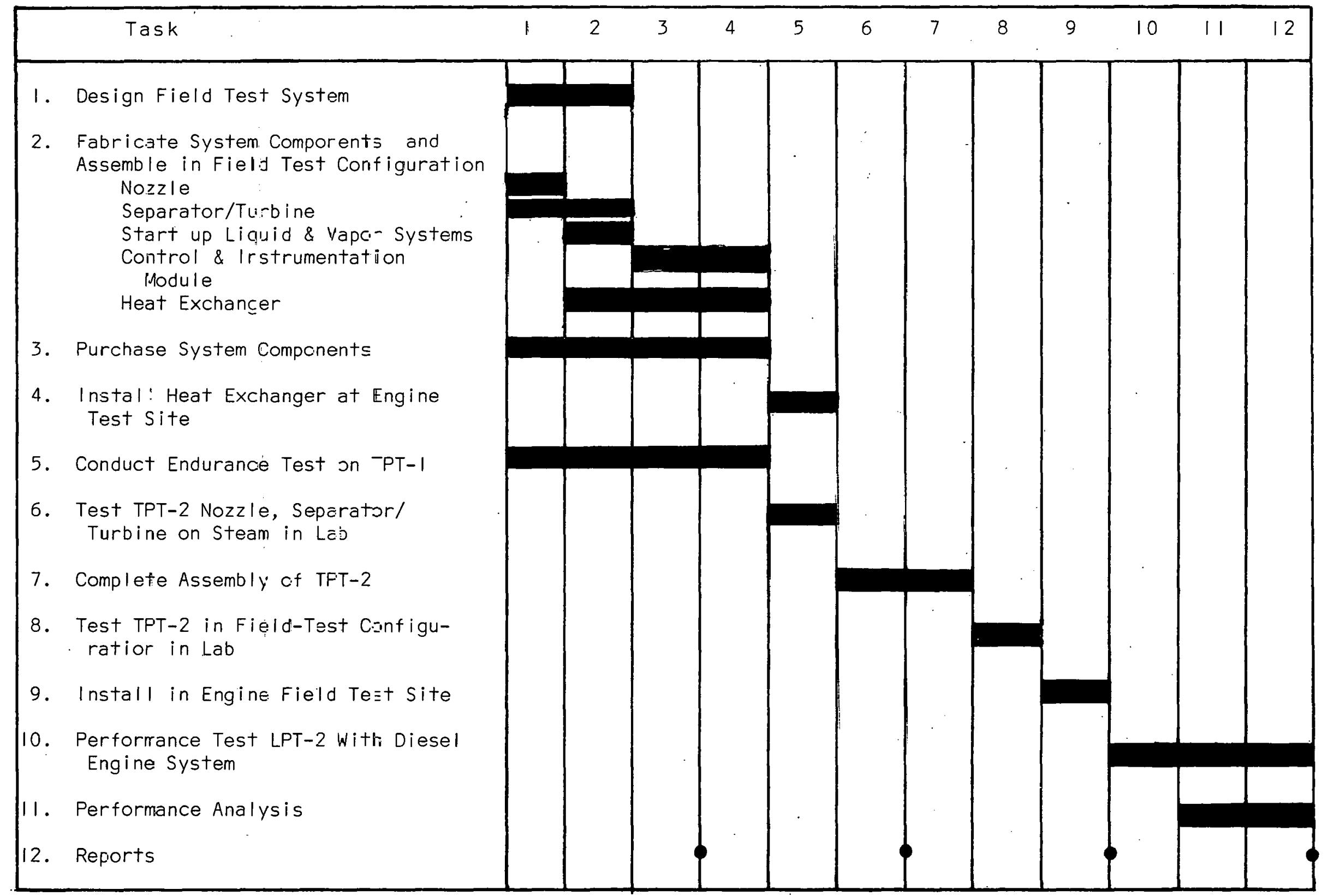

Fig. $4 \bar{t}$ - Sshedule for Demonstration of a Biphase Bottoming Cycle - Year 3 


\section{COST SUMMARY OF FIRST YEAR'S PROGRAM}

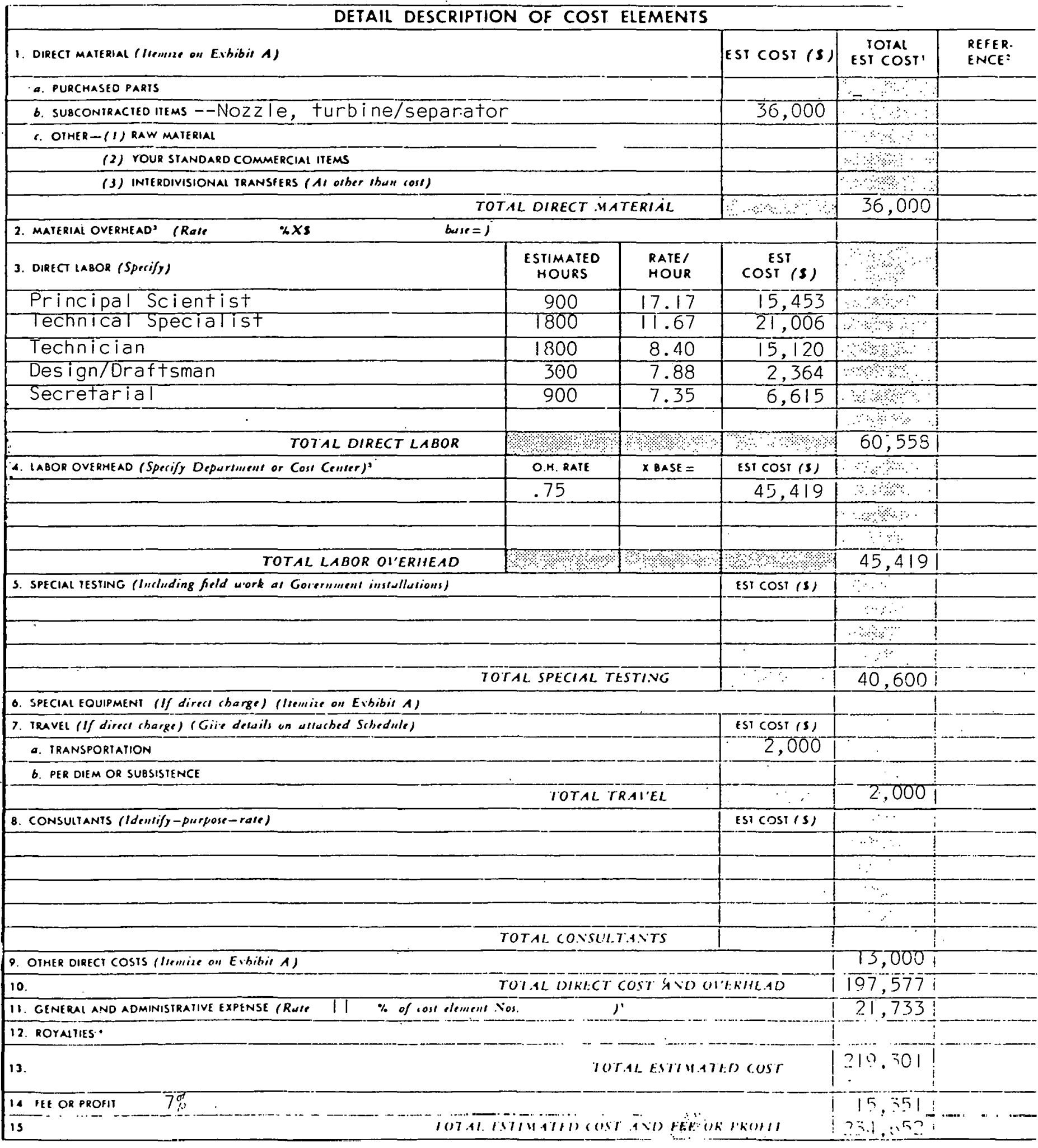


TABLE 9 - CONT'D

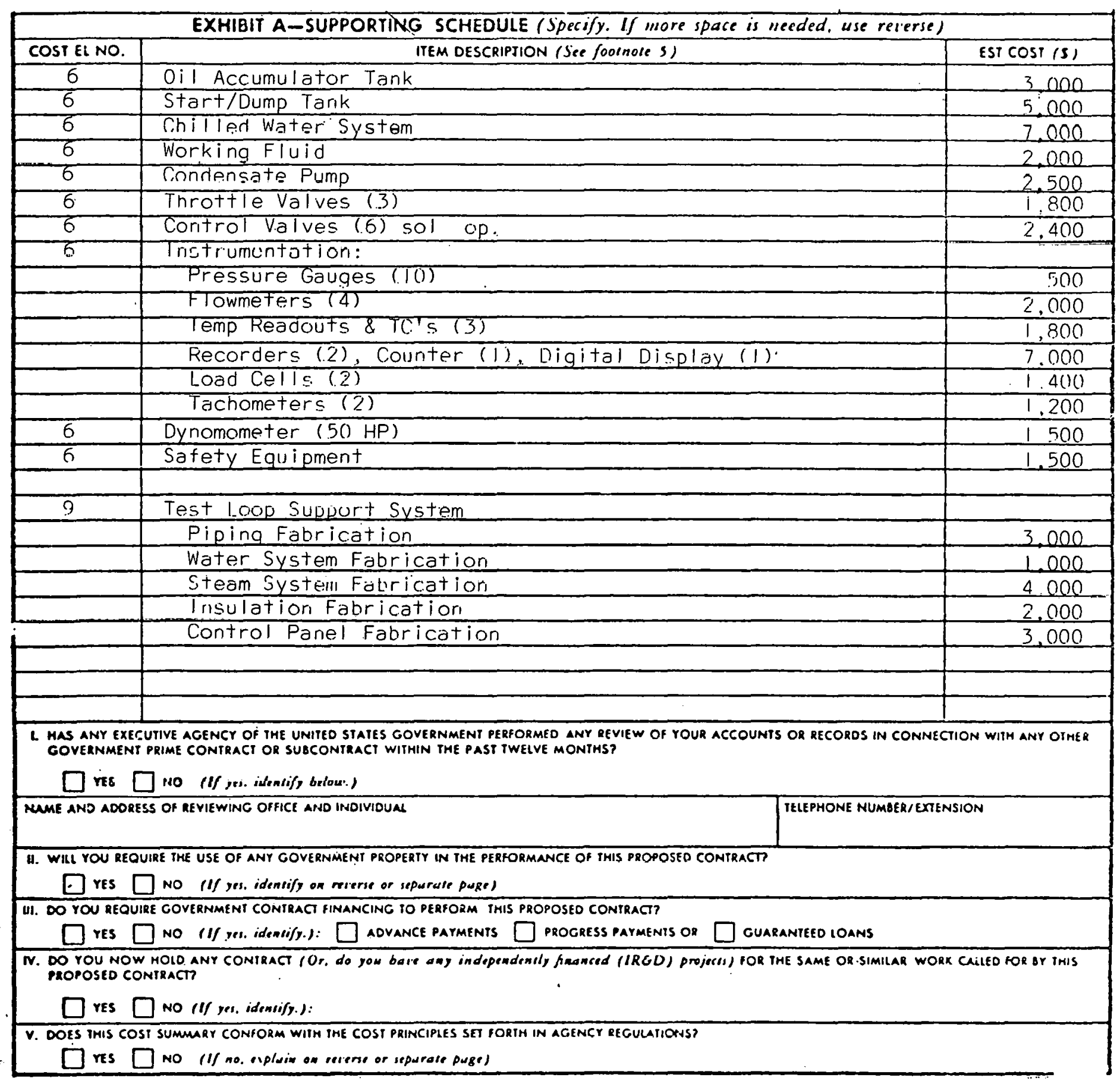


TABLE 10

COST SUMMARY OF SECOND YEAR'S PROGRAM

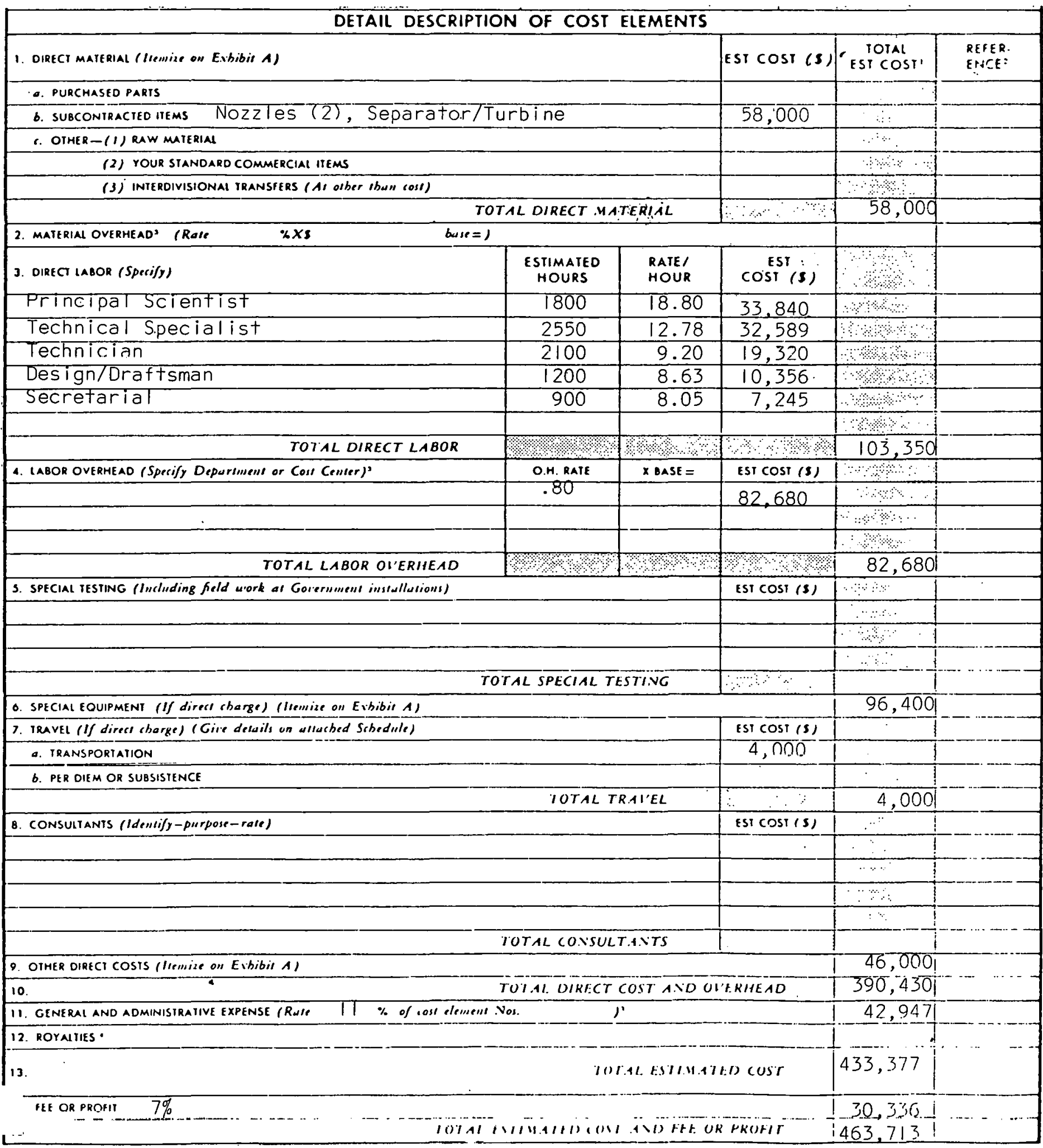


TABLE $10-$ CONT'D $^{\prime}$

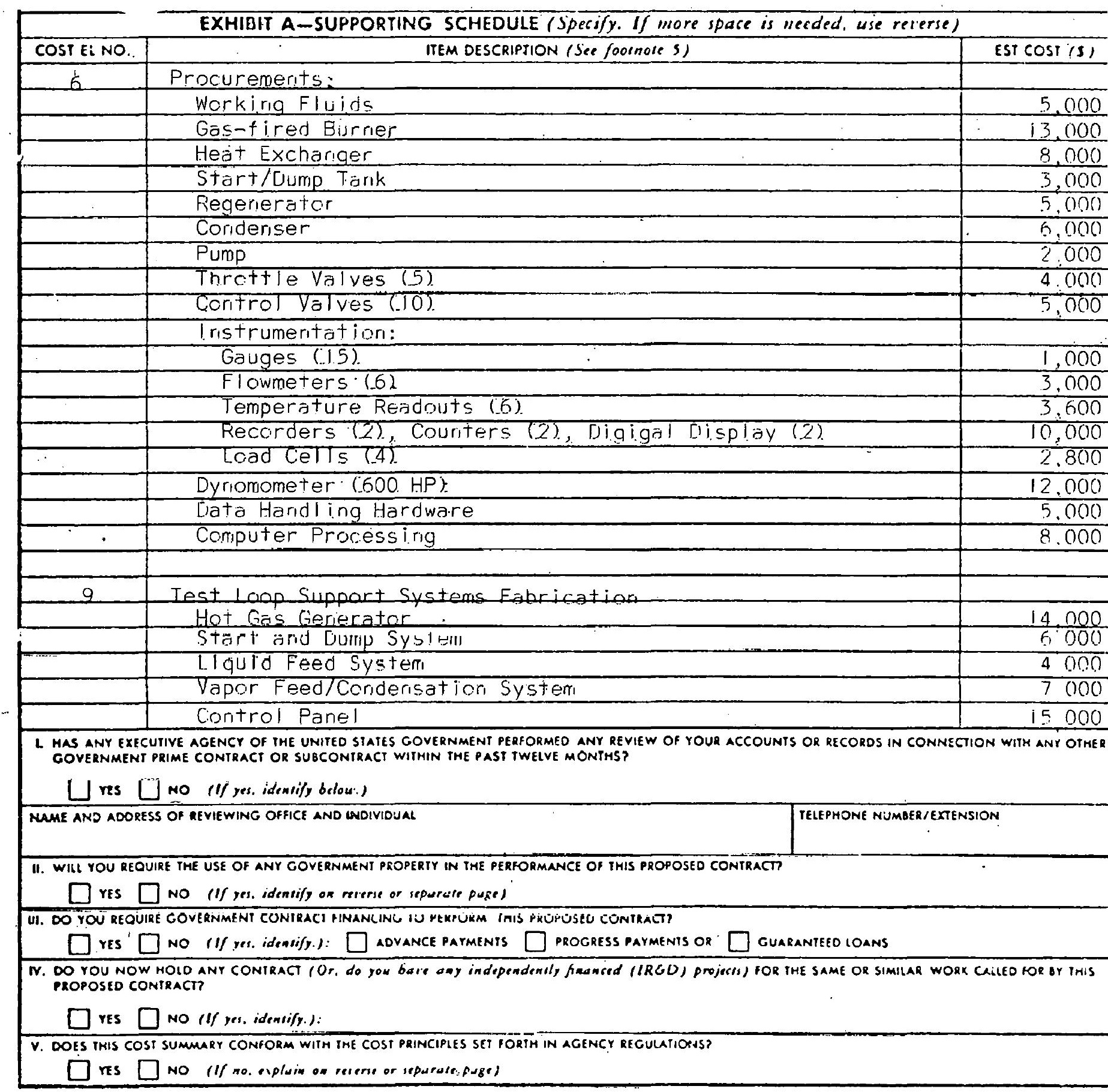


TABLE 11

COST SUMMARY OF THIRD YEAR'S PROGRAM

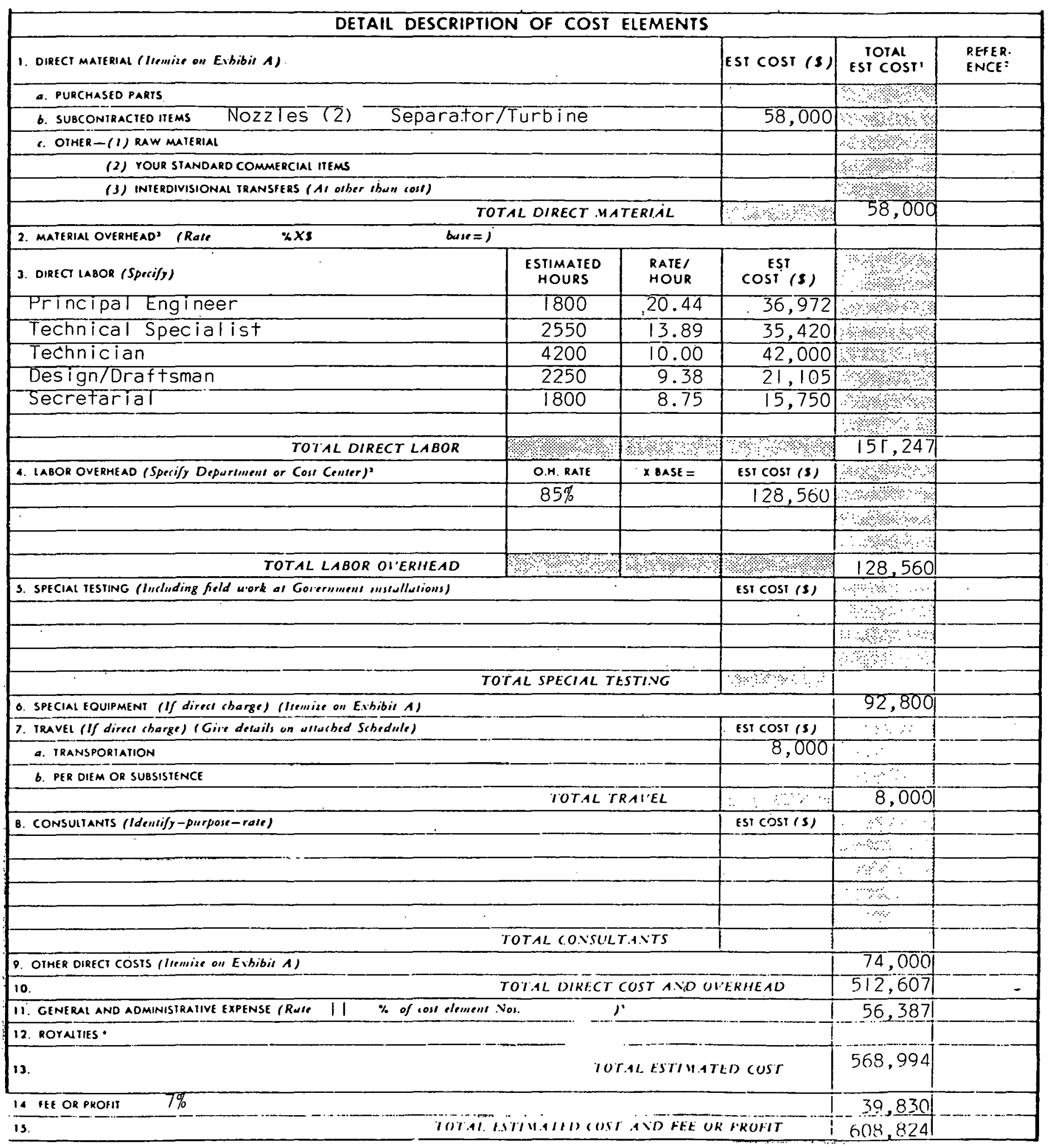


TABLE $\|$ - CONT'D

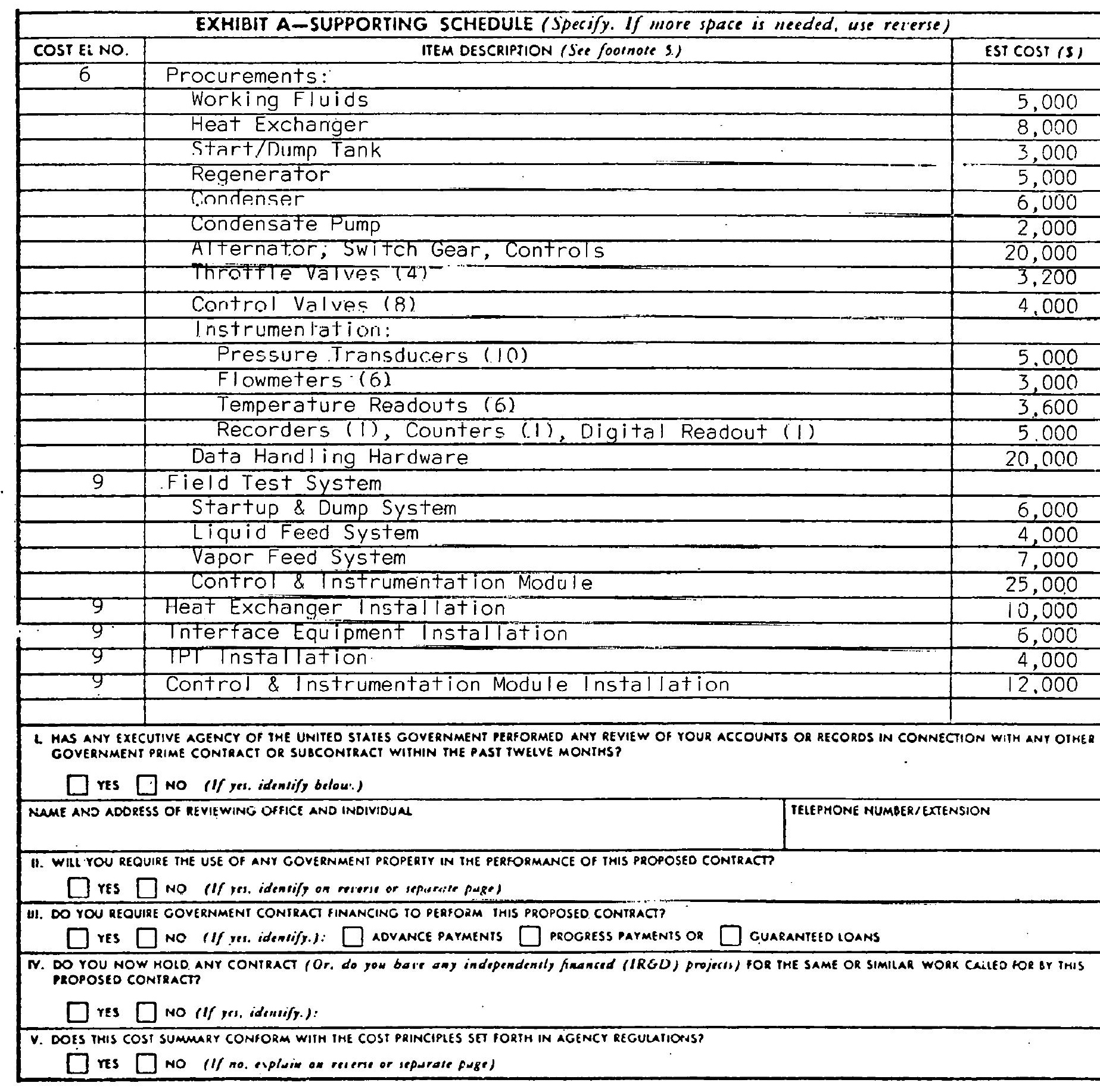




\section{XI1. CONCLUSIONS}

Cycle calculations for the two-phase turbine bottoming showed the efficiency to be superior to, or competitive with, organic vapor turbine system, depending on the assumptions of the analysis. The two-phase turbine appears to be much simpler than an organic or steam vapor turbine because of the following reasons:

1) One stage versus four stages

2) Lower rpm than a vapor turbine

3) Simple construction with very few close tolerances

Other advantages for the designed two-phase system relative to an organic Rankine cycle are:

1) No regenerator

2) No toxic fluids (the working fluids of candidate organic systems are Toluene and FS-85, both of which are toxic)

3) Smaller, simpler condenser (steam condensing instead of organic vapor)

4) Substantial cost savings because of the addition of a contact heat exchanger - $\$ 35-52 / \mathrm{kWe}$ compared to $\$ 98 / \mathrm{kWe}$ for a tube$f$ in exchanger

5) Scaling and fouling tendencies should be eliminated due to the addition of a contact exchanger resulting in low maintainance and operational costs

The main disadvantages appear to be:

1) Liquid contamination or degradation may be a problem in a direct contact exchanger 
2) The required pump is larger than for an organic vapor system

3) The state of development is low relative to organic or steam Rankine cycles

Because of the advantages cited it appears that two-phase bottoming systems have the potential of early commercialization as well as greater long term fuel savings. 


\section{EXPANDER RELATIONS}

\section{Nomenclature}

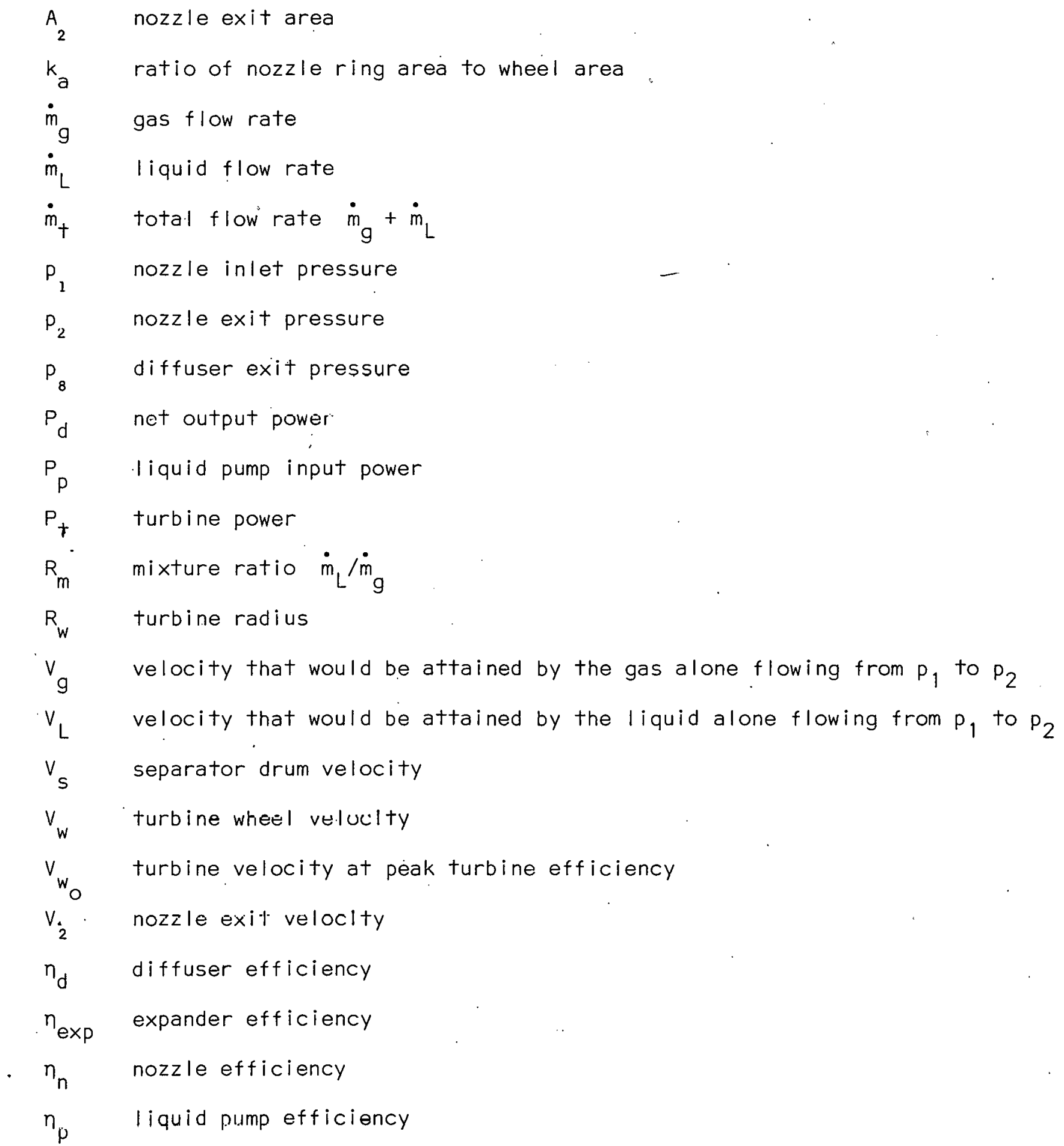




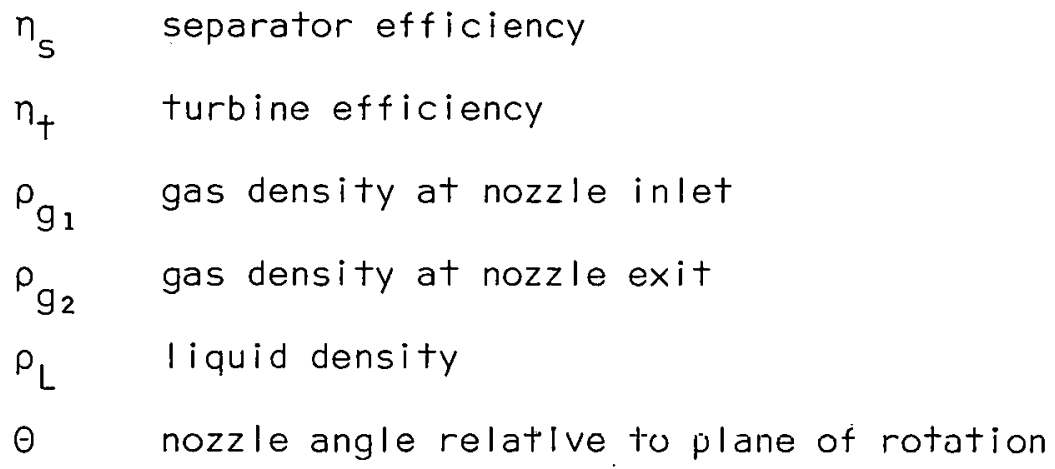




\section{Two-Phase Nozzle}

As shown previously, the kinetic energy attained in isentropic. two-phase nozzle flow at mixture ratios high enough to give negligible temperature drop, is the sum of the kinetic energies that would be attained by the gas and liquid phases alone. The liquid energy would be:

$$
\dot{m}_{L} V_{L}^{2} / 2=\dot{m}_{L}\left(p_{1}-p_{2}\right) / \rho_{L}
$$

and the gas energy would be:

$$
\dot{m}_{g} v_{g}^{2} / 2=\dot{m}_{g} p_{1} \log \left(p_{1} / p_{2}\right) / \rho_{g}
$$

The two-phase jet energy is the sum of these two energies times the nozzle efficiency $n_{n}$, which is determined from existing algorithms of Biphase Engines, Inc.

$$
\dot{m}_{+} V_{2}^{2} / 2=\eta_{n}\left(\dot{m}_{g} V_{g}^{2}+\dot{m}_{L} V_{L}^{2}\right) / 2
$$

The ratio of two-phase jet velocity $V_{2}$ to liquid-alone velocity $V_{L}$ is given by:

$$
\left(V_{2} / V_{L}\right)^{2}=\left(n_{n} \dot{m}_{L} / \dot{m}_{t}\right)\left[\left(V_{g} / V_{L}\right)^{2} / R_{m}+1\right]
$$

where $R_{m}$ is the mass ratio of liquid to gas

\section{Turbine Expander}

Wheel velocity.

An impulse turbine has peak efficiency when the blade speed is $v_{w}=V_{2} / 2$. From Eq. (4), neglecting the small difference between $\dot{m}_{\dagger}$ and $\dot{m}_{L}$ at high mixture ratios, the wheel speed is given by: 


$$
\left(V_{w} / V_{L}\right)^{2}=\left(n_{n} / 4\right)\left[\left(V_{g} / V_{L}\right)^{2} / R_{m}+1\right]
$$

Thus, the mixture ratio $R_{m}$ required for a specified ratio of wheel velocity $V_{w}$ to liquid velocity $V_{L}$ is given by:

$$
\left(V_{g} / V_{L}\right)^{2} / R_{m}=\left(4 / \eta_{n}\right)\left(V_{w} / V_{L}\right)^{2}-1
$$

\section{Efficiency}

The turbine output power is:

$$
P_{t}=n_{t} \dot{m}_{t} v_{2}^{2} / 2
$$

where $\eta_{+}$is calculated from existing algorithms of Biphase Engines, Inc.

Tle liquid pump Input power is:

$$
P_{p}=\dot{m}_{L}\left(p_{1}-p_{2}\right) / \eta_{p} \rho_{L}=\dot{m}_{L} V_{L}^{2} / 2 n_{p}
$$

The net output, or drive, power is:

$$
P_{d}=P_{t}-P_{P}
$$

Substituting $V_{2}$ from Eq. (4), the net power is:

$$
P_{d}=\dot{m}_{L} v_{L}^{2}\left\{n_{t} n_{n}\left[\left(V_{g} / V_{L}\right)^{2} / R_{m}+1\right]-\left(1 / n_{p}\right)\right\} / 2
$$

The available input powor to the expander is llie yas energy $\dot{\mathrm{m}}_{\mathrm{g}} \mathrm{g}_{\mathrm{g}}{ }^{2} / 2$ from Eq. (2). The expander efficiency is:

$$
\eta_{\exp }=P_{d} / \dot{m}_{g}{ }^{2} v_{g}{ }^{2} / 2
$$

Substituting $P_{A}$ from Eq. (10) and replacing the expression $R_{m}\left(V_{g} / V_{L}\right)^{2}$ by the expression in terms of $V_{w} / V_{L}$ from Eq. (6), the turbopump expander efficiency as a function of the ratio of wheel velocity $v_{w}$ to liquid-alone velocity is:

$$
n_{\exp }-\frac{4 n_{t}\left(V_{w} / V_{L}\right)^{2}-1 / n_{D}}{4\left(V_{w} / V_{L}\right)^{2} / \eta_{n}-1}
$$


This expression gives the efficiency only at a turbine speed $V_{w}$ equal to half the jet speed $V_{2}$. As $V_{w}$ and $V_{2}$ are reduced, a point is reached where further reduction in $V_{w}$ can more efficiently be accomplished by reducing $V_{W}$ and leaving $V_{2}$ fixed; the added turbine :oss is less than the increased liquid pumping loss. As $v_{w}$ is reduced below $v_{2} / 2$, the torque increases approximately by the factor $\left(2-v_{w} / v_{w_{0}}\right)$ where $v_{w_{0}}=v_{2} / 2$. Therefore, the efficiency decreases by the factor:

$$
n_{\exp }=\left\{\left.n_{\exp }\right|_{v_{w}}=v_{w_{0}}\right\}\left(2-v_{w} / v_{w_{0}}\right)\left(v_{w} / v_{w_{0}}\right)
$$

The attainable expander efficiency is the larger of the two values given by Eqs. (12) and (13).

\section{Rotopitot Expander}

Wheel velocity

The separator efficiency $n_{s}$ is defined as the ratio of the liquid energy in the separator to the two-phase jet energy and can be calculated from previously determined two-phase flow relations. Thus, the separator velocity $v_{s}$ is given by:

$$
\dot{m}_{L} v_{s}^{2} / 2-r_{s} \dot{m}_{t} v_{: 2}^{2} / 2
$$

Substituting $V_{2}$ from Eq. (4), the ratio of separator velocity $v_{s}$ to liquid-alone velocity $V_{L}$ is given by:

$$
\left(V_{s} / V_{L}\right)^{2}=n_{n} n_{s}\left(V_{g} / V_{L}\right)^{2} / R_{m}+1
$$

The pressure at the exit of the diffuser is:

$$
P_{8}=\mu_{2}+\|_{j} \rho_{L}\left(V_{S}-V_{W}\right)^{2} / \%
$$


The pressure at the liquid outlet, which must be equal to $\mathrm{p}_{i}$, is $P_{8}$ minus the centrifugal pressure.

$$
P_{I}=P_{8}-\rho_{L} V_{W}{ }^{2} / 2
$$

Combining Eqs. (16) and (17) and replacing $\left(p_{1}-p_{2}\right) / \rho_{L}$ by $V_{L}{ }^{2} / 2$; the ratio of wheel velocity to separator drum velocity is given by:

$$
\left(V_{L} / V_{s}\right)^{2}=n_{d}\left(1-2 V_{w} / V_{s}\right)-\left(1-n_{d}\right)\left(V_{w} / V_{s}\right)^{2}
$$

which can be solved for $V_{w}$ using the quadratic formula.

\section{Efficiency}

The liquid flow $\dot{m}_{L}$ of velocity $V_{s}$ is brouglit to rest in passing radially inward through the turbine. Therefore, the torque on the turbine is $\dot{m}_{L} V_{S} R_{w}$, and the power output, equal to torque times angular velocity, is:

$$
P_{d}=\dot{m}_{L} V_{s} V_{W}
$$

The expander efficiency is:

$$
\begin{aligned}
n_{\text {exp }} & =P_{d} / \dot{m}_{g} V_{g}{ }^{2} / 2 \\
& =2 R_{m} V_{s} V_{w} / V_{g}{ }^{2} \\
& =2 R_{m}\left(V_{s} / V_{L}\right)^{2}\left(V_{w} / V_{s}\right)\left(V_{L} / V_{g}\right)^{2}
\end{aligned}
$$

Substituting the expression for $R_{m}\left(V_{L} / V_{g}\right)^{2}$ in terms of $\left(V_{s} / V_{L}\right)^{2}$ from Eq. (15) and the expression for $\left(V_{S} / V_{L}\right)^{2}$ in terms of $V_{W} / V_{S}$ from Eq. (18), the rotopitot expander efficiency is:

$$
n_{\exp }=\left\{n_{d}+\left[\left(1 / n_{n} n_{s}\right)-n_{d}\right] /\left(v_{w} / v_{s}\right) 2+\left(1-n_{d}\right)\left(v_{w} / v_{s}\right) / 2\right\}^{-1}
$$

The dependence of $\eta_{\exp }$ on $V_{w} / V_{L}$ can be found by choosing a value of $V_{w} / V_{s}$ (between 0 and $1 / 2$ ), finding the efficiency from Eq. (21), the 
ratio $V_{L} / V_{S}$ from Eq. (18), and then determining $V_{W} / V_{L}$ from:

$$
v_{w} / V_{L}=\frac{v_{w} / V_{S}}{v_{L} / V_{S}}
$$

\section{Flow Rate and Power Limitations}

If the nozzle ring is confined to a fraction $k_{a}$ of the turbine wheel area and the nozzles are tilted at an angle $\theta$ relative to the plane of rotation, then the allowable nozzle exit area is:

$$
A_{2}=\pi R_{w}^{2}{ }_{k} \sin \theta
$$

The fraction of the nozzle exit area used by the liquid can be neglected, at least for the low prèssure stages where flow area limitations are a problem. Hence, the gas flow rate is:

$$
\dot{m}_{g}=\rho_{g_{2} V_{2}} A_{2}
$$

The output power is:

$$
P_{d}=n_{\exp } \dot{m}_{g} V_{g}^{2} / 2
$$

Substituting $V_{g}$ from Eq. (2), $\dot{m}_{g}$ from.Eq. (24), and $A_{2}$ from Eq. (23), the area-limited output power is:

$$
P_{d}=\eta_{\exp } k_{a} \sin \theta \pi R_{w}{ }^{2} V_{2} p_{2} \log \left(p_{1} / p_{2}\right)
$$




\section{Two-Phase Bottoming Cycles}

The single component-single stage system is shown in Figure 4. The waste heat from a diesel engine (or gas turbine) enters the heat exchanger at temperature $T_{i}$ with an exhaust flow rate of $\dot{m}_{e}$. The exhaust heat of an amount $Q_{i}$ is transferred to a slingle phase liquid in a counter current heat exchanger. The exhaust gas exits at temperature $T_{\theta}$. The heated liquid is flashed in a nozzle and expanded to pressure $p_{2}$ from pressure $p_{1}$. The saturated mixture of vapor and liquid with a quality $x_{2}$ impinges on a rotary separator. The vapor flows through a radial inflow turbine and the liquid flows through a radial inflow turbine, each on a common shaft, producing a net power output $P_{S}$. The vapor exhausts to the condenser where a heat of $Q_{C}$ is rejected. The condensate is pressurized and merged with the high pressure outlet from the liquid turbine. The liquid flows back to the heater, closing the cycle.

A multistage version of the single component cycle is shown in Figure 5 .

In this version, the exit flow from the first stage is remixed and passed through a regenerative heat exchanger, condensing part of the tirst stage vapor. The mixture is expanded through the second stage nozzle and turbine (as in the single stage cycle). The condensate and liquid discharge from the final (second) stage is passed through the regenerative heat exchanger, increasing the temperature 
to the minumum dictated by combustor material considerations. The advantage of staging is that lower shaft rpm results and the lower velocities result in more efficient nozzle and turbine operation. Against these gains must be balanced the added complexity and possible inter-stage losses.

The use of two components al lows more flexibility in the choice of shaft rpm. A single stage two component cycle is shown in Figure 6 .

In this cycle the thermodynamic working fluid is component $A$. It is supplied to the nozzle as a liquid and flash vaporizes upon contact with the heated I iquid, component B. Another variation of the two-component cycle is to mix the condensate (component A) with the turbine discharge (component B) circulating the mixture through the heater. This variation has the same cycle diagram as the singlecomponent variation.

The final variation considered uses two components in a manner to enable the use of a contact heat exchanger for the waste gases. This version is illustrated by the schematic of Figure 7 .

Component $B$ is sprayed into the contact heat exchanger vessel and flows counter to the direction of the exhaust gases, picking up heat in the process. The hot liquid is collected in the bottom of the vessel and is pressurized by a pump, and injected into the nozzle. The thermodynamic working fluid $A$ is vaporized upon contact with the component $B$ and the mixture is expanded through the nozzle. Component B is separated in the rotary separator turbine driving the hydraulic turbine. Sufficient pressure is left in B to return it to the vessel and spray it into the contact heat exchanger. The vapor exhaust from the rotary separator is condensed, pressurized and returned to the nozzle. 


\section{Single Component - Single Stage Analysis}

Consider Figure 4, the heat rejected is given by:

$$
Q_{C}=x_{v_{7}} \dot{m}_{T} L_{v_{7}}+\left\{\left(1-\phi_{s}\right)\left(1-x_{v_{7}}\right)+x_{v_{7}}\right\}\left\{\dot{m}_{T} C_{p_{7}}^{\prime \prime} \Delta T_{s c}\right\}
$$

where. $Q_{C}=$ cycle heat rejection

$$
\begin{aligned}
& x_{v_{7}}=\text { vapor quality at condenser inlet } . \\
& L_{v_{7}}=\text { latent heat at condenser inlet } \\
& \phi_{S}=\text { separation efficiency }=\dot{m}_{5} /\left(1-x_{v_{4}}\right)\left(\dot{m}_{T}\right) \\
& \dot{m}_{T}=\text { total mass flow rate } \\
& C_{P_{7}}^{\prime \prime}=\text { liquid specific heat at condenser inlet } \\
& \Delta T_{S c}=\text { sulucuuling. }
\end{aligned}
$$

The maximum power output from the turbine is:

$$
P_{+}=\Psi_{V} \eta_{T}^{\prime} x_{V_{4}} \dot{m}_{T}\left(V_{2}^{\prime}\right)^{2} / 2 g_{C} J+\phi_{S} \eta_{T}^{\prime \prime}\left(1-x_{V_{4}}\right) \dot{m}_{T}\left(V_{2}^{\prime \prime}\right)^{2} / 2 g_{C} J
$$

where $\Psi_{v}=$ fraction of gas energy extracted in turbine, 0 or 1

$$
\begin{aligned}
& n_{+}^{\prime}=\text { efficiency of gas turbine } \\
& x_{v_{4}}=\text { vapor quality at } 4 \\
& v_{2}^{\prime}=\text { vapor exit velocity from nozzle } \\
& g_{c}=32.16 \mathrm{ft} / \mathrm{s}^{2} \\
& J=778 \mathrm{~B} / 1 \mathrm{~b} \cdot \mathrm{ft} \\
& n_{+}^{\prime \prime}=\text { liquid turbine efficiency }
\end{aligned}
$$

The liquid pumping work is given by:

$$
P_{P_{1}}=\frac{\psi_{S}\left(1-x_{V_{4}}\right) \dot{m}_{T}\left(p_{6}-p_{4}\right)(144)}{n_{d} \rho_{t}^{11 J}}
$$

where $n_{d}=$ diffuser efficiency

$$
\begin{aligned}
& P_{6}=\text { heater inlet pressure } \\
& P_{4}=\text { separator casing pressure } \\
& \rho_{4}^{\prime \prime}=\text { liquid density at liquid turbine inlet temperature }
\end{aligned}
$$


This power must be subtracted from the liquid. turbine power if it is recovered in the diffuser of a radial inflow turbine. The pumping power required for the condensate is:

$$
P_{P_{2}}=\frac{\left\{\left(1-\phi_{S}\right)\left(1-x_{V_{4}}\right)+x_{V_{4}}\right\}\left(p_{9}-p_{8}\right)(144) \dot{m}_{T}}{\eta_{p} \rho_{8}^{11} J}
$$

The net power available from the turbine is:

$$
\begin{aligned}
P_{n}= & \frac{\Psi_{v} n_{t}^{\prime} x_{v_{4}} \dot{m}_{T}\left(v_{2}^{\prime}\right)^{2}}{2 g_{C} J}+\frac{n_{t}^{\prime \prime} \phi_{S}\left(1-x_{v_{4}}\right) \dot{m}_{T}}{g_{C}^{J}}\left[\frac{\left(v_{2}^{\prime \prime}\right)^{2}}{2}-\frac{(144)\left(p_{6}-p_{4}\right) g_{C}}{n_{d} \rho_{4}^{\prime \prime}}\right] \\
& -\frac{(144)\left\{\left(1-\phi_{s}\right)\left(1-x_{v_{4}}\right)+x_{v_{4}}\right\}\left(p_{g}-p_{8}\right) \dot{m}_{T}}{n_{p} \rho_{8}^{\prime \prime J}}
\end{aligned}
$$

The cycle efficiency is given by:

$$
n_{c}=\frac{P_{n}}{P_{n}+Q_{c}}
$$

If an exhaust gas to working fluid temperature difference of $\Delta T_{\text {he }}$ is maintained, then the heat input is given by:

$$
Q_{i_{0}}=\eta_{h e} \dot{m}_{e} C_{p e}\left(T_{i}-T_{f}\right)
$$

and

$$
\begin{aligned}
& T_{1}=T_{i}-\Delta T_{h e} \\
& T_{f}=T_{6}+\Delta T_{h e}
\end{aligned}
$$

where $n_{\text {he }}=$ heat exchanger efficiency

$$
\begin{aligned}
& \dot{m}_{e}=\text { exhaust gas mass flow rate, } \mathrm{lb} / \mathrm{s} \\
& \mathrm{C}_{p e}=\text { exhaust gas specific heat, } \mathrm{B} / \mathrm{Ib}{ }^{\circ} \mathrm{F} \\
& \mathrm{T}_{i}=\text { exhaust gas initial temperature, }{ }^{\circ} \mathrm{F} \\
& \mathrm{T}_{f} \text { - cxhaust gas final tompcraturc, }{ }^{\circ} \mathrm{F}
\end{aligned}
$$

The engine efficiency is then:

$$
n_{e}=n_{h e} n_{c}
$$


If the exhaust gases are cooled below the dew point, then

$$
Q_{i_{1}}=\eta_{h e} \dot{m}_{e}\left\{C_{p e}\left(T_{i}-T_{f}\right)+x_{w} L_{v w}\right\}
$$

The nozzle exit velocities $V_{2}^{\prime}$ and $V_{2}^{\prime \prime}$ can be estimated as:

$$
v_{2}^{\prime} \simeq V_{2}^{\prime \prime}=\prod_{n} v_{2} i
$$

where $V_{2} i$ is the isentropic expansion velocity for the saturated liquid-from $T_{1}$ to $T_{2}$

$$
n_{n}=\text { nozzle energy efficiency }(0.7 \text { to } 0.88)
$$

The vapor quality at the nozzle exit is determined by the approximation

$$
x_{v_{2}} \simeq x_{v_{2} i}+\left(1-n_{n}\right) \frac{v_{2} i^{2}}{2 g_{c} J C_{p}^{\prime \prime}} \frac{1}{L_{v_{2}}}
$$

where $x_{v_{2} i}=$ the isentropic expansion exit quality

$$
L_{v_{2}}=\text { latent heat at station 2, nozzle exit }
$$

The rpm is given by:

$$
\begin{aligned}
& \omega=P_{n} / L \\
& L=\frac{\dot{m}_{T} V_{2}^{\prime} r_{t}}{g_{C}}
\end{aligned}
$$

\section{Single Component - Multislage}

In the two-stage system shown in Figure 5, the exit flow from the first stage is passed through a regenerative heat exchanger to reduce the quality to the second stage in order to reduce the spouting velocity and to increase the heat exchanger inlet temperature to a value above the dewpoint of the exhaust gases.

The heat rejected from the condenser is:

$$
Q_{C}=x_{v_{9}} \dot{m}_{T} L_{v_{9}}+\left\{\left(1-\phi_{S_{2}}\right)\left(1-x_{v_{9}}\right)+x_{v_{9}}\right\} C_{P_{g}}^{\prime \prime} \Delta T_{s c} \dot{m}_{T}
$$

The power output from the first stage turbine is:

$$
P_{t_{1}}=\frac{\Psi_{V_{1}} n_{t_{1}}^{\prime} x_{V_{4}} \dot{m}_{T}\left(v_{i_{2}^{\prime}}^{\prime}\right)^{2}}{2 g_{C} J}+\frac{\phi_{S_{1}} \eta_{t_{1}}^{\prime \prime}\left(1-x_{V_{4}}\right) \dot{m}_{T}\left(V_{2}^{\prime \prime}\right)^{2}}{2 g_{C} J}
$$


The change in temperature through the regenerator in the flow to the heater is given by:

$$
\dot{\mathrm{m}}_{T}\left(x_{v_{5}}-x_{V_{6}}\right) L_{v_{5}}=\dot{m}_{T} C_{P_{11}}^{\prime \prime}\left(T_{12}-T_{11}\right)
$$

where $T_{12}=$ minimum metal surface temperature for exhaust gas

$$
\left(\equiv 217^{\circ} \mathrm{F}\right. \text { from Ref. 7) }
$$

or

$$
x_{v_{6}}=\frac{L_{v_{5}} x_{v_{5}}-C_{P_{1}}^{\prime \prime}\left(T_{12}-T_{21}\right)}{L_{v_{5}}}
$$

The power output from the second stage is:

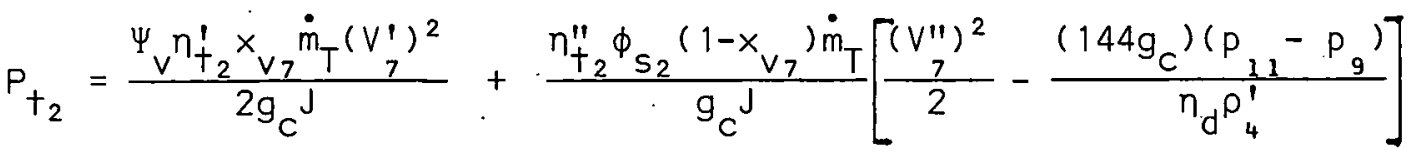

$$
\begin{aligned}
& -\frac{(144)\left\{\left(1-\phi_{S_{2}}\right)\left(1-x_{V_{7}}\right)+x_{V_{7}}\right\}\left(p_{11}-p_{9}\right)\left(\dot{m}_{T}\right)}{\eta_{p} p_{11}^{\prime \prime} J}
\end{aligned}
$$

where the nozzle exit parameters $\dot{x}_{v}, v_{7}^{\prime}$, and $v_{7}^{\prime \prime}$ are found by considering an isentropic expansion of the saturated liquid-vapor mixture from quality $\times_{v_{6}}$ at temperature $T_{6}$ to a pressure of $P_{7}$; and subsequently applying corrections for the actual nozzle efficiency, $n_{n_{2}}$.

The cycle efficiency is subsequently given by:

$$
n_{c}=\frac{P_{t_{1}}+P_{t_{2}}}{P_{t_{1}}+P_{t_{2}}+\dot{q}_{C}}
$$

Methods of determining engine efficiency and other parameters follow those outlined in the single component single stage analysis. 
Two-Component - Conventional Heat Exchanger

The most efficient two-component system is achieved by circulating both components through the heater. Considering the cycle diagram of Figure 4 with components $A$ and $B$, the heat rejected in the condenser is given by:

$$
\begin{aligned}
& Q_{C} \simeq \frac{m_{T} L_{v a}}{(1+r)}\left[1+\frac{C_{1} L_{v b}}{1-C_{1} \frac{L_{v a}^{\prime \prime}}{L_{p a}}+\frac{T_{S C}}{L_{v a}}+\frac{C_{1}}{1-C_{1}} \frac{C_{p b}^{\prime \prime} \Delta T_{s c}}{L_{v a}}}\right. \\
&\left.+\frac{\left(1-\psi_{s}\right)(1+r) C_{p b}^{\prime \prime} \Delta T s c}{L_{v a}}\right] \\
& \simeq \frac{\dot{m}_{1}}{(1+r)}\left\{L_{v a}+\frac{C_{1}}{1-C_{1}} L_{v b}+C_{p a}^{\prime \prime} \Delta T \cdot s c\right. \\
&
\end{aligned}
$$

$$
\begin{aligned}
& \text { where } L_{v a, b}=\text { latent heat of vaporization of } A, B(B / \mid b) \\
& r=\text { mass flow ratio of } B \text { to } A \\
& C_{1}=\text { vapor fraction of } B \text { in gas }=\frac{W_{b_{7}} p_{b_{7}}}{W_{7} p_{7}} \\
& \mathrm{~W}_{\mathrm{b}_{7}}=\text { molecular weight of } \mathrm{B} \text { at } \mathrm{T}_{7} \text { ( } \mathrm{lb} / \mathrm{lb} \text { mole) } \\
& P_{b} \quad=\text { vapor pressure of } B \text { at } T \text { (psia) } \\
& W_{7}=\text { molesular woight of gas at } T_{7}(\mid \mathrm{h} / \mathrm{l} \text { h mole) } \\
& \mathrm{P}_{7} \quad=\text { condenser inlet pressure (psia) } \\
& \mathrm{C}_{\mathrm{pa}, \mathrm{b}}^{\prime \prime}=\text { specific heat of } \mathrm{A}, \mathrm{B}\left(\mathrm{B} / \mathrm{I} \mathrm{b}^{\circ} \mathrm{F}\right) \\
& \phi_{s}=\text { separator efficiency for l iquid }=\frac{\dot{m}_{b_{5}}}{m_{t}} \frac{(1+r)}{r} \\
& \Delta T_{S E}=\text { subcooling }=T_{7}-T_{8},\left({ }^{n} \mathrm{~F}\right)
\end{aligned}
$$

The exit velocity from the nozzle is given by:

$$
\begin{aligned}
& v_{2}=v_{2}=\sqrt{\eta_{n}} v_{2} i \\
& \text { where } v_{2} i=\text { the isentropic exit velocity }
\end{aligned}
$$


The power output is given by:

$$
\begin{aligned}
P_{w} & =\frac{\Psi_{V} n_{t}^{\prime} \dot{m}_{t}\left(V_{2}^{\prime}\right)^{2}}{2 g_{c} J(1+r)}+\frac{\eta_{t}^{\prime \prime} \phi_{s} \dot{m}_{t} r}{g_{c} J(1+r)}\left[\frac{\left(V^{\prime \prime}\right)^{2}}{2}-\frac{(144)\left(p_{6}-p_{4}\right) g_{c}}{n_{d} \rho_{b_{4}}^{\prime \prime}}\right] \\
& -\frac{(144)\left(1-\phi_{s}\right) \dot{m}_{t} r\left(p_{g}-p_{8}\right)}{\eta_{p} \rho_{b_{8}}^{\prime \prime} J(1+r)}-\frac{(144) \dot{m}_{t}\left(p_{g}-p_{8}\right)}{\eta_{p} \rho_{a_{8}}^{\prime \prime} J(1+r)}
\end{aligned}
$$

In order to determine the mass ratio of component $B$ to component $A$ the flow in the nozzle must be considered. If $A$ and $B$ enter the nozzle in the liquid state and if $A$ is entirely vaporized until only B remains in the liquid state then for an isentropic process:

$$
\dot{m}_{a} s_{a_{1}}^{\prime \prime}+\dot{m}_{b} s_{b}^{\prime \prime}=\phi_{x} \dot{m}_{a} s_{a x}^{\prime}+\left(1-\phi_{x}\right) \dot{m}_{a} s_{a x}^{\prime \prime}+\dot{m}_{b} s_{b x}^{\prime \prime}
$$

rearranging gives:

$$
\phi_{x} s_{a x}^{\prime}-\phi_{x} s_{a x}^{\prime \prime}=s_{a_{1}}^{\prime \prime}+r s_{b_{1}}^{\prime \prime}-s_{a x}^{\prime \prime}-r s_{b x}^{\prime \prime}
$$

or

$$
\phi_{x}=\frac{r\left(s_{b_{1}}^{\prime \prime}-s_{b x}^{\prime \prime}\right)}{\Delta s_{a x}}+\frac{s_{a_{1}}^{\prime \prime}-s_{a x}^{\prime \prime}}{\Delta s_{a x}}
$$

If $\phi=1$

$$
r=\frac{\Delta s_{a x}-\left(s_{a_{1}}^{\prime \prime}-s_{a x}^{\prime \prime}\right)}{s_{b_{1}}^{\prime \prime}-s_{b x}^{\prime \prime}}
$$

where $\phi_{x}$. = the mass fraction of $A$ vaporized by station $x$

$$
\begin{aligned}
\dot{m}_{a}= & \text { mass flow rate of component } A \\
\dot{m}_{b}= & \text { mass flow rate of component } B . \\
s_{a_{1}}^{\prime \prime}= & \text { entropy of liquid } A \text { at the conditions of } \\
& \text { station } 1 \text { (inlet) } \\
\Delta s_{a x}= & \text { entropy of vaporization of component } A \text { at station } x
\end{aligned}
$$

The velocity at $x$ for an isentropic process is given by:

$$
\dot{m}_{a} h_{a_{1}}^{\prime \prime}+\dot{m}_{b} h_{b_{1}}^{\prime \prime}=\phi_{x} \dot{m}_{a} h_{a x}^{\prime}+\left(1-\phi_{x}\right) \dot{m}_{a} h_{a x}^{\prime \prime}+\dot{m}_{b} h_{b x}^{\prime \prime}+\left(\dot{m}_{a}+\dot{m}_{b}\right) v_{x i}^{2} / 2
$$


Solving for $V_{x i}{ }^{2}$ :

$$
\begin{aligned}
v_{x i}^{2} & =\frac{2}{1+r}\left[h_{a_{1}}^{\prime \prime}-\left(1-\phi_{x}\right) h_{a x}^{\prime \prime}-\phi_{x} h_{a x}^{\prime}+r h_{b_{1}}^{\prime \prime}-r h_{b x}^{\prime \prime}\right] \\
& =\frac{2}{1+r}\left[h_{a_{1}}^{\prime \prime}-h_{a x}^{\prime \prime}+\phi_{x} h_{a x}^{\prime \prime}-\phi_{x} h_{a x}^{\prime}+r\left(h_{b_{1}}^{\prime \prime}-h_{b x}^{\prime \prime}\right)\right] \\
& =\frac{2}{1+r}\left[\left(C_{p a}^{\prime \prime}+r C_{p b}^{\prime \prime}\right)\left(T_{1}-T_{x}\right)-\phi_{x} L_{v a}+\frac{p_{1}-p_{x}}{\rho_{a x}^{\prime \prime}}\left(1+r \frac{\rho_{a x}^{\prime \prime}}{\rho_{b x}^{\prime \prime}}\right]\right.
\end{aligned}
$$

And

$$
\begin{aligned}
& A_{x i}-\frac{\dot{m}_{a} \phi_{x}}{\rho_{a x}^{\prime} V V_{x i}}+\frac{\dot{m}_{a}\left(1-\phi_{x}\right)}{\rho_{a x}^{\prime \prime} V_{x i}}+\frac{\dot{m}_{b}}{\rho_{b x}^{\prime \prime} V_{x i}} \\
& A_{x}=\frac{A_{x i}}{\sqrt{\pi ! n}} \\
& \text { where } v_{x i}=v_{x i}^{\prime}=v_{x i}^{\prime \prime}=\text { velocity of two-phase mixture after an } \\
& \text { isentropic expansion from station } 1 \text { to } x \\
& h_{a_{1}}^{\prime \prime}=\text { enthalpy of component } A \text { liquid at station. } 1 \\
& \mathrm{C}_{\mathrm{pa}}^{\prime \prime}=\text { specific heat of component A liquid } \\
& T=\text { temperature } \\
& L_{v a}=\text { latent heat of vaporization of component } A \\
& \text { P = pressure } \\
& \rho_{\text {ax }}^{\prime \prime}=\text { density of component } A \text { liquid at station } x \\
& A_{x i}=\text { area at station } x \text { for an isentropic expansion from } 1 \text { to } x \\
& A_{x}=\text { area for a real expansion from } 1 \text { to } x \\
& n_{n}=v_{x}^{2} / v_{x i}^{2}
\end{aligned}
$$




\section{Two Components with Contact Heat Exchanger}

The contact heat exchanger variation of Figure 4 has the primary pump as an added component, but replacement of the primary tube and fin heat exchanger by a simple contact unit should result in a sugnificant savings in cost.

The heat transferred from the condenser is:

$$
Q_{c}=\frac{\dot{m}_{t}}{1+r}\left\{L_{v a}+\left(\frac{C_{1}}{1-C_{1}}\right) L_{v b}+C_{p a}^{\prime \prime} \Delta T_{s c}+\left|\left(\frac{C_{1}}{1-C_{1}}\right)+\left(1-\phi_{s}\right)(1+r)\right| C_{p b}^{\prime \prime} \Delta T_{s c}\right\}
$$

where the nomenclature was defined previously.

The turbine output power now becomes:

$$
\begin{aligned}
P_{n} & =\frac{\psi_{v} n_{t}^{\prime} \dot{m}_{t}\left(v^{\prime}\right)^{2}}{2 g_{C} J(1+r)}+\frac{n_{t}^{\prime \prime} \phi_{s} \dot{m}_{t} r}{g_{C} J(1+r)}\left[\frac{\left(v^{\prime \prime}\right)^{2}}{2}-\frac{(144)\left(\Delta p_{i}\right) g_{c}}{n_{d} \rho_{b_{4}}^{\prime \prime}}\right] \\
& -\frac{(144)\left(1-\phi_{s}\right) \dot{m}_{t} r\left(p_{g}-p_{8}\right)}{n_{p_{1}} \rho_{b_{8}}^{\prime \prime} J(1+r)}-\frac{(144) \dot{m}_{t}\left(p_{g}-p_{8}\right)}{n_{p_{1}} \rho_{a_{8}}^{\prime \prime} J(1+r)} \\
& -\frac{(144)\left(\phi_{s}\right) \dot{m}_{t} r\left(p_{1}-p_{6}\right)}{n_{p_{2}} \rho_{b_{1}}^{\prime \prime} J(1+r)}
\end{aligned}
$$

The same expression for mass ratio holds, but in general the temperature of the thermodynamic working fluid at the nozzle inlet will be equal to the condenser temperature instead of the peak cycle temperature.

\section{Single Component Single Stage ralrulations}

The engine chosen for consideration is the 38-TD8-1/8. The exhaust temperature and flow rate at full power are:

$$
\begin{aligned}
& T_{i}=719^{\circ} \mathrm{F} \\
& \dot{m}_{e} / P_{d}=15.17 \mathrm{lb} / \mathrm{bHP} \cdot \mathrm{h} \\
& \dot{P}_{d}=1980 \mathrm{bHP} \\
& \dot{m}_{e}=3.004 \times 10^{4} \mathrm{lb} / \mathrm{h}=8.344 \mathrm{lb} / \mathrm{s}
\end{aligned}
$$


If we chose a heat exchanger $\Delta T$ of $25^{\circ} \mathrm{F}$ (pgs. 3-26 of ref. 7), then the peak temperature of the bottoming cycle is:

$$
T \cdot=696^{\circ} \mathrm{F}
$$

In order to limit the pressure and provide a consistent calculational basis, let $\mathrm{T}_{1}=680^{\circ} \mathrm{F}$. For saturated liquid, $P_{1}=2708.1$ psia.

The other conditions at state point 1 are:

$$
\begin{aligned}
v_{1}^{\prime \prime} & =.0305 \mathrm{ft}^{3} / \mathrm{lb} \\
v_{1}^{\prime} & =.1115 \mathrm{ft}^{3} / \mathrm{lb} \\
h_{1}^{\prime \prime} & =757.3 \mathrm{~B} / \mathrm{lb} \\
h_{1}^{\prime} & =1067.2 \mathrm{~B} / \mathrm{lb} \\
L_{v_{1}} & =309.9 \mathrm{~B} / 1 \mathrm{~b} \\
s_{1}^{\prime \prime} & =.9351 \mathrm{~B} / 1 \mathrm{~b}^{\circ} \mathrm{F} \\
s_{1}^{\prime} & =1.2071 \mathrm{~B} / \mathrm{lb}^{\circ} \mathrm{F} \\
{ }_{1} & =.2719 \mathrm{~B} / 1 \mathrm{~b}^{\circ} \mathrm{F}
\end{aligned}
$$

The first case considered will be a condensing temperature of $212^{\circ} \mathrm{F}$. In this case:

$$
\begin{aligned}
& T_{2}=212^{\circ} \mathrm{F} \\
& P_{2}=14.7 \text { psia } \\
& v_{2}^{\prime \prime}=.01672 \\
& v_{2}^{\prime}=26.80 \\
& h_{2}^{\prime \prime}=180.07 \\
& h_{2}^{\prime}=1150.4 \\
& L_{v_{2}}=970.3 \\
& s_{2}^{\prime \prime}=.3120 \\
& s_{2}^{\prime}=1.7566 \\
& \Delta s_{v_{2}}=1.4446
\end{aligned}
$$


Isentropic expansion would yield:

$$
\begin{aligned}
\Delta h_{i} & =h_{1}^{\prime \prime}-h_{2}^{\prime \prime}-T_{2}\left(s_{1}^{\prime \prime}-s_{2}^{\prime \prime}\right) \\
x_{2} & =\frac{T_{2}\left(s_{1}^{\prime \prime}-s_{2}^{\prime \prime}\right)}{L_{v_{2}}} \\
\Delta h & =(757.3-180.07)-672(.9351-.3120) \\
& =577.23-418.723=158.507 \mathrm{~B} / 1 \mathrm{~b}=158.507 \mathrm{~B} / \mathrm{s} / \mathrm{lb} / \mathrm{s} \\
x_{2} & =(672)(.9351-.3120) /(970.3)=.432 .
\end{aligned}
$$

The heat rejected is:

$$
\begin{aligned}
Q_{C} & =(.432)(1)(970.3)+[(.99)(1)+(.432)(1)](1.0)(10) \\
& =419.7+14.22=433.39 \mathrm{~B} / \mathrm{s}
\end{aligned}
$$

For a nozzle efficiency of 0.85 , the exit velocity is:

$$
\begin{aligned}
& v_{2}{ }^{2} / 2 g_{C} J=n_{n} \Delta h_{i}=(158.507)(.85) \\
& v_{2}=\sqrt{(64.4)(778)(158.57)(.85)}=2598.68 \mathrm{ft} / \mathrm{s}
\end{aligned}
$$

For a turbine efficiency of .85 and a diffuser efficiency of .85 and $\dot{\Psi}_{v}=1$ :

$$
\begin{aligned}
P_{n}= & \frac{(1)(.85)(.432)(1)(2598.68)^{2}}{(64.4)(778)}+\frac{(.85)(.99)(.568)(1)}{(32.2)(778)}\left[\frac{(2598.68)^{2}}{2}-\right. \\
& \left.\frac{(144)(2693.4+40)(32.2)}{(.85)(59.81)}\right]-\frac{(144)(.432+.01)(1)(2693.4+40)}{(.75)(59.81)(778)} \\
= & 49.49+59.667-4.883=104.27 \mathrm{~B} / \mathrm{s} .
\end{aligned}
$$

The cycle efficiency is therefore:

$$
n_{c}=\frac{104.27}{104.27+433.39}=.1939
$$




\section{APPENDIX C \\ SUMMARY OF TURBINE DESIGN \\ METHODS AND PARAMETERS}

\section{Mechanical Design Procedure}

1. Make use of standard and conventional parts and materials.

2. Estimate rotor component weights.

3. Calculate rotor shaft size by:
A. Minimum static deflection with load (.001")
B. Bearing size for rotor speed and load
C. Material selection.

4. Calculate shaft stresses based on size, material, and drive hor"sepower.

5. Estimate first critical speed.

6. Adjust any of the above parameters as required.

7. Determine component balance required to minimize total load.

8. Calculate housing stresses and determine minimum thicknesses aird bolt size.

9. Calculate inlet line size and outlet li ne size required for standard flow.

10. Design support members for maximum rigidity.

\section{Turbine Parameters*}

1. Two inlet nozzles - .939" exit diameter

2. Steam mass flowrate $=.659 \mathrm{lb} / \mathrm{s}$

3. DTA mass flowrate $=2.16 \mathrm{lb} / \mathrm{s}$

4. Separator $\mathrm{rpm}=16,322$

5. Turbine rpm $=8,161$

6. Separator speed $=1,600 \mathrm{ft} / \mathrm{s}$

* The final turbine parameters changed somewhat due to iterations, but not significantly enough to affect the mechanical design. 
7. Turbine power $=160 \mathrm{HP}$

8. Steam turbine power $=137.4 \mathrm{HP}$

9. Pump power $=38.7 \mathrm{HP} @ 75 \%$ efficiency

10. Nozzle exit velocity $=1,841 \mathrm{ft} / \mathrm{s}\left(@ 15^{\circ}\right.$ )

11. Separator (nozzle exit) pressure $=14.7$ psia

12. Separator (nozzle exit) temperature $=212^{\circ} \mathrm{F}$

13. Turbine discharge pressure $=1.2$ psia (.7 psia minimum)

14. Separator drum inner diameter $=24 "$

15. Nozzle length $=12^{\prime \prime}$

Throat diameter $=.90^{\prime \prime}$

Exit diameter $=.939^{\prime \prime}$

16. Separator drum material - titanium

Numerical Calculations

1. Estimated rotor weights:

Steam turbine -20 lbs
Separator disc -20 lbs
Liquid turbine -5 lbs
Shaft
Sh 8.5 lbs

2. Rotor unbalance load:

$$
\begin{aligned}
& \text { Vapor turbine: } \quad 8,161 \mathrm{rpm} \\
& .04 \text { ounce inches maximum } \\
& \text { Force }=\frac{\text { Ounces } \times \text { inches }}{6172} \times(.1045 \times \mathrm{rpm})^{2} \\
& \text { Force }=\frac{.04}{6172}(728,702) \\
& \text { Force }=2.72 \mathrm{lbs} \\
& \text { Separator disc: } 16,322 \mathrm{rpm} \\
& .016 \text { ounce inches maximum } \\
& \text { Force }=\frac{.016}{6172}(2,914,809) \\
& \text { Force }=7.5 \mathrm{lbs}
\end{aligned}
$$

Liquid turbine and shaft $=$ Negligible

$$
\text { Total Rotor Load }=65.7 \% \mathrm{lbs}
$$


3. Rotor shaft size:

$$
\begin{aligned}
& \text { Deflection }=\frac{W C^{2}}{3 E I} \times(c+\ell) \\
& .001=\frac{(65.72)(4)^{2}}{3\left(30 \times 10^{6}\right) \ell}(4+7) \\
& I=.129=.049\left(d^{4}\right) \\
& d=1.344^{\prime \prime} \\
& \text { where } W=\text { Rotor weight - Ibs } \\
& E=30 \times 10^{6} \\
& I=.049\left(d^{4}\right) \\
& c=\text { Rotor overhang - inches } \\
& \ell=\text { Dearing spacing . inches } \\
& d \text { = Shaft diameter - inches } \\
& \text { Typical Bearing Type = Fafnir Medium } 2 M M 307 \text { WI single and } \\
& =X_{2} R+Y_{3} T \text { Equation } 2=52.23 \\
& Y_{1}=0 \\
& X_{2}=.45 \\
& Y_{2}=1.8 \\
& R=65.72 \\
& c_{n}=.16 \times 7,250
\end{aligned}
$$




$$
C_{n}=1,160
$$

Therefore, $\mathrm{L}_{10}=82 \times 10^{6}$

Standard grease packed double seal bearings rated at $250^{\circ} \mathrm{F}$ are therefore suitable.

4. Rotor shaft size by stress:

ASME Power Code Equation: =

$$
d^{3}=\frac{16}{S_{s}} \cdot \sqrt{\left(K_{b} M_{b}\right)^{2}+\left(K_{t} M_{t}\right)^{2}}
$$

where $d=$ Shaft $\cdot$ diameter - inches

$$
\begin{aligned}
s_{s}= & \begin{array}{l}
\text { Maximum shear stress - torsion, bending } \\
\text { and axial, Code for standard commercial } \\
\\
\text { with keyway }=6,000 \text { psi }
\end{array} \\
K_{b}= & \text { Combined shock and fatigue - bending } \\
M_{b}= & \text { Bending moment }- \text { in } / 1 \mathrm{~b} \\
K_{+}= & \text {Combined shock and fatigue - torsional } \\
& \text { Code }-1.5 \text { for minor shock } \\
M_{+}= & \text {Torsional moment }- \text { in/lb }
\end{aligned}
$$

Neglecting bending stresses: @ $300 \mathrm{HP}$

$$
\begin{aligned}
d^{3} & =\frac{16}{\pi S_{s}} K_{t} M_{t} \\
\text { where } M_{+} & =\frac{H P(33,000)(12)}{2 \pi r p m} \\
& =2,318 \mathrm{in} / 1 \mathrm{~b} \\
d^{3} & =\frac{16}{\pi 6,000} 1.5(2,318) \\
d^{3} & =z .95^{\prime \prime}
\end{aligned}
$$

Therefore, $d=1.37^{\prime \prime}$

The $35 \mathrm{~mm}$. bearing size (1.3780) is correct. 
The two-phase nozzle accelerates a steam/Dow-Therm A mixture. In the separator, the two fluids are separated and each is allowed to exchange momentum in a turbine wheel.

In the separator process, the liquid Dow-Therm $A$ is centrifuged to the inside of the rotating separator rim. The steam, at esserilially rim speed, exists bclow the liquid. If the pressule gradient is sufficieril to initiate flow radially inward, the flow can be directed through properly shaped vanes and energy can be extracted. This would then be a radial inflow turbine configuration, and is selected here because it adapts so well to the rest of the geometry. Actually, a small performance penalty will be paid because the jet-speed ratio $\left(U / C_{0}\right)$ is somewhat low, even if two stages are used.

Operating Conditions

The conditlons for which the turbine was designed are listed in Table D-1.

Analysis

In contradistinction to the ordinary radial inflow turbine where the working fluid is accelerated in a regular nozzle located in the plane of the wheel and directed to provide a radial inflow component to the volocity, herc the fluid is separated on the rotating diund dirl is directed with a slight axial component. Therefore, the analysis begins with the already accelerated steam jet assuming a realistic value of velocity (tangential component $=1,800 \mathrm{ft} / \mathrm{sec}$, radial component $=250 \mathrm{ft} / \mathrm{sec}$ ). The steam is also assumed to be saturated vapor at 14.7 psia. The 
TABLE D-1

OPERATING CONDITIONS

Nozzle Exit Diameter, in.

0.939

Steam Mass Flowrate, $\mathrm{lb} / \mathrm{sec}$

0.659

Dow-Therm Mass Flowrate, Ib/sec

2.16

Separator Speed, rpm

16,322

Turbine Speed, rpm

8,161

Nozzle Exit Velocity, $f t / s e c$

1,841

Nozzle Angle, degrees

12

Separator Diameter, in.

24.0

Nozzle Exit Pressure, psia

14.7

Turbine Dischargé Pressure, psia

1.2 maximum

0.7 minimum 
separator and nozzle diameters set the allowable inlet diameter to the turbine at 22.0 inches, making the tip speed $783 \mathrm{ft} / \mathrm{sec}$ at $8,161 \mathrm{rpm}$. This is the starting point of the analysis.

The variables which operate in the trade-off analysis include:

Diameter at inlet and outlet of each stage

Intermediate stage pressures

Blade angles

Absolute velocities (mach numbers)

Radial acceleration permissible

The objective, of course, is to minimize losses and maximize power output. In terms of the turbine analysis, the absolute leaving velocity should have the smallest possible tangential (whirl) component.

A preliminary trade-off was made to determine some of the variables. Diameters were selected and the radial acceleration was set at 20 percent. It would be best to have no acceleration but blade angles will be very shallow. Throughtlow velocity was chosen to give leasurlable blade height. A parametric analysis of intermediate stage pressures was performed.

Table D-2 lists the constraints imposed on the analysis. Figure D-1 shows the nomenclature used. Table D-3 is a summary of the calculations and Figures D-2 through D-5 show the results. From these data the selected configuration is as summarized in Table D-4. 
TABLE D-2

CONSTRAINTS AND EQUATIONS

$$
\begin{aligned}
& C_{u_{2}}=1,800 \mathrm{ft} / \mathrm{sec} \\
& \text { Assumed, set by drum speed } \\
& c_{r_{2}}=250 \mathrm{ft} / \mathrm{sec} \\
& \text { Assumed, reasonable blade height. } \\
& w_{3 i}{ }^{2}=w_{2}^{2}+2 g J\left(h_{2}-h_{3 \cdot i}\right) \\
& \text { First Law } \\
& w_{3}=0.9 w_{3} \mathbf{i} \\
& \text { Assumed, Losses } \\
& \text { Stage Work }=\frac{\mathrm{C}_{\mathrm{U}_{2} \mathrm{U}_{2}}-\mathrm{C}_{\mathrm{U}_{3} \mathrm{U}_{3}}}{\mathrm{gJ}} \\
& c_{r_{3}}=1.2 c_{r_{2}}=300 \mathrm{ft} / \mathrm{sec} \\
& C_{U_{4}}=C_{u_{3}}\left(D_{4} / D_{3}\right) \\
& C_{r_{5}}=1.2 C_{r_{4}}=360 \mathrm{ft} / \mathrm{sec} \\
& C_{5} i^{2}=C_{4}^{2}+2 g J\left(h_{4}-h_{5} i^{2}\right) \\
& C_{5}=0.9 C_{5 i} \\
& h_{6}=h_{4}-C_{0}^{2} / 2 g J \\
& c_{r_{7}}=1.2 C_{r_{6}}=432 \mathrm{ft} / \mathrm{sec} \\
& \text { Stage Work }=\frac{C_{U_{6} U_{6}}-C_{U_{7}{ }_{7}}}{g J} \\
& \text { Euler Equation } \\
& \text { Reasonable acceleration } \\
& \text { Vortex Law } \\
& \text { Reasonable acceleration } \\
& \text { First Law } \\
& \text { Assumed, Losses } \\
& \text { First Law } \\
& \text { Reasonable acceleration }
\end{aligned}
$$


Fig. D-1 - Typical Diagrams
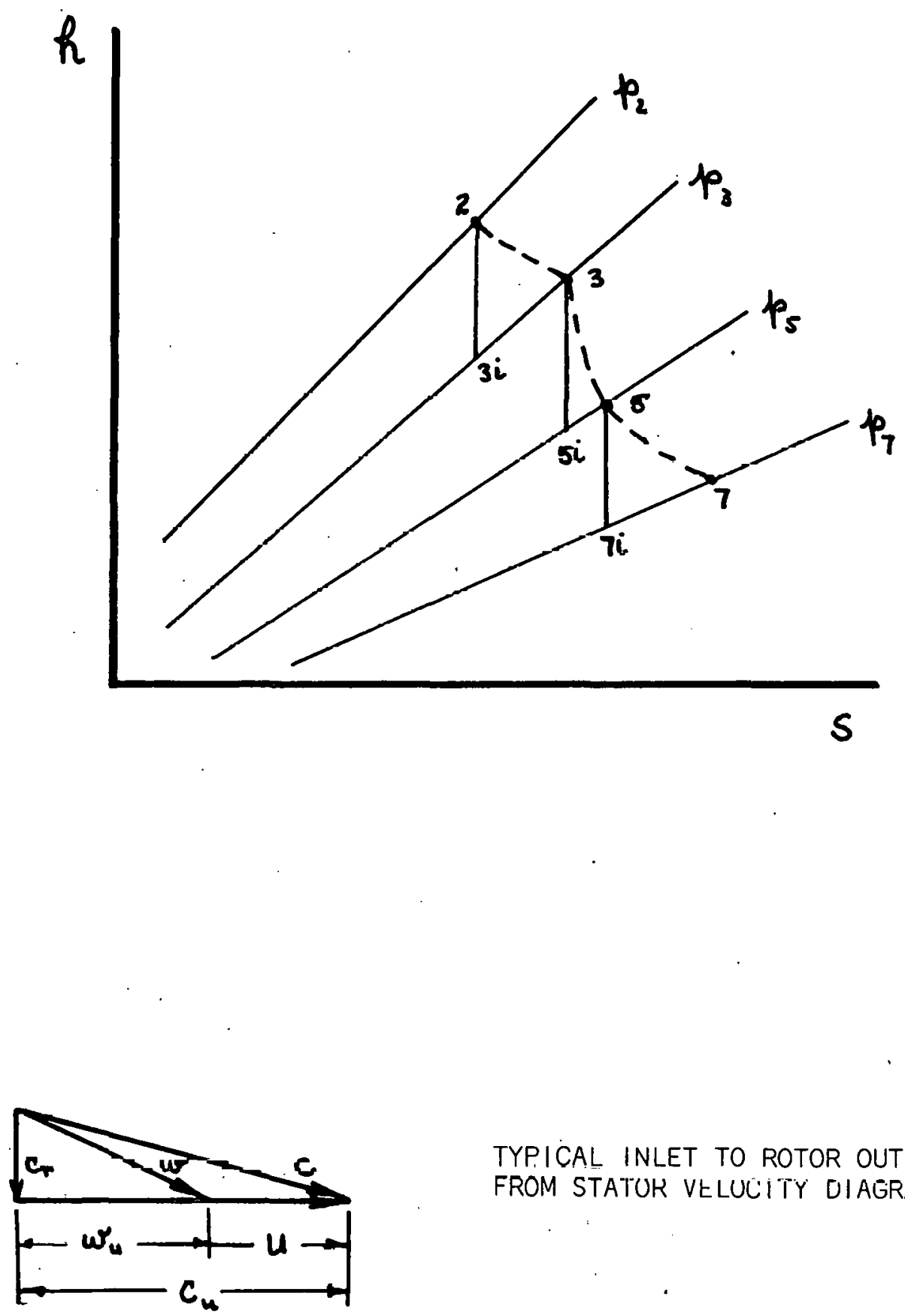

TYPICAL INLET TO ROTOR OUTLET

FROM STATOK VLLUCITY OIAGRAM

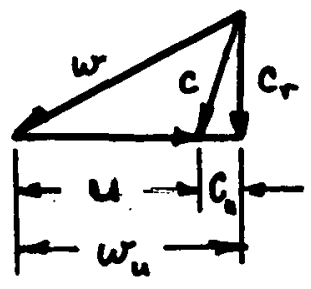

TYPICAL OUTLET FROM ROTOR INLET TO STATOR VELOCITY DIAGRAM 
TABLE D-3

TYPICAL CALCULATIONS

\section{Point 2}

$$
\begin{aligned}
& p_{2}=14.7 \text { psia } \\
& h_{2}=1,150.5 \mathrm{~B} / \mathrm{lb} \\
& c_{2}=1,817.3 \mathrm{ft} / \mathrm{sec} \\
& u_{2}=783.4 \mathrm{ft} / \mathrm{sec} \\
& \omega_{2}=1,046.9 \mathrm{ft} / \mathrm{sec} \\
& c_{u_{2}}=1,800 \mathrm{ft} / \mathrm{sec} \\
& c_{r_{2}}=250 \mathrm{ft} / \mathrm{sec}
\end{aligned}
$$

\begin{tabular}{|c|c|c|c|c|c|c|c|c|}
\hline$P_{3}$ & $=$ & 14.7 & psia & 12.0 & 8.0 & 6.0 & 4.0 & 1.2 \\
\hline$h_{3 i}$. & $=$ &, 150.5 & $B / I b$ & $1,1.36$ & 1,108 & 1,089 & 1,063 & 992 \\
\hline$\omega_{3}$ & $=-$ & 942 & $\mathrm{ft} / \mathrm{sec}$ & $-1,215$ & $-1,616$ & $-1,845$ & $-2,112$ & $-2,706$ \\
\hline$U_{3}$ & $=$ & 712 & $\mathrm{ft} / \mathrm{sec}$ & 712 & 712 & 712 & 712 & 7.12 \\
\hline $\mathrm{C}_{\mathrm{r}_{3}}$ & $=$ & 300 & $\mathrm{ft} / \mathrm{sec}$ & 300 & 300 & 300 & 300 & 300 \\
\hline $\mathrm{C}_{\mathrm{u}_{3}}$ & $=-$ & 181 & $\mathrm{ft} / \mathrm{sec}$ & -465 & -876 & $-1,108$ & $-1,379$ & $-1,977$ \\
\hline Stag & ge W & $k=61$ & $1.4 \mathrm{~B} / \mathrm{lb}$ & 69.5 & 81.2 & 87.8 & 95.5 & 112.5 \\
\hline
\end{tabular}

\begin{tabular}{|c|c|c|c|c|c|c|c|c|}
\hline $\mathrm{C}_{\mathrm{UL}_{4}}$ & $=-$ & 181 & $\mathrm{ft} / \mathrm{sec}$ & -470 & - 885 & $-1,119$ & $-1,393$ & $-1,997$ \\
\hline $\mathrm{C}_{r_{4}}$ & $=$ & 300 & $f t / \sec$ & 300 & $3(0)$ & 300 & 300 & 300 \\
\hline
\end{tabular}

\section{Point 3}

\section{Point 4}


TABLE D-3 - continued

Point 5

$p_{5}=10$ psia

$h_{5 i}=1,132 \quad B / / b$

$C_{5}=883 \mathrm{ft} / \mathrm{sec}$

$C_{r_{5}}=360 \mathrm{ft} / \mathrm{sec}$

$\mathrm{C}_{\mathrm{u}_{5}}=806 \mathrm{ft} / \mathrm{sec}$

$r_{u_{6}}=815 \mathrm{ft} / \mathrm{sen}$

$U_{6}=627 \mathrm{ft} / \mathrm{sec}$

$\omega_{u_{6}}=188 \mathrm{ft} / \mathrm{sec}$.

$c_{r_{6}}=360 \mathrm{ft} / \mathrm{sec}$.

$\omega_{6}=406 \mathrm{ft} / \mathrm{sec}$

$\mathrm{C}_{6}=891 \mathrm{ft} / \mathrm{sec}$

$h_{G}=1,135 \quad B / 1 b$

$p_{7}=1.2 \mathrm{psia}$

$h_{7 l}=1,003 \quad B / I b$

$\omega_{7}=-2,338 \mathrm{t}+\mathrm{sec}$

$\mathrm{U}_{7}=556 \mathrm{ft} / \mathrm{ser}$.

$\mathrm{C}_{r_{7}}=432 \mathrm{ft} / \mathrm{sec}$

$c_{u_{7}}=-1,7.42 \mathrm{ft} / \mathrm{sec}$

Stage Work $=59.0 \mathrm{~B} / \mathrm{Ib}$

Power

$$
=120 \mathrm{HP}
$$

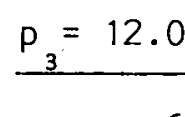

1,097

1,490

360

1,446

1,462

627

835

360

909

1,506

1,106

1.2

1.2

1,006

$-2,171$

556

432

. 2,485

360

2,459

2,487

627

1,860

360

1,895

2,513

1,027

1,027

432

$-1,572$

$-1,094$

86.5

71.4

132
1,017

$-2,121$

556

432

6

$\frac{p_{3}=8.0}{4}$

1,088

1,015

1,750

2,557

360

360

1,712

1,732

627

627

1,105

1,933

360

360

1,966

2,585

1,021

1.2

1.2

1.2

1,021

1,018

$-2,012$

$-1,769$

556

556

432

432

$-1,520$

$-1,409$

$-1,160$

66.4

74.6

89.3

137

1.45

.2

5


Fig. D-2

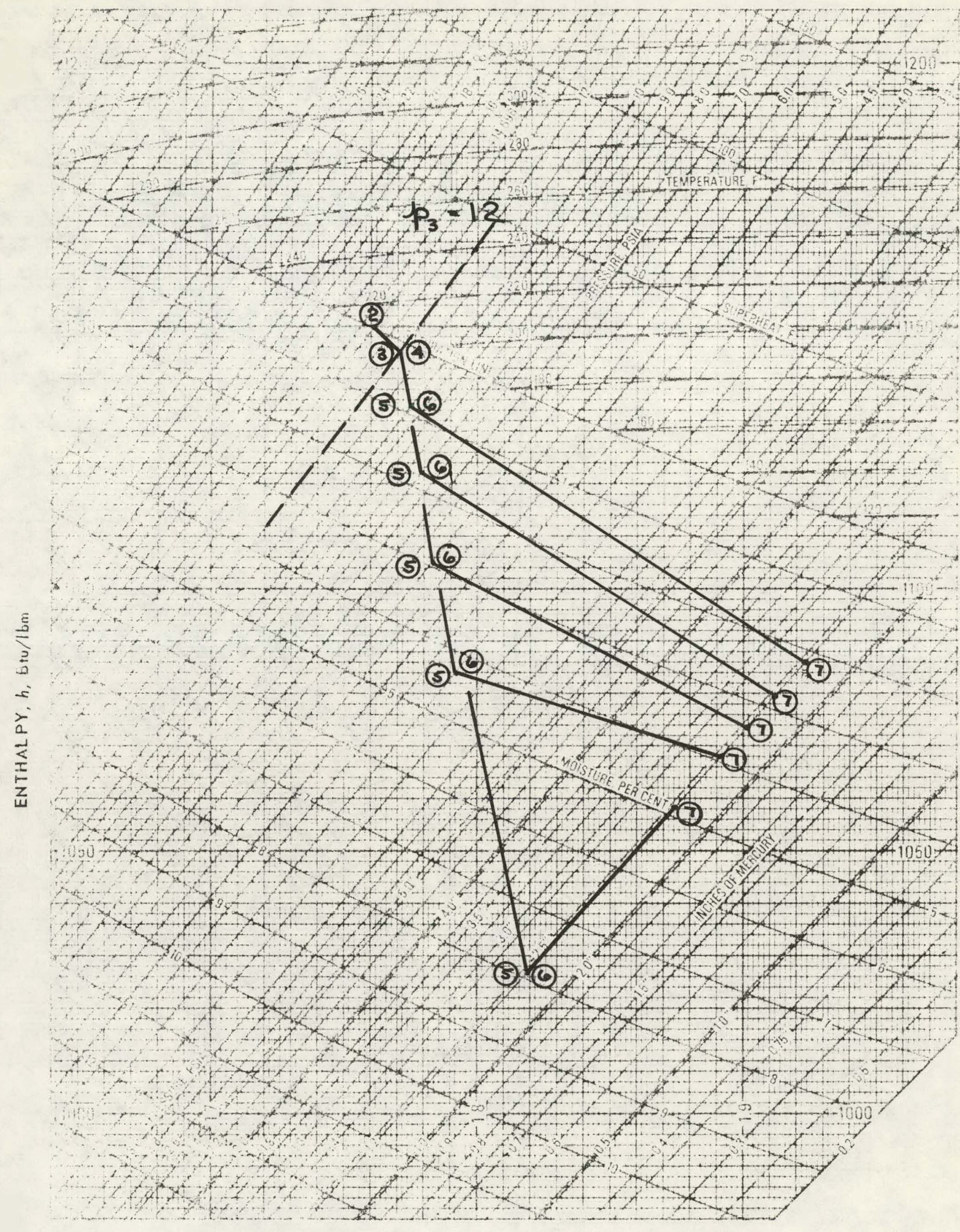

ENTROPY, s, Btu/ $\mathrm{lbm} \times \mathrm{F}$ 


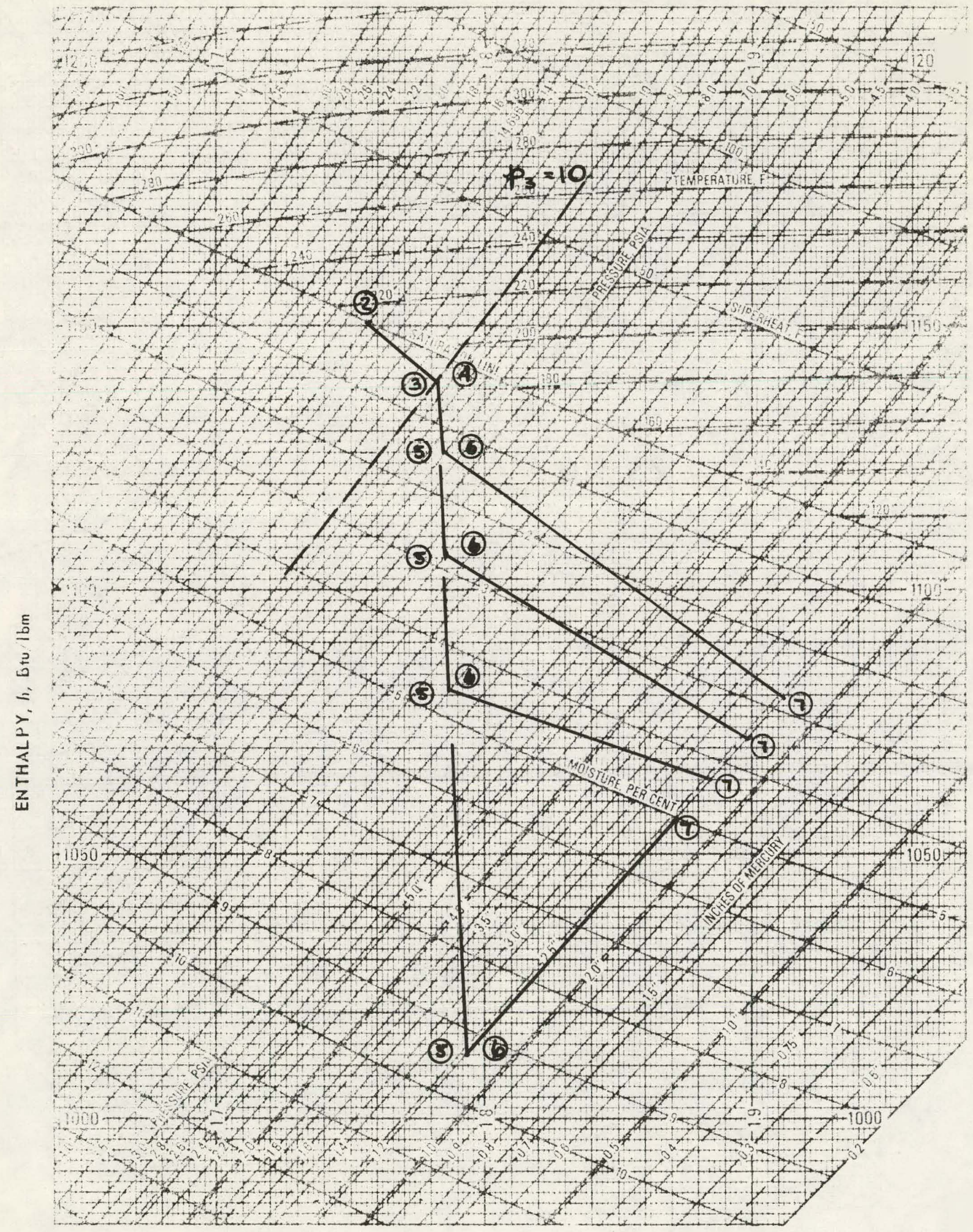

ENTROPY, s, Btu/lbm F 


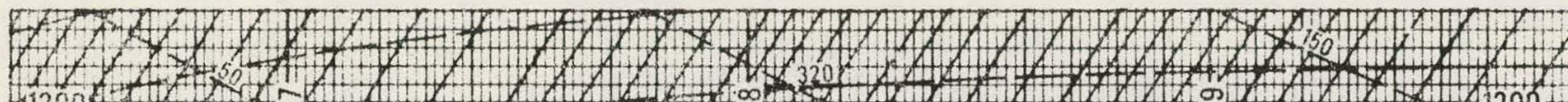

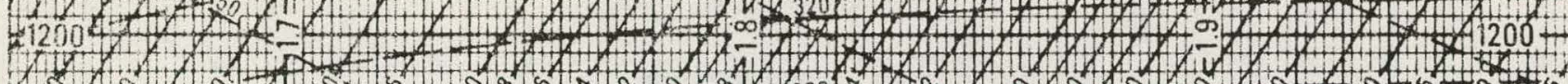

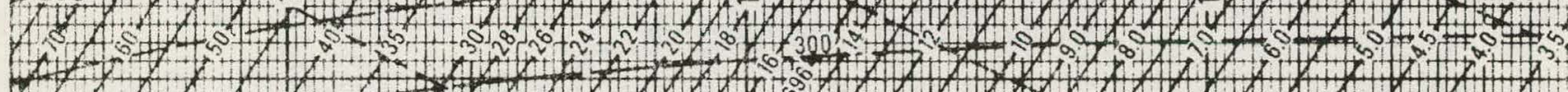

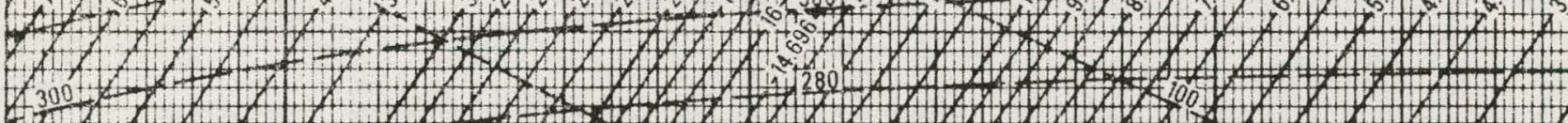

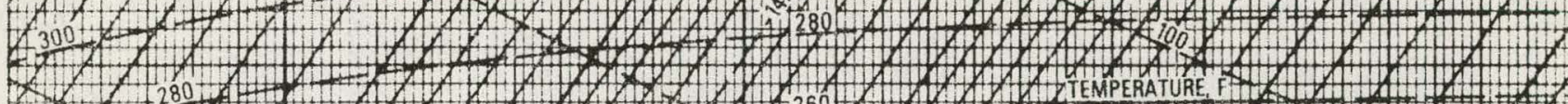
L.

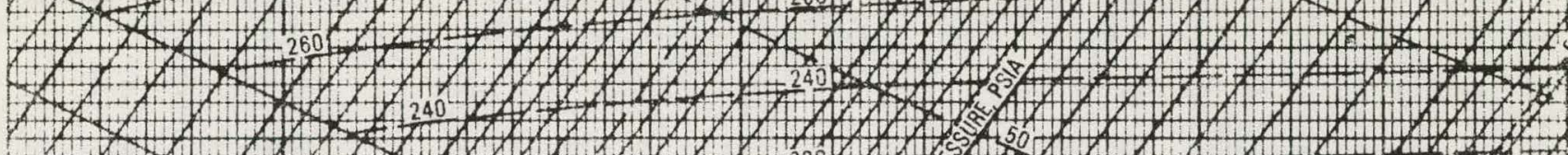

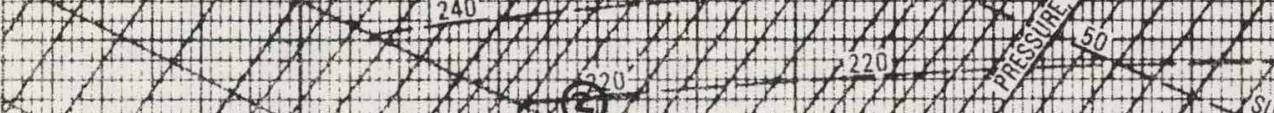

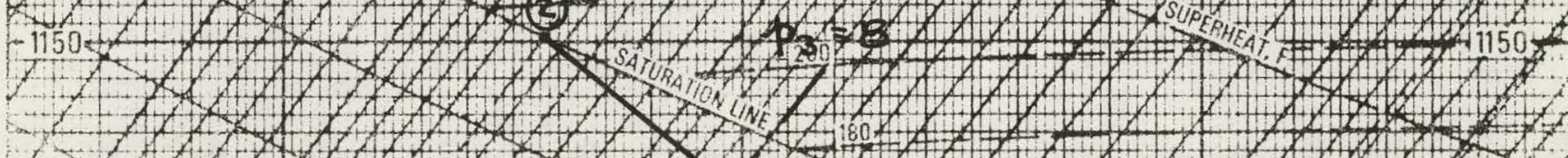

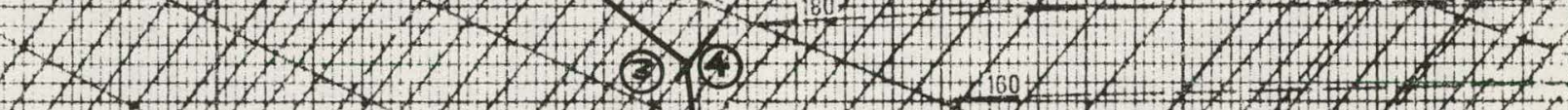

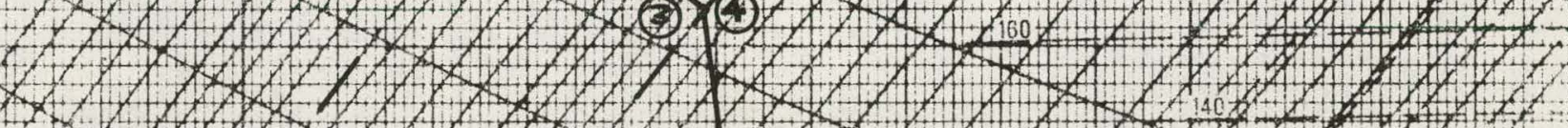

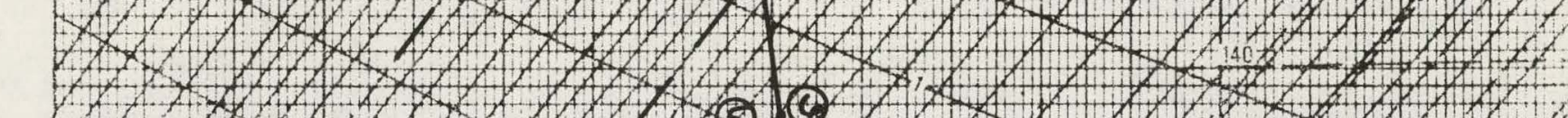

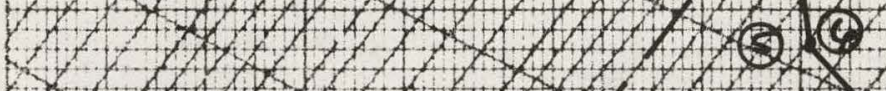

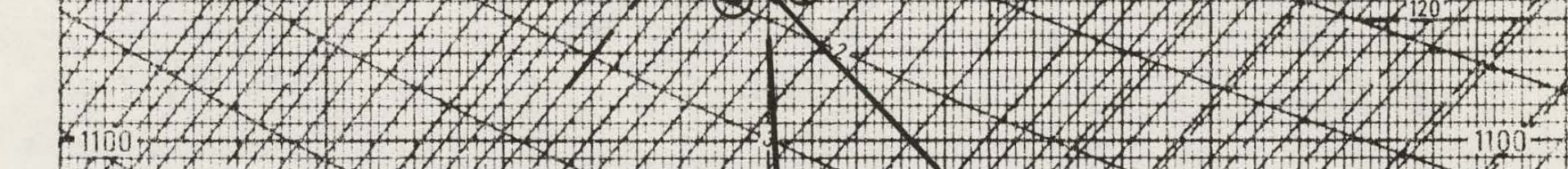

ENTROPY, s, Btu/I $b m \times F$ 
TABLE D-4

CONFIGURATION DATA

FIRST STAGE

STATOR

SECOND SINGL
Inlet

Exit

Inlet

Exit

Inlet

Exit

$$
\begin{aligned}
& P=14.7 \text { psia } \\
& D=22.0 \quad \mathrm{in} . \\
& b=0.185 \mathrm{in} . \\
& B=13.8 \text { degrees }
\end{aligned}
$$$$
p=8.0 \text { psia }
$$$$
D=20.0 \text { in. }
$$$$
b=0.296 \mathrm{in} .
$$$$
\beta=10.7 \text { degrees }
$$

$$
p=8.0 \text { psia }
$$$$
D=19.8 \text { in. }
$$$$
b=0.300 \mathrm{in} .
$$$$
\alpha=18.7 \text { degrecs }
$$$$
p=4.0 \text { psia }
$$$$
D=17.8 \mathrm{in} .
$$

$b=0.514 \mathrm{in}$.

$\alpha=11.9$ degroos

$p=4.0$ psia

$D=17.6$ in.

$b=0.520 \mathrm{in}$.

$\beta=18.1$ degrees

$p=1.2$ psia

$D=15.6 \mathrm{in}$.

$b=1.49 \mathrm{in}$.

$\beta=12.49$ degrees 


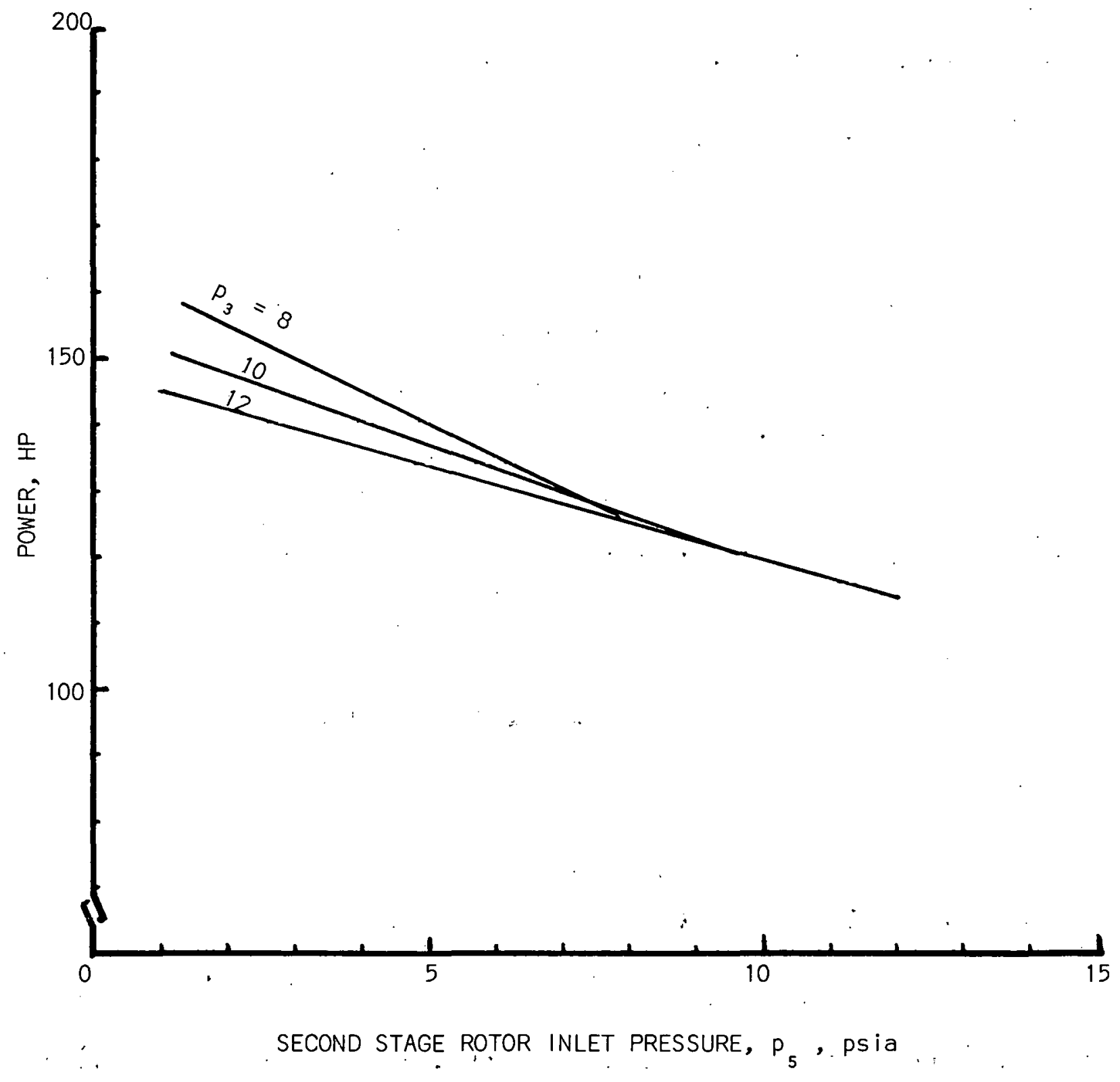

Fig. D-5 - Results of Trade-off Study 


\section{APPENDIX E \\ CONTACT HEAT EXCHANGER CYCLE EQUATIONS}

The mass ratio was calculated for isentropic nozzle expansion:

We know for isentropic processes

$$
\dot{m}_{a} s_{a 1}^{\prime \prime}+\dot{m}_{b} s_{b 1}^{\prime \prime}=\dot{m}_{a} s_{a 2}^{\prime}+\dot{m}_{b} s_{b 2}{ }_{2}
$$

Where

$$
\begin{aligned}
& \dot{m}_{d}=\text { mass flow rate of water } \\
& \dot{m}_{b}=\text { mass flow rate of therminol } 66 . \\
& s_{a}^{\prime \prime} 1=\text { entropy of wator at mixor inlet } \\
& s_{a}^{\prime}=\text { entropy of steam at nozzle inlet } \\
& s_{b}^{\prime \prime} 1=\text { entropy of tenrminol } 66 \text { at mixer inlet } \\
& s_{b 2}^{\prime \prime}=\text { entropy of therminol } 66 \text { at nozzle exit }
\end{aligned}
$$

So mass ratio, $r$, is

$$
r=\frac{\dot{m}_{b}}{\dot{m}_{a}}=\frac{s_{a}^{\prime} 2-s_{a}^{\prime \prime}}{s_{b !}^{\prime \prime}-s_{b 2}^{\prime \prime}}=\frac{s_{a}{ }^{\prime}-s_{a}{ }^{\prime \prime}}{-c_{p b} \ln T_{2}}
$$

Where

$$
\begin{aligned}
& T_{2}=\text { nozzle exit temperature } \\
& T_{1 b}=\text { mixer inlet termperature of therminol } 66
\end{aligned}
$$

The mixed termperature of therminol 66 and water was determined by a heat balance at nozzle inlet, assuming they were mixed at a common pressure.

$$
\begin{aligned}
& \dot{m}_{b} c_{p b}^{\prime \prime}\left(T_{1 b}-T_{1 m}\right)=\dot{m}_{a} c_{p a}^{\prime \prime}\left({ }_{1 m}-T_{1 a}\right) \\
& \text { So } \quad T_{1 m}=\frac{\gamma c_{p b}^{\prime \prime} T_{1 b}+c_{p a}^{\prime \prime} T_{1 a}}{c_{p a}^{\prime \prime}+\dot{\gamma} c_{p b}^{\prime \prime}}
\end{aligned}
$$


Where

$$
\begin{aligned}
& c_{p b}^{\prime \prime}=\text { specific heat of Therminol } 66 \\
& c_{p a}^{\prime \prime}=\text { specific heat of water } \\
& T_{1 a}=\text { water temperature at the mixer inlet } \\
& T_{1 m}=\text { mixed temperature at ther nozzle inlet }
\end{aligned}
$$

The velocity at $x$ for isentropic processes is given by:

$$
v_{a i}{ }^{2}=\frac{2}{1+\gamma} h_{a 1}^{\prime \prime}-h_{a 2}^{\prime}+\gamma c_{p b}^{\prime}\left(T_{1 m}-T_{2}\right)
$$

Where

$$
\begin{aligned}
& h_{a 1}^{\prime \prime}=\text { enthalpy of liquid water at nozzle inlet } \\
& h_{a 2}^{\prime}=\text { enthalpy of stema at nozzle exit }
\end{aligned}
$$

The exit velocity from the nozzle is then:

$$
v_{2}=n_{n} v_{x i}
$$

The power is therefore:

$$
P_{+}=\frac{\dot{m}_{T} v_{2}^{2} n_{T}}{2 g_{C} J} \text {. }
$$

Where:

$$
\begin{aligned}
& \eta_{n}, \eta_{T}=\text { nozzle and turbine efficiency } \\
& \dot{m}_{T}=\text { total mass of Therminol } 66 \text { and water }
\end{aligned}
$$

The pumping power required is:

$$
P_{P}=\frac{\dot{m}_{T} \Lambda P}{n_{p} J \rho_{a v}}
$$


Where

$$
\begin{aligned}
& n_{p}=\text { pumping efficiency } \\
& \rho_{a v}=\text { average density of fluids }
\end{aligned}
$$

The heat rejection from the systems is:

$$
\left.Q_{c}=\dot{m}_{a} L_{v a} x_{v y}+l_{\text {Tsup }}-h_{\text {Tsat }}\right)^{\prime} \dot{m}_{0}
$$

Wher

$$
\begin{aligned}
& L_{v a}=\text { latent heat of vaporization } \\
& x_{\text {va }}=\text { quality of steam } \\
& h_{\text {Tsup }}=\text { enthalpy at super heat } \\
& h_{\text {Tsat }}=\text { enthalpy at saturation }
\end{aligned}
$$

The cycle efficiency is then determined by:

$$
n_{c}=\frac{P_{\text {net }}}{Q_{c}+P_{\text {net }}}
$$

Where

$$
P_{n \in t}=P_{+}-P_{P}
$$

The flow conditions were chosen to provide a slight degree of super heat to avoid Wilson line if there is further expansion. 
APPENDIX F

COMPARISON OF FLUID PROPERTIES 
TABLE IA. - VAPOR PRESSLRE ( $\left.16 / i_{i}^{2}{ }^{2}\right)$

\begin{tabular}{|c|c|c|c|c|c|c|c|c|c|c|c|}
\hline $\begin{array}{c}\text { Temperature } \\
\mathrm{O}_{\mathrm{F}}\end{array}$ & $\begin{array}{c}\text { Therminol } \\
66\end{array}$ & $\begin{array}{l}\text {-herminol } \\
60\end{array}$ & $\begin{array}{c}\text { Therminol } \\
55 .\end{array}$ & $\begin{array}{c}\text { Dowtherm } \\
G\end{array}$ & $\begin{array}{c}\text { Dowtherm. } \\
\text { A }\end{array}$ & $\begin{array}{c}\text { Mob i I therm } \\
600\end{array}$ & $\begin{array}{l}\text { Cheviron } \\
\text { Tekri i fax }\end{array}$ & $\begin{array}{c}\text { EowCorning } \\
550\end{array}$ & $\begin{array}{c}\text { DowCorning } \\
710\end{array}$ & $\mid \begin{array}{l}\text { Arco } \\
\text { Rubilene }\end{array}$ & Thermof I uid \\
\hline 100 & -- & -- & 0.0967 & -- & 0.001 & -- & -- & -- & -- & -- & -- \\
\hline 200 & 0.00193 & $<0.038$ & 0.058 &.-- & 0.051 & -- & -- & -- & -- & -- & 0.15 \\
\hline 300 & 0.0386 & 0.23 & 0.193 & 0.2 & 0.63 & 0.386 & .- & -- & $<0.00193$ & -- & 0.35 \\
\hline 400 & 0.386 & 1.25 & 0.77 & 1.3 & 3.96 & 1.16 & -- & 0.01015 & -- & - & 0.70 \\
\hline 500 & 1.93 & 4.64 & 1.93 & 5.5 & $i 5.65$ & 3.384 & 0.232 & 0.012 & 0.077 & 0.116 & 1.30 \\
\hline 600 & 6.76 & 14.7 & 4.83 & 17.5 & 45.34 & 7.73 & -- & $\begin{array}{r}1.9300 \\
7.60^{\circ}\end{array}$ & 0.425 & -- & 2.6 \\
\hline 650 & 14.7 & 23.21 & -- & - & -- & -- & -- & -- & $\begin{array}{r}1.586 @ \\
700^{\circ} \mathrm{F}\end{array}$ & -- & 4.5 \\
\hline
\end{tabular}


TABLE $1 B$ - SPECIFIC HEAT $\left(B / / b^{\circ} F\right)$

\begin{tabular}{|c|c|c|c|c|c|c|c|c|c|c|c|}
\hline$\underset{\mathrm{F}}{\text { Temperature }}$ & $\begin{array}{c}\text { Therminol } \\
66\end{array}$ & $\begin{array}{c}\text { Therminol } \\
60\end{array}$ & $\begin{array}{c}\text { Therminol } \\
55\end{array}$ & $\begin{array}{c}\text { Dowtherm } \\
G\end{array}$ & $\begin{array}{c}\text { Dowtherm } \\
\text { A }\end{array}$ & $\begin{array}{c}\text { Mob il therm } \\
600\end{array}$ & $\begin{array}{l}\text { Chevron } \\
\text { Teknifax }\end{array}$ & $\begin{array}{c}\text { DowCorning } \\
550\end{array}$ & $\begin{array}{c}\text { DowCorning } \\
710\end{array}$ & $\begin{array}{l}\text { Arco } \\
\text { Rubilene }\end{array}$ & Thermof I uid \\
\hline 100 & 0.380 & 0.395 & 0.472 & 0.395 & 0.38880 & 0.39 & 0.45 & 0.358 & 0.363 & -- & 0.485 \\
\hline 200 & 0.430 & 0.445 & 0.522 & 0.42 & 0.4260 & 0.438 & -- & 0.386 & 0.454 & -- & 0.550 \\
\hline 300 & 0.480 & 0.495 & 0.572 & 0.454 & 0.463 & 0.485 & $0.555^{\circ}$ & -- & -- & -- & 0.610 \\
\hline 400 & 0.530 & 0.543 & C. 620 & 0.478 & 0.500 & 0.532 & -- & 0.433 & 0.505 & -- & 0.674 \\
\hline 500 & 0.57 & 0.593 & 0.670 & 0.510 & 0.537 & 0.578 & 0.66 & -- & -- & 0.685 & 0.730 \\
\hline 600 & 0.63 & 0.643 & 0.718 & 0.541 & 0.579 & 0.625 & -- & -- & -- & -- & 0.800 \\
\hline 700 & 0.68 & $\begin{array}{r}0.6680^{\varrho} \\
\quad 6.50 \mathrm{~F}\end{array}$ & -- & 0.5670 & 0.611 & 0.671 & -- & - & - & -- & $\begin{array}{r}0.82 @ 0 \\
650^{\circ} \mathrm{F}\end{array}$ \\
\hline
\end{tabular}


7.ABLE $1 \mathrm{C}-$ DENSITY $\left(\mathrm{lb} / \mathrm{ft}^{3}\right)$

\begin{tabular}{|c|c|c|c|c|c|c|c|c|c|c|c|}
\hline Temperature $_{F}$ & $\begin{array}{c}\text { Therminol } \\
66\end{array}$ & $\begin{array}{c}\text { Therminol } \\
60\end{array}$ & $\begin{array}{c}\text { T-erminol } \\
55\end{array}$ & $\begin{array}{c}\text { Dowtherm } \\
G\end{array}$ & $\begin{array}{c}\text { Dowtherm } \\
A\end{array}$ & $\begin{array}{c}\text { Mob i I therm } \\
600\end{array}$ & $\begin{array}{l}\text { Chevron } \\
\text { Tekn'ثax }\end{array}$ & $\begin{array}{c}\text { Cowzorning } \\
550\end{array}$ & $\begin{array}{c}\text { DowCorning } \\
710\end{array}$ & $\begin{array}{l}\text { Arco } \\
\text { Rubiliene }\end{array}$ & Thermofluid \\
\hline 100 & 61.7 & $6 i . z$ & 54.8 & 68.210 & 65.27 & 58.4 & $\begin{array}{l}0.879 \\
\text { Speci ic } \\
\text { Sravity } \\
060^{\circ} \mathrm{F}\end{array}$ & $\begin{array}{c}1.068 \\
\text { Specific } \\
\text { Gravity } \\
\text { 匹 7? F }\end{array}$ & $\begin{array}{c}1.11 \\
\text { Specific } \\
\text { Gravity } \\
\text { @ } 77^{\circ} \mathrm{F}\end{array}$ & -- & 49.5 \\
\hline 200 & 59.3 & 59.1 & 52.4 & 65.27 & 62.46 & 55.27 & -- & -- & -- & -- & 47.3 \\
\hline 300 & 56.7 & 55.9 & 50.1 & 62.47 & 59.50 & 54.28 & -- & - & - & -- & 45.2 \\
\hline 400 & 53.7 & 57.6 & 47.8 & 59.62 & 56.67 & 52.16 & -- & -- & -- & - & 43.0 \\
\hline 500 & 50.5 & 52.0 & 45.5 & 57.12 & 53.00 & 50.17 & -- & -- & -- & -- & 40.5 \\
\hline 600 & 48.1 & 49.7 & 43.1 & 54.25 & 49.29 & 48.11 & -- & -- & -- & -- & 37.9 \\
\hline 700 & 45.6 & $\begin{array}{r}48.6 \\
650^{\circ} \mathrm{F}\end{array}$ & -- & 51.4 & 45.03 & 45.60 & -- & -- & -- & -- & $\begin{array}{l}37 @ 8 \\
650 \mathrm{~F}\end{array}$ \\
\hline
\end{tabular}


TABLE $1 D-$ VISCOSITY

\begin{tabular}{|c|c|c|c|c|c|c|c|c|c|c|c|}
\hline $\begin{array}{c}\text { Temperature } \\
\end{array}$ & $\begin{array}{c}\text { Thermincl } \\
66\end{array}$ & $\begin{array}{c}\text { Therminol } \\
6.0\end{array}$ & $\begin{array}{c}\text { Therminol } \\
55\end{array}$ & $\begin{array}{c}\text { Dowtherm } \\
.\end{array}$ & $\begin{array}{c}\text { Dowtherm } \\
\text { A }\end{array}$ & $\begin{array}{c}\text { Mob i I therm } \\
600\end{array}$ & $\begin{array}{l}\text { Chevron } \\
\text { Teknifax }\end{array}$ & $\begin{array}{c}\text { DowCorn ing } \\
550\end{array}$ & $\begin{array}{c}\text { DowCorning } \\
710\end{array}$ & $\begin{array}{l}\text { Arco } \\
\text { Rubilitene }\end{array}$ & Thermofluid \\
\hline \multicolumn{7}{|c|}{$(1 b / h r-f t)$} & $\begin{array}{l}\text { (Centi- } \\
\text { stokes) } \\
\end{array}$ & $\begin{array}{l}\text { (Centi- } \\
\text { stokes) }\end{array}$ & $\begin{array}{l}\text { (Centi- } \\
\text { stokes) }\end{array}$ & (S.U.S.) & $(1 b / h r-f t)$ \\
\hline 100 & 72.00 & 11.7 & 6.1 .5 & 36.2 & 6.29 & 136.00 & 48.0 & 84 & $\begin{array}{l}500 @ \mathrm{O} \\
77^{\circ} \mathrm{F}\end{array}$ & $\begin{array}{l}201{ }^{@} \\
100^{\circ}\end{array}$ & -- \\
\hline 200 & 10.15 & 4.0 & 10.3 & 7.02 & 2.57 & 15.25 - & - & 20 & -- & $\begin{array}{l}47.30 @ \\
200^{\circ} \mathrm{F}\end{array}$ & 0.002 \\
\hline 300 & 3.76 & 2.1 & 4.09 & 2.9 & 1.4 & 4.84 & 2.80 & -- & & -- & 0.00076 \\
\hline 400 & 1.88 & 1.3 & 2.18 & 1.65 & 0.9 & 2.83 & -- & -- & -- & -- & 0.00055 \\
\hline 500 & 1.08 & 0.93 & 1.41 & 1.06 & 0.65 & 1.46 & 0.94 & -- & -- & -- & 0.00049 \\
\hline 600 & 0.749 & 0.69 & 1.01 & 0.77 & 0.46 & 0.95 & -- & -- & -- & - & 0.000393 \\
\hline 700 & 0.549 & $\begin{array}{r}0.600 \\
650^{\circ} \mathrm{F}\end{array}$ & -- & 0.6 & 0.36 & 0.535 & -- & -- & -- & -- & 0.00038 \\
\hline
\end{tabular}


TABLE 1 - THERMAL CONDUCTIVITY (B/hr-f $\mathrm{t}^{2}-\mathrm{O}^{\mathrm{F}}$ )

\begin{tabular}{|c|c|c|c|c|c|c|c|c|c|c|c|}
\hline Temperature & $\begin{array}{c}\text { Therminol } \\
66\end{array}$ & $\begin{array}{c}\text { Therminol } \\
6.0\end{array}$ & $\begin{array}{c}\text { Trerminol } \\
55\end{array}$ & $\begin{array}{c}\text { Dowtherm } \\
G\end{array}$ & $\begin{array}{c}\text { Dowtherm } \\
\text { A }\end{array}$ & $\begin{array}{c}\text { Mob i itherm } \\
600\end{array}$ & $\begin{array}{l}\text { Chevron } \\
\text { Tekni }=\text { ax }\end{array}$ & $\begin{array}{c}\text { DowCorning } \\
.550\end{array}$ & $\begin{array}{c}\text { DowCorning } \\
710\end{array}$ & $\mid \begin{array}{l}\text { Arco } \\
\text { Rubilene }\end{array}$ & Thermof I uid \\
\hline 100 & 0.0703 & 0.0755 & 0.0784 & $0.075 \overline{5}$ & 0.0805 & 0.0695 & 0.0595 & $\begin{array}{r}0.0850^{0} \\
7 ?^{\circ}\end{array}$ & $\begin{array}{r}0.0850^{@} \\
77^{\circ}\end{array}$ & $\begin{array}{r}0.0710^{0} \\
500^{\circ} \mathrm{F}\end{array}$ & $\begin{array}{r}0.0806 \mathrm{o}^{\mathrm{O}} \\
212^{\mathrm{F}}\end{array}$ \\
\hline 200 & 0.0685 & 0.0731 & 0.0753 & 0.07 .42 & 0.0765 & 0.0675 & 0.0575 & & & & $\begin{array}{r}0.0699 @ 9 \\
662^{\circ} \mathrm{F}\end{array}$ \\
\hline 300 & 0.0670 & 0.0705 & 0.0724 & $0.0,31$ & 0.0725 & 0.0653 & 0.0553 & & & & \\
\hline 400 & 0.0657 & 0.10681 & 0.0592 & 0.0 .20 & 0.0685 & 0.0631 & 0.0631 & & & & \\
\hline 500 & 0.0640 & 0.3656 & 0.0561 & $0 . c . c 6$ & 0.0645 & 0.0611 & $0 . c 611$ & & & & \\
\hline 600 & 0.0620 & 0.2630 & 3.0630 & $0.016 \subseteq 3$ & 0.0607 & 0.0589 & $0 . C 589$ & & & & . \\
\hline 700 & 0.0605 & $\begin{array}{l}0.0618 \\
06510^{\circ} \mathrm{F}\end{array}$ & -- & 0.0581 & 0.0568 & 0.0566 & -0.01566 & . & & & \\
\hline
\end{tabular}


APPENDIX G

SUMMARY OF CONTACT HEAT EXCHANGER CALCULATIONS 
TABLE

Using 3" ceramic saddles, diameter=5.5ft $\overline{\mathrm{C}}$ 0.5. " $\mathrm{H}_{2} \mathrm{O} / \mathrm{ft}$ of packed bed

\begin{tabular}{|c|c|c|c|c|c|c|}
\hline Temp ${ }^{\circ} \mathrm{F}$ & $\begin{array}{c}D_{\ell} \\
f t^{2} / f \dot{r}\end{array}$ & $\begin{array}{c}a_{w} \\
f t^{2} / f t^{3}\end{array}$ & $\frac{K_{L}}{\frac{1 b_{\text {moles }}}{h r-f t^{2}-1 b_{\text {moles }} / f t^{3}}}$ & $\begin{array}{c}\mathrm{D}_{\mathrm{g}} \\
\mathrm{ft} \mathrm{t}^{2} \mathrm{hr}\end{array}$ & $\begin{array}{c}K_{G} \\
\text { moles } / h r-f t^{2}-a t m\end{array}$ & $\begin{array}{l}\text { liq̆uid } \\
\frac{\mu}{\rho D_{g, l}}\end{array}$ \\
\hline 200 & $1.22 \times 10^{-5}$ & 21 & 0.0701 & 0.0339 & 0.086 & $1.403 \times 10^{4}$ \\
\hline 400 & $8.6 \times 10^{-5}$ & 21 & 0.7433 & 0.0493 & 0.088 & $4.07 \times 10^{2}$ \\
\hline 550 & $20.5 \times 10^{-5}$ & 21 & 2. 15135 & 0.613 & 0.086 & 85.76 \\
\hline 720 & $32.5 \times 10^{-5}$ & 21 & 4.31290 & 0.11 & 0.11 & 33.08 \\
\hline
\end{tabular}

$\stackrel{\overrightarrow{\mathrm{N}}}{ }$

\begin{tabular}{|c|c|c|c|c|c|c|}
\hline $\begin{array}{l}\text { l iquid } \\
c_{p} \mu / k\end{array}$ & $\begin{array}{c}h_{L} \\
B / h r-f t^{2}-{ }^{\circ} F\end{array}$ & $\begin{array}{l}\begin{array}{c}\text { Sc } \\
\text { găs }\end{array} \\
\frac{\mu}{\rho D_{g, l}}\end{array}$ & $\begin{array}{l}\underset{\text { gr }}{\text { gas }} \\
C_{p} / k\end{array}$ & $\begin{array}{c}h_{E} \\
E / h r-f t^{2}-{ }_{F}\end{array}$ & $\frac{1}{U}=\frac{1}{h g}+\frac{1}{h_{\ell}}$ & U \\
\hline 63.40 & 66.57 & 25.4 & 0.72 & $6.6 \epsilon$ & 0.165 & 6.054 \\
\hline 15.17 & 191.32 & 29.0 & 0.69 & 7.65 & 0.136 & 7.360 \\
\hline 8.38 & 305.98 & 20.4 & 1).69. & 7.72 & 0.133 & 7.53 \\
\hline 5.507 & 444.57 & 29.3 & 1.68 & 7.55 & 0.1346 & 7.42 \\
\hline
\end{tabular}


TABLE 2

\begin{tabular}{c|c|c|c|c} 
Gas & $U_{\text {AV }}$ & $H_{\text {og }}$ & $N_{\text {og }}$ & $\Delta . Z$ \\
\hline $240-400$ & 6.705 & 1.71607 & 3.107 & 5.314 \\
$400-550$ & 7.443 & 1.54592 & 2.752 & 4.254 \\
$550-720$ & 7.477 & 1.5388 & 2.931 & 4.510
\end{tabular}

$Z=\sum_{i=1}^{3} Z i=14.078 \mathrm{ft}$. with $10 \%$ safety factor,

total height of tower $\simeq 16 \mathrm{ft}$ which is appoximately

equal to overall calculations.

TABLE 3

\begin{tabular}{l|c|c|c|c} 
Gas & $U_{\text {AV }}$ & $H_{\text {og }}$ & $N_{\text {og }}$ & $\Delta Z$ \\
\hline $240-400$ & 11.7465 & 1.09346 & 3.107 & 3.40 \\
$400-550$ & 13.370 & 0.96056 & 2.752 & 2.64 \\
$550-720$ & .13 .68 & 0.96 & 2.931 & 2.81
\end{tabular}

Which is approximately equal. to over all calculations

$$
Z=\sum_{i=1}^{3} Z i=8.86 \mathrm{ft}
$$


TABLE 4

2" Pall meta, ring at pressure drop 0.8 inches $\frac{1}{2} \mathrm{~J} / \mathrm{ft}$ of packed bed, $\mathrm{D}=4.65 \mathrm{ft}$.

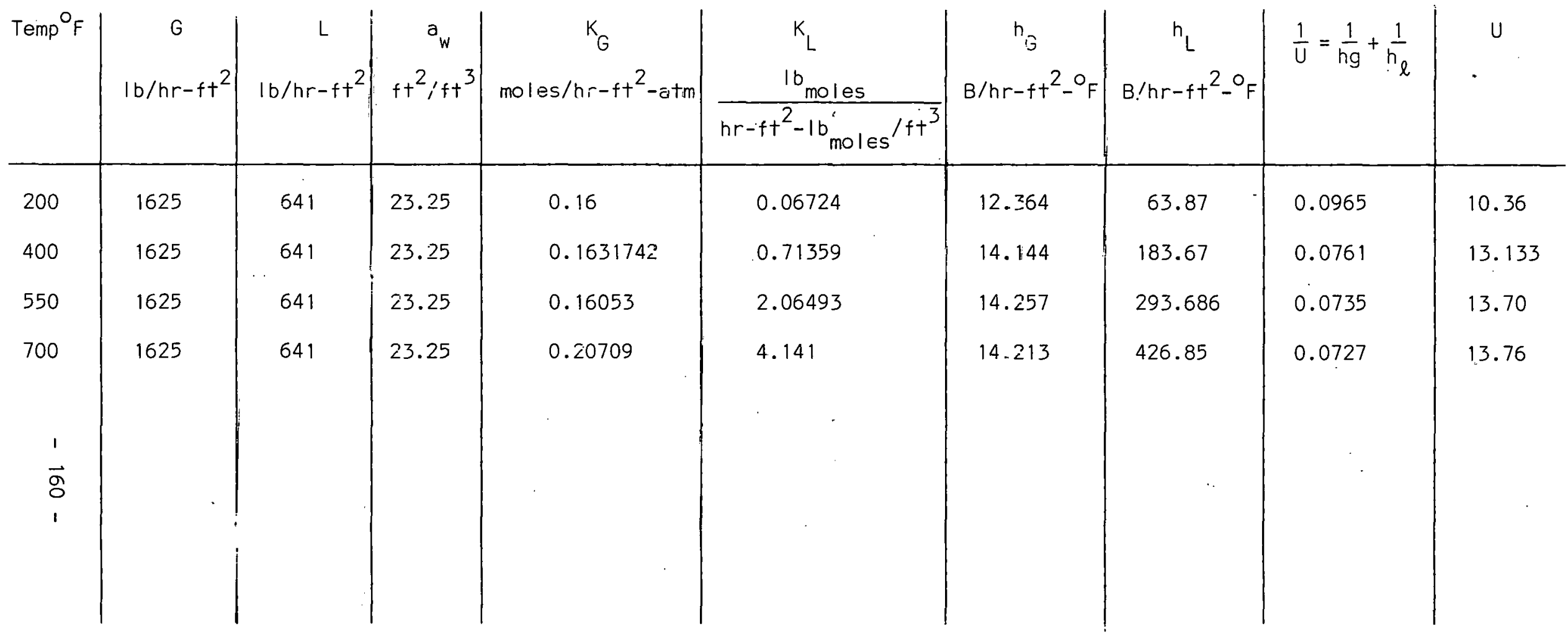

$U_{A V}=12.7133$

$H_{o g}=\frac{1625 \times 0.245}{12.7133 \times 31}=1.01$

$$
\Delta \vec{c}=H_{\text {og }} N \text { og }
$$

Height o: tower $\simeq 9.1=t$.

Witi a safety factor oí 10\%,

Total height of tower $10 \mathrm{ft}$. 


\section{REFERENCES}

1. Hays, L., Design Study of a. Two-Phase Turbine Bottoming Cycle, Report 101-M1, Biphase Engines, Inc., Santa Monica, California, April. 1976.

2. Diamant, R., Total Energy, Pergamon Press, Oxford, 1970.

3. Smith, A. J. and Crabtree, L. C., "Salt Grass - 300 MW Combined Cycle," 16th Annual International Gas Turbine Conference, American Society of Mechanical Engineers, March 1971.

4. The Westinghouse Pace 260 Combined Cycle Power Plant, Synoptic Presentation M271S, Westinghouse Electric Corporation, Philadelphia.

5. Advanced Automotive Power Systems Contractors Coordination Meeting, Seventh Summary Report, Washington D.C., 1975.

6. Stengel, R. F., "'Freon' Engine Boosts IC Engine Fuel. Economy," Design News, February 17, 1975.

7. Morgan, D. T. and Davis, J. P., High Efficiency Decentralized Electrical Power Generation Utilizing Diesel Engines Coupled with Organic Working Fluid Rankine Cycle Engines Operating on Diesel Reject Heat, Report TE4186-27-75, ThermoElectron Corporation, Boston, Massachusetts, November November 1974.

8. Alger, T. W., The Performance of Two-Phase Nozzles For Total Flow Geothermal Impulse Turbines, UCRL - 76417, Lawrence Livermore Laboratory, Livermore, Cali fornia, May 1975.

9. Csanady, G. T., Theory of Turbomachines, McGraw-Hill, New York, 1964.

10. Pouchot, W. D., Basic Investigation of Turbine Erosion Phenomena, WANL - TME - 1977, Westinghouse Astronuclear Laboratory, Pittsburg, Pennsylivania, January 1971.

11. Sherman, P.M. and Lincoln, F. W., "Rain Inlet Systems for Waterjet - Propulsors," AIAA 2nd Advanced Marine Vehicles and Propulsion Meeting, Paper No. 69-418, Seattle, Washington, May 1969.

12. Eckert, E. R. G. and Drake, S. M., Heat Transfer, McGraw-Hill.

13. Cerini, D. J., "Circulation of Liquids for MHD Power Generation," SM - 107/40, EZectricity from MHD, 1968, Volume III. International Atomic Energy Agency, Vienna, 1968. 
14. Elliott, D. G. and Weinberg, E. W., Acceleration of Liquids in TwoPhase Nozzles, Technical Report 32-987, Jet Propulsion Laboratory, Pasadena, California, July 1968.

15. Aircraft Hydroforming, Inc., Personnal Communication.

16. Kobe Pump, Sales Literature.

17. Henein, A. N., Wayne State University, Detroit, Michigan, Analysis of Pollutant Formation and Control and Fuel Economy in Diesel Engines, Prog. Energy Combust. Sci., Vol. 1, 1976.

18. Perry, R. H. and Chilton, C. H., Chemical Engineers Handbook, 5th Edition, McGraw-Hill, Inc..

19. Nemunaitis, R.R. alid Eckert, J. S., "Heat Transter in Packed Towers," Chemical Engineering Progress, Vol. 71, No. 8, pp. 60-67, August 1975:

20. Nemunaitis, R. R., Eckert, J. S., Foote, E. H., Rollison, L. R., Heat Transfer in Packed Towers, Norton Company, Chemical Process Products Division, Akron, Ohio, 1975.

21. Sideman, S., "Direct Contact Heat Transfer Between Immiscible Liquids," Advanced Chemical Engineering, Vol. 6, 1966.

22. Foust, A. S., Wenzel, L. A., Clump, C. W., Maus,' L., Anderson, L. B., Principles of Unit Operations, John Willey and Sons, Inc., 1960.

23. McCabe, W. C. and Smith, J. C., Unit Operatione of Chemical Engineering, McGraw-Hill, Inc., 1976. 